\title{
AVTA Federal Fleet PEV Readiness Data Logging and Characterization Study for NASA White Sands Test Facility
}

Stephen Schey

Jim Francfort

October 2014

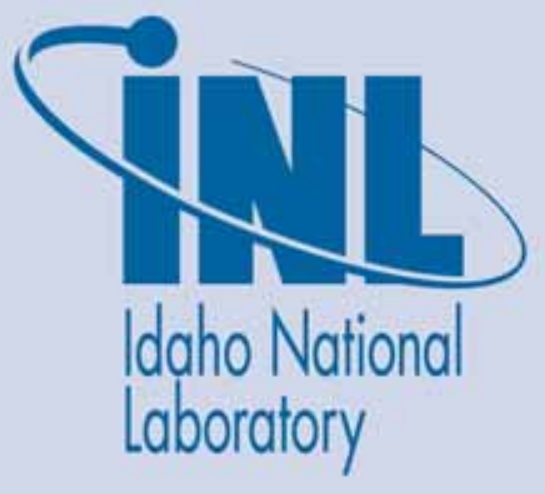

The INL is a U.S. Department of Energy National Laboratory operated by Battelle Energy Alliance 


\section{DISCLAIMER}

This information was prepared as an account of work sponsored by an agency of the U.S. Government. Neither the U.S. Government nor any agency thereof, nor any of their employees, makes any warranty, expressed or implied, or assumes any legal liability or responsibility for the accuracy, completeness, or usefulness, of any information, apparatus, product, or process disclosed, or represents that its use would not infringe privately owned rights. References herein to any specific commercial product, process, or service by trade name, trade mark, manufacturer, or otherwise, does not necessarily constitute or imply its endorsement, recommendation, or favoring by the U.S. Government or any agency thereof. The views and opinions of authors expressed herein do not necessarily state or reflect those of the U.S. Government or any agency thereof. 
INL/EXT-14-33338

\title{
AVTA Federal Fleet PEV Readiness Data Logging and Characterization Study for NASA White Sands Test Facility
}

\author{
Stephen Schey \\ Jim Francfort ${ }^{2}$
${ }^{1}$ Stephen Schey, Project Manager, Infrastructure Planning and Analysis, Intertek Testing Services, North America, Phoenix, AZ
${ }^{2}$ Jim Francfort, Vehicle Systems Principal Investigator, Idaho National Laboratory operated by Battelle Energy Alliance, Idaho Falls, ID

October 2014

\author{
Idaho National Laboratory \\ Idaho Falls, Idaho 83415
}

http:/lavt.inl.gov

Prepared for the

U.S. Department of Energy

Office of Nuclear Energy

Under DOE Idaho Operations Office

Contract DE-AC07-05ID14517 


\section{ABSTRACT}

Battelle Energy Alliance, LLC, managing and operating contractor for the U.S. Department of Energy's Idaho National Laboratory, is the lead laboratory for U.S. Department of Energy Advanced Vehicle Testing. Battelle Energy Alliance, LLC contracted with Intertek Testing Services, North America (Intertek) to collect and evaluate data on federal fleet operations as part of the Advanced Vehicle Testing Activity's Federal Fleet Vehicle Data Logging and Characterization study. The Advanced Vehicle Testing Activity study seeks to collect and evaluate data to validate the utilization of advanced plug-in electric vehicle (PEV) transportation.

This report focuses on the National Aeronautics and Space Administration White Sands Test Facility fleet to identify daily operational characteristics of select vehicles and report findings on vehicle and mission characterizations to support the successful introduction of PEVs into the agencies' fleets.

Individual observations of these selected vehicles provide the basis for recommendations related to electric vehicle adoption and whether a battery electric vehicle or plug-in hybrid electric vehicle (collectively PEVs) can fulfill the mission requirements.

Intertek acknowledges the support of Idaho National Laboratory and White Sands Test Facility for participation in the study.

Intertek is pleased to provide this report and is encouraged by enthusiasm and support from National Aeronautics and Space Administration personnel. 


\section{EXECUTIVE SUMMARY}

Federal agencies are mandated to purchase alternative fuel vehicles, increase consumption of alternative fuels, and reduce petroleum consumption. Available plug-in electric vehicles (PEVs) provide an attractive option in the selection of alternative fuel vehicles. PEVs, which consist of both battery electric vehicles (BEVs) and plug-in hybrid electric vehicles (PHEVs), have significant advantages over internal combustion engine (ICE) vehicles in terms of energy efficiency, reduced petroleum consumption, and reduced production of greenhouse gas (GHG) emissions, and they provide performance benefits with quieter, smoother operation. This study intends to evaluate the extent to which the National Aeronautics and Space Administration's White Sands Test Facility (WSTF) could convert part or all of their fleet of vehicles from petroleum-fueled vehicles to PEVs.

It is likely that more fuel efficient ICE vehicles, including hybrid electric vehicles, exist, which may provide improvements for the current fleet; however, this study's focus is on replacing ICE vehicles with suitable PEVs.

BEVs provide the greatest benefit when it comes to fuel and emissions savings, because all motive power is provided by the energy stored in the onboard battery pack. These vehicles use no petroleum and emit no pollutants at their point of use. PHEVs provide similar savings when their battery provides the motive power; however, they also have the ability to extend their operating range with an onboard ICE. Because a PHEV can meet all transportation range needs, the adoption of a PHEV will be dependent on its ability to meet other transportation needs such as cargo or passenger carrying. Operation of PHEVs in battery-only mode can be increased with opportunity charging at available charging stations; however, it should be noted that not all PHEVs have a mode in which the battery provides all motive power at all speeds. This study focuses on the mission requirements of the fleet vehicles, with the objective of identifying vehicles that may be replaced with PEVs (emphasis being on BEVs that provide maximum benefit).

WSTF, located east of Las Cruces, New Mexico, has supported every U.S. human space flight from Apollo through the Shuttle Program. It offers numerous ambient pressure and altitude simulations stands to test rocket propulsion test systems and single rocket engines. WSTF performs testing of materials and components used in space flight and is one of ten NASA centers. It employs approximately 650 people, including civil servants and onsite contractors. Because WSTF is a protected and hazardous testing facility, visitor processing is necessary and the facility is not open to the general public.

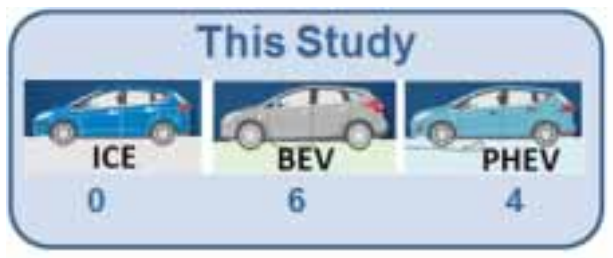

WSTF has 137 vehicles in its fleet, with ten of those vehicles being identified as representative of the fleet and instrumented for data collection and analysis. Fleet vehicle mission categories are defined in Section 4 of this report and, while the WSTF vehicles conduct many different missions, two missions (i.e., support and enforcement) were selected by agency management to be part of this fleet 
evaluation. These two mission categories accounted for 45 of the 137 total fleet vehicles. The remaining vehicles were pool, transport, and specialty vehicles.

This report observes that a mix of BEVs and PHEVs are capable of

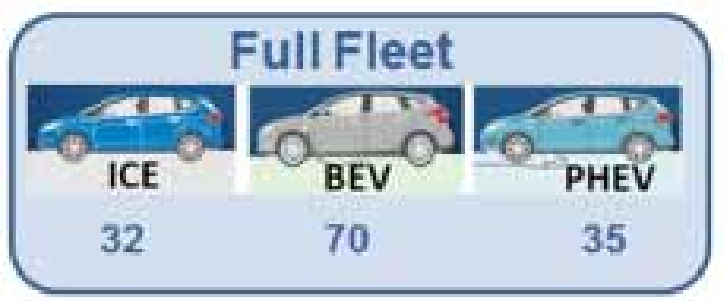
performing most of the required missions and of providing an alternative vehicle for the pool, support, transport, and enforcement vehicles, because even though some vehicles travel long distances, the group could support some BEVs for the short trips and PHEVs for the longer trips. The recommended mix of vehicles

\section{Fuel Cost for All Fleet Vehicles}

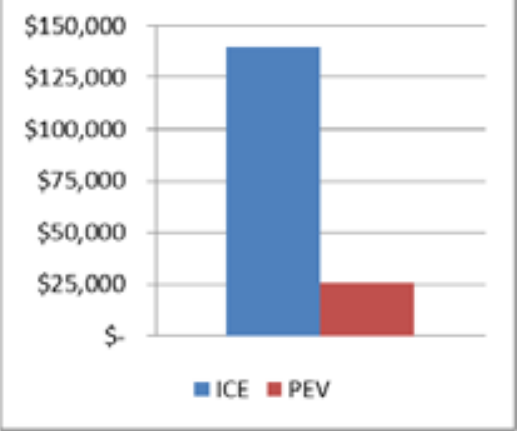

will provide sufficient range for individual trips and time is available each day for charging to accommodate multiple trips per day. These charging events could occur at the vehicle home base. Replacement of vehicles in the current fleet would result in significant reductions in the emission of GHGs and in petroleum use, as well as reduced fleet operating costs.

Based on data collected for the monitored vehicles, the 10-vehicle fleet subset could possibly consist of six BEVs and four PHEVs. The replacement of these 10 ICE vehicles with PEVs could result in annual GHG savings over $47,219 \mathrm{lb}-\mathrm{CO}_{2}{ }^{\mathrm{e}}$ (55\% reduction) and an annual fuel cost savings of $\$ 11,575$ (81\% reduction).

Based on data collected from the monitored vehicles and extrapolating to the 45 vehicles and those with transport and pool missions, a fleet consisting of 19 specialty vehicles, two conventional heavy-duty trucks,one1 conventional passenger van, 10 additional ICE vehicles, 70 BEVs, and 35 PHEVs may meet the facility's needs. The replacement of 105 ICE vehicles with PEVs could result in an annual GHG savings over $472,800 \mathrm{lb}-\mathrm{CO}_{2}{ }^{\mathrm{e}}$ (56\% reduction) and an annual fuel cost savings of over $\$ 113,000$ (81\% reduction).

PEV charging stations could be located in various locations of WSTF and could benefit WSTF's own fleet vehicles, as well as those of employees and the visiting public who own PEVs.

Intertek suggests that WSTF, in the near future, may wish to move forward with replacement of pool, support, transport, and enforcement vehicles with PEVs as current budget and vehicle replacement schedules allow. Certainly, the vehicle types studied in this report may be candidates for immediate replacement. 


\section{CONTENTS}

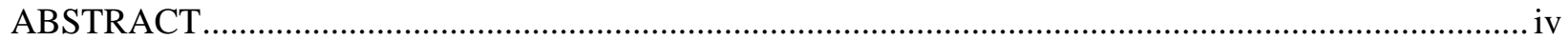

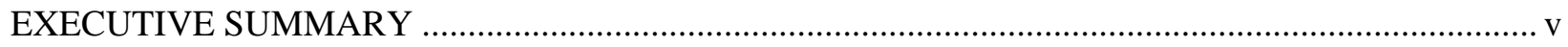

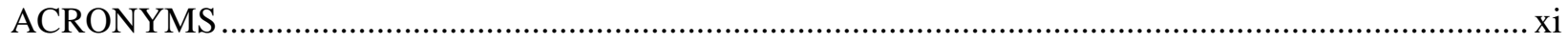

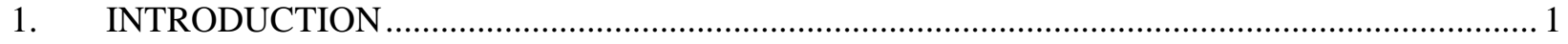

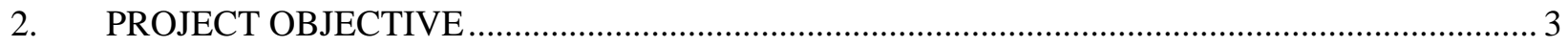

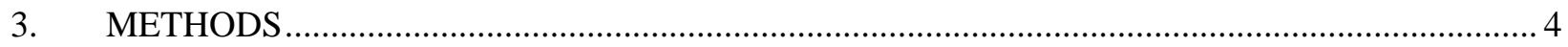

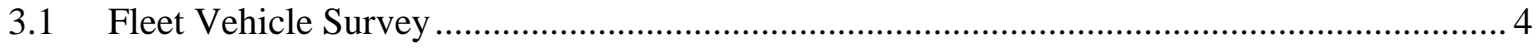

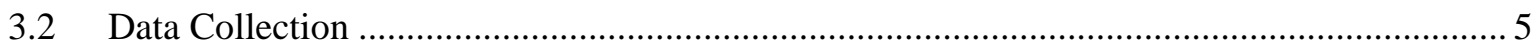

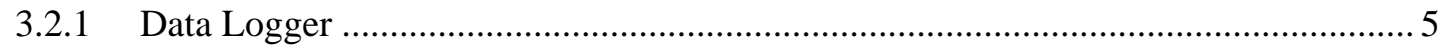

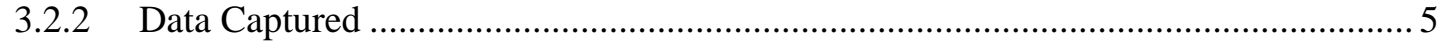

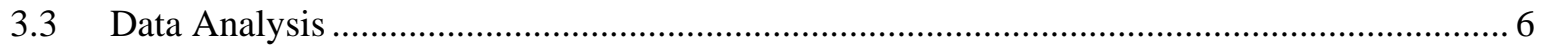

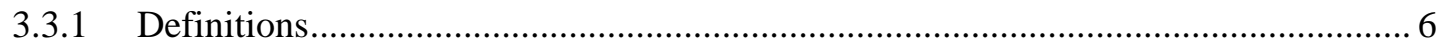

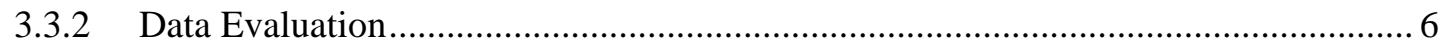

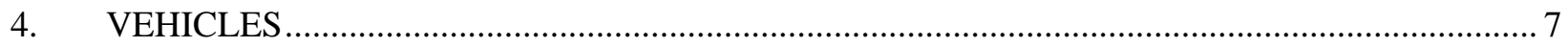

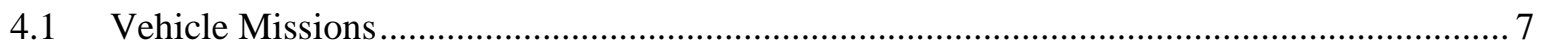

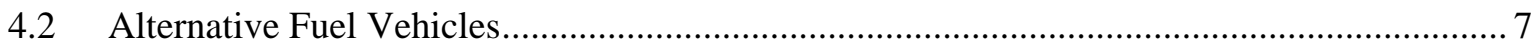

4.3 Battery Electric Vehicle and Plug-In Hybrid Electric Vehicle Benefits/Challenges .............. 8

4.3.1 Battery Electric Vehicle Benefits/Challenges ....................................................... 9

4.3.2 Plug-in Hybrid Electric Vehicle Benefits/Challenges.............................................. 9

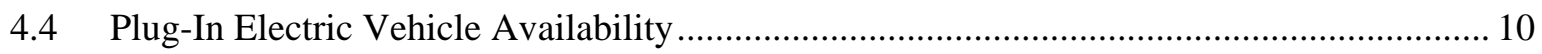

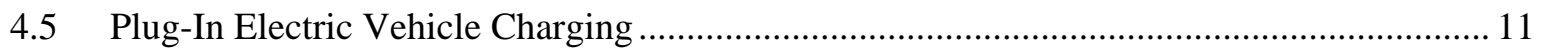

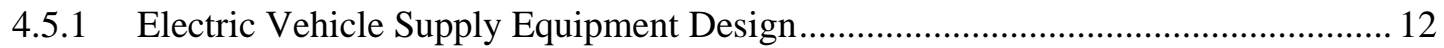

4.5.2 Electric Vehicle Supply Equipment Stations ........................................................ 15

5. NATIONAL AERONAUTICE AND SPACE ADMINISTRATION WHITE SANDS

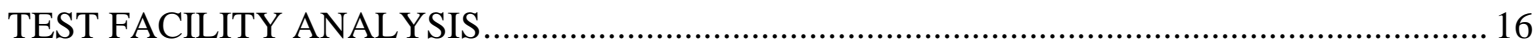

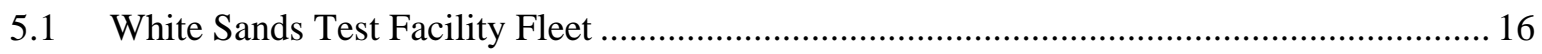

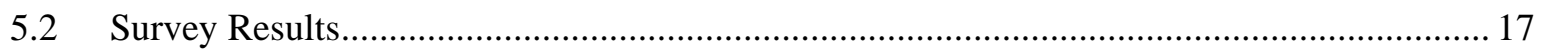

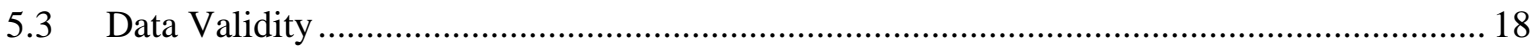




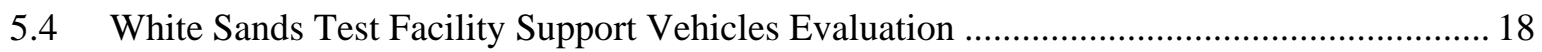

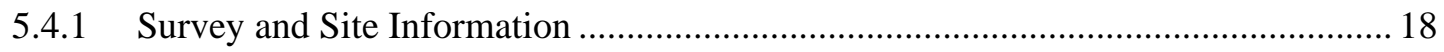

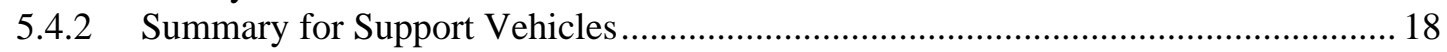

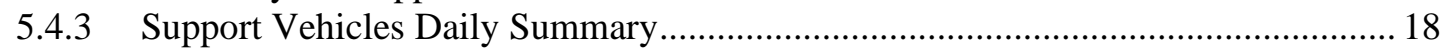

5.4.4 White Sands Test Facility Support Vehicle Observations/Summary......................... 21

5.4.5 White Sands Test Facility Support Vehicle Charging Needs ..................................... 22

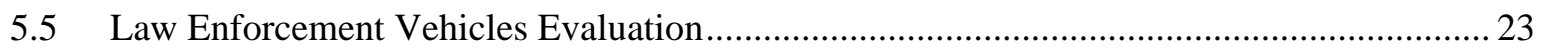

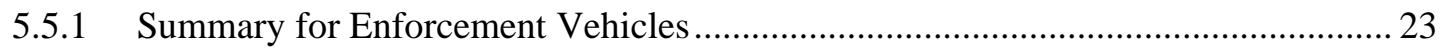

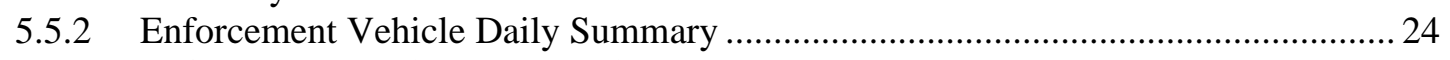

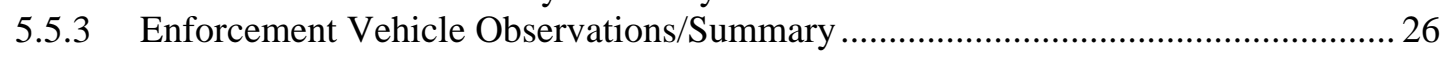

5.5.4 Enforcement Vehicle Charging Needs ................................................................ 27

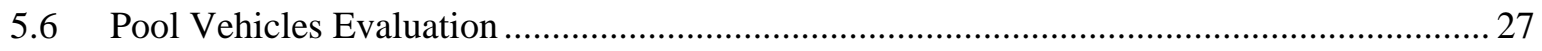

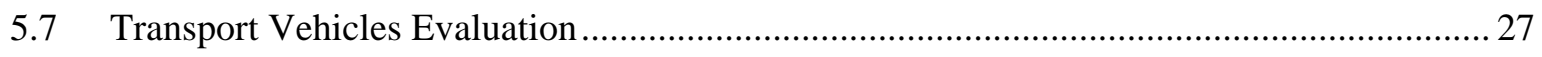

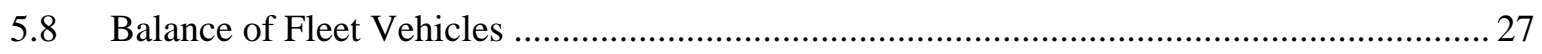

\section{GREENHOUSE GAS EMISSIONS AVOIDED AND FUEL COST REDUCTION}

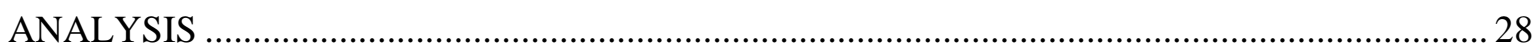

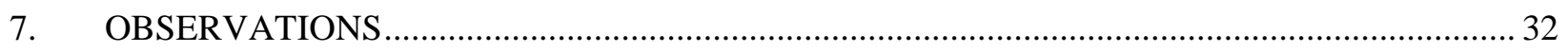

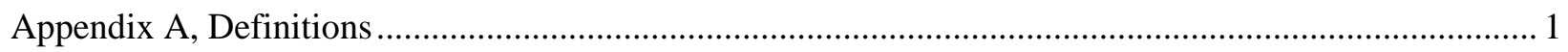

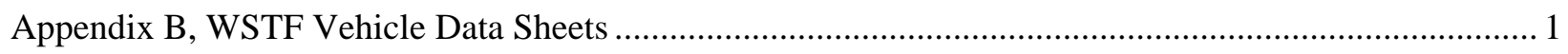

Appendix C, National Fuel Cost and GHG Savings ...................................................................... 1

\section{FIGURES}

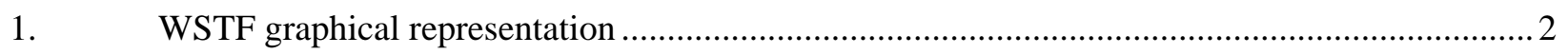

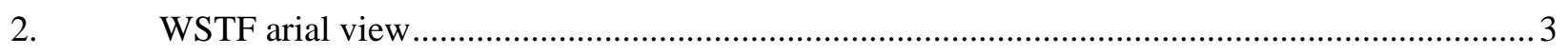

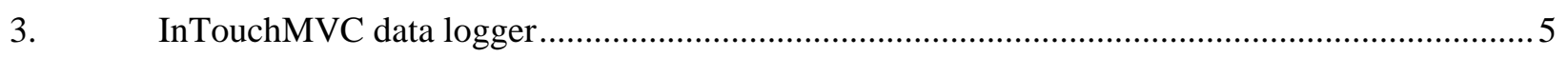

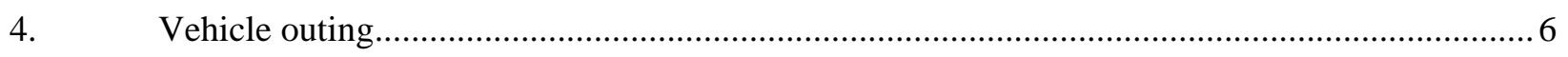

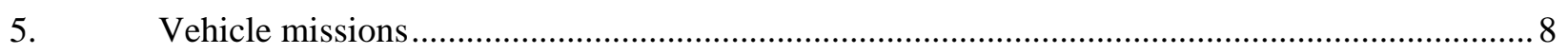

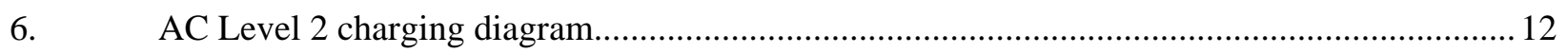

7. Society of Automotive Engineers charging configurations and ratings terminology ................ 13

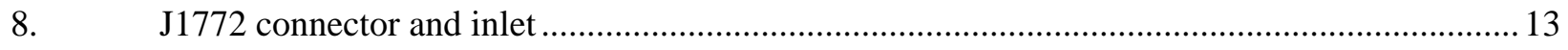




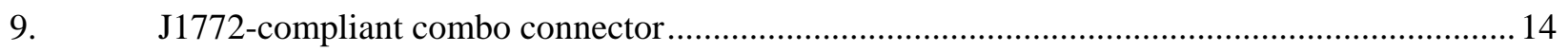

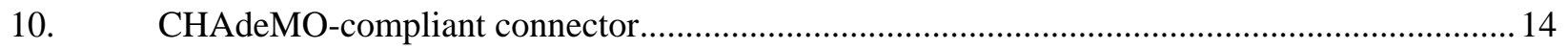

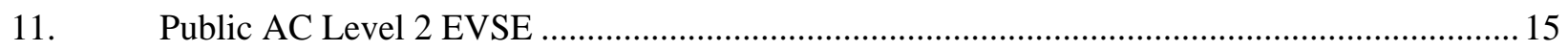

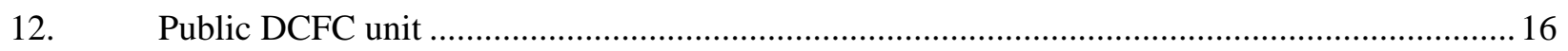

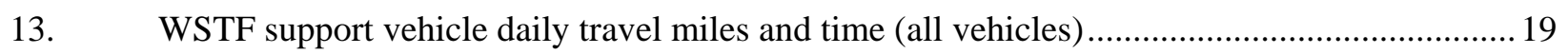

14. WSTF support vehicle daily travel history (all vehicles) ….............................................. 19

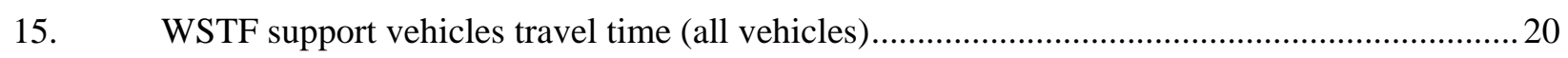

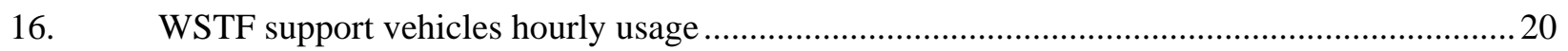

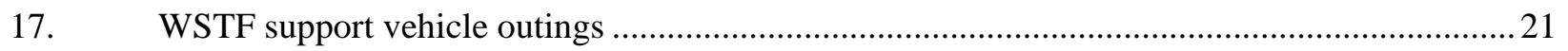

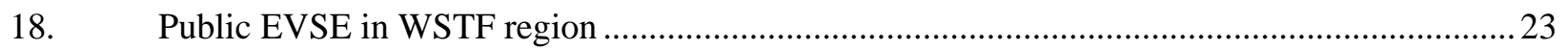

19. Enforcement vehicle percentage of daily use versus daily travel miles and time (all

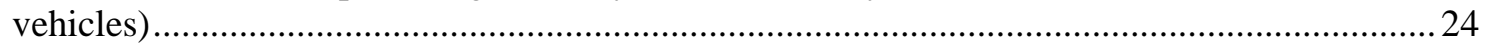

20. Enforcement vehicle daily travel miles (all vehicles).........................................................24

21. Enforcement vehicle daily travel time (all vehicles) …...................................................... 25

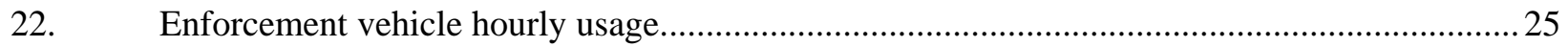

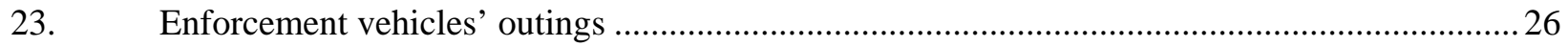

\section{TABLES}

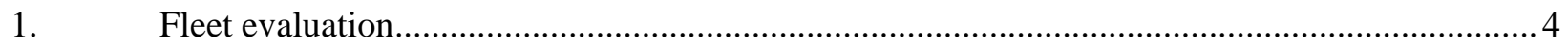

2. General Services Administration vehicle replacement requirements ...................................... 8

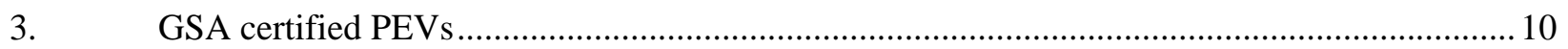

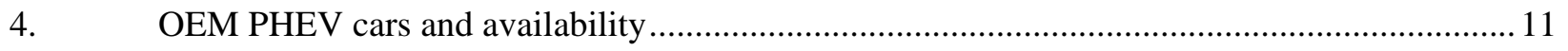

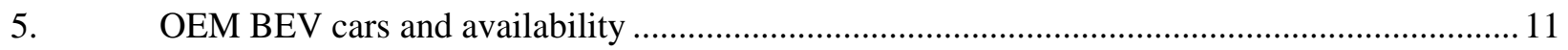

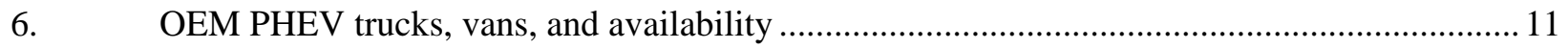

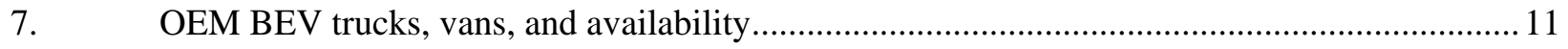

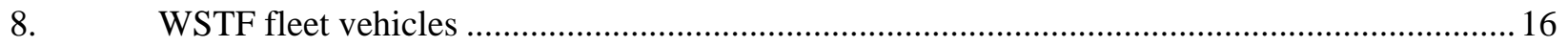

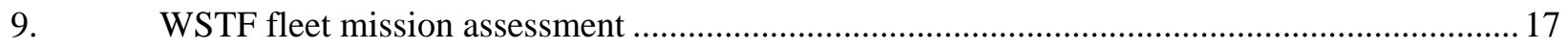




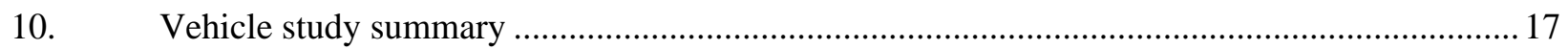

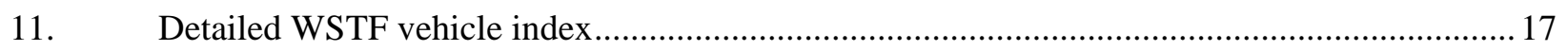

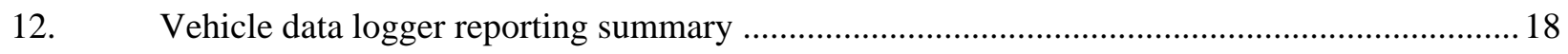

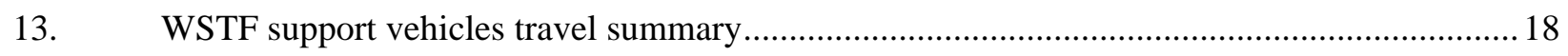

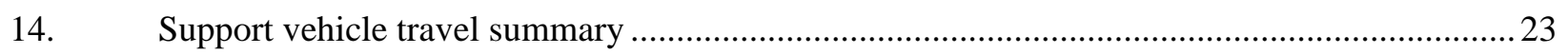

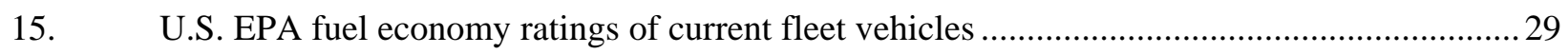

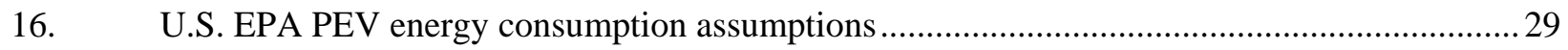

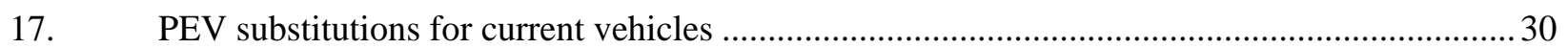

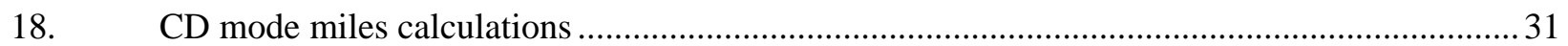

19. Greenhouse gas emissions avoidance and fuel cost reduction analysis summar......................31

20. Extrapolated greenhouse gas emissions avoided and fuel cost savings for the entire fleet ........32 


\section{ACRONYMS}

AC alternating current

BEV battery electric vehicle

CD charge depleting

CS charge sustaining

DC direct current

EPA U.S. Environmental Protection Agency

EVSE electric vehicle supply equipment

GHG greenhouse gas emissions

GSA General Services Administration

ICE internal combustion engine

Intertek Intertek Testing Services, North America

NASA National Aeronautics and Space Administration

OEM original equipment manufacturers

PEV plug-in electric vehicle (includes BEVs and PHEVs, but not hybrid electric vehicles)

PHEV plug-in hybrid electric vehicle

VIN vehicle identification number

WSTF White Sands Test Facility 


\section{AVTA Federal Fleet PEV Readiness Data Logging and Characterization Study for NASA White Sands Test Facility}

\section{INTRODUCTION}

Federal agencies are mandated by the Energy Policy Act of $1992^{1}$, Energy Policy Act of $2005^{2}$, Executive Order 13423 (President Bush 2007) ${ }^{3}$, Executive Order 13514 (President Obama), ${ }^{4}$ and the Energy Independence and Security Act of $2007^{5}$ to purchase alternative fuel vehicles, increase consumption of alternative fuels, reduce petroleum consumption, and reduce greenhouse gas (GHG) emissions.

Battelle Energy Alliance, LLC, managing and operating contractor for Idaho National Laboratory, is the lead laboratory for the U.S. Department of Energy's advanced vehicle testing and manages the Advanced Vehicle Testing Activity Federal Fleet Vehicle Data Logging and Characterization Study, which promotes utilization of advanced electric drive vehicle transportation technologies. The Advanced Vehicle Testing Activity focuses its testing activities on emerging and newly

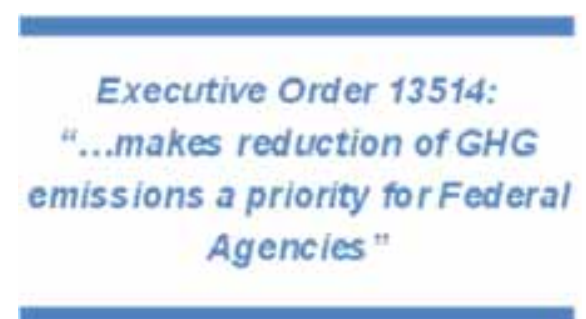
commercialized plug-in electric vehicle (PEV) technologies because of the high-energy efficiencies and reduced consumption of petroleum by the use of electric-drive vehicles. Battelle Energy Alliance, LLC selected Intertek Testing Services, North America (Intertek) to collect data on federal fleet operations and report the findings on vehicle and mission characterizations to support the successful introduction of PEVs into federal fleets.

It is likely that more fuel efficient internal combustion engine (ICE) vehicles, including hybrid electric vehicles, exist that may provide improvements for the current fleet; however, they are not the focus of this study.

Because of the large number of vehicles in federal fleets in the United States, these fleets provide a substantial opportunity for the introduction of battery electric vehicles (BEVs) and plug-in hybrid electric vehicles (PHEVs) (collectively PEVs). However, to assess the scale of this opportunity, additional data are required to characterize the various missions performed by each fleet and to determine which existing vehicles are most suitable for replacement by a PEV.

The National Aeronautics and Space Administration's (NASA) White Sands Test Facility (WSTF), located just east of Las Cruces, New Mexico (Figures 1 and 2), employs approximately 650 people, including civil servants and onsite contractors.

WSTF is an excellent site for fleet evaluation because of its size, location, and travel between the site, local destinations, and within the WSTF perimeter. WSTF has an opportunity to be a leader in the adoption of BEVs and PHEVs for its fleet.

\footnotetext{
${ }^{1}$ http://thomas.loc.gov/cgi-bin/query/z?c102:h.r.776.enr [accessed January 10, 2014].

${ }^{2}$ http://www.gpo.gov/fdsys/pkg/BILLS-109hr6enr/pdf/BILLS-109hr6enr.pdf [accessed January 10, 2014 ].

${ }^{3}$ http://www.gsa.gov/portal/content/102452 [accessed January 10, 2014].

${ }^{4}$ https://www.fedcenter.gov/programs/eo13514/ [accessed September 1, 2014].

${ }^{5}$ http://www.gpo.gov/fdsys/pkg/PLAW-110publ140/pdf/PLAW-110publ140.pdf [accessed January 10, 2014].
} 


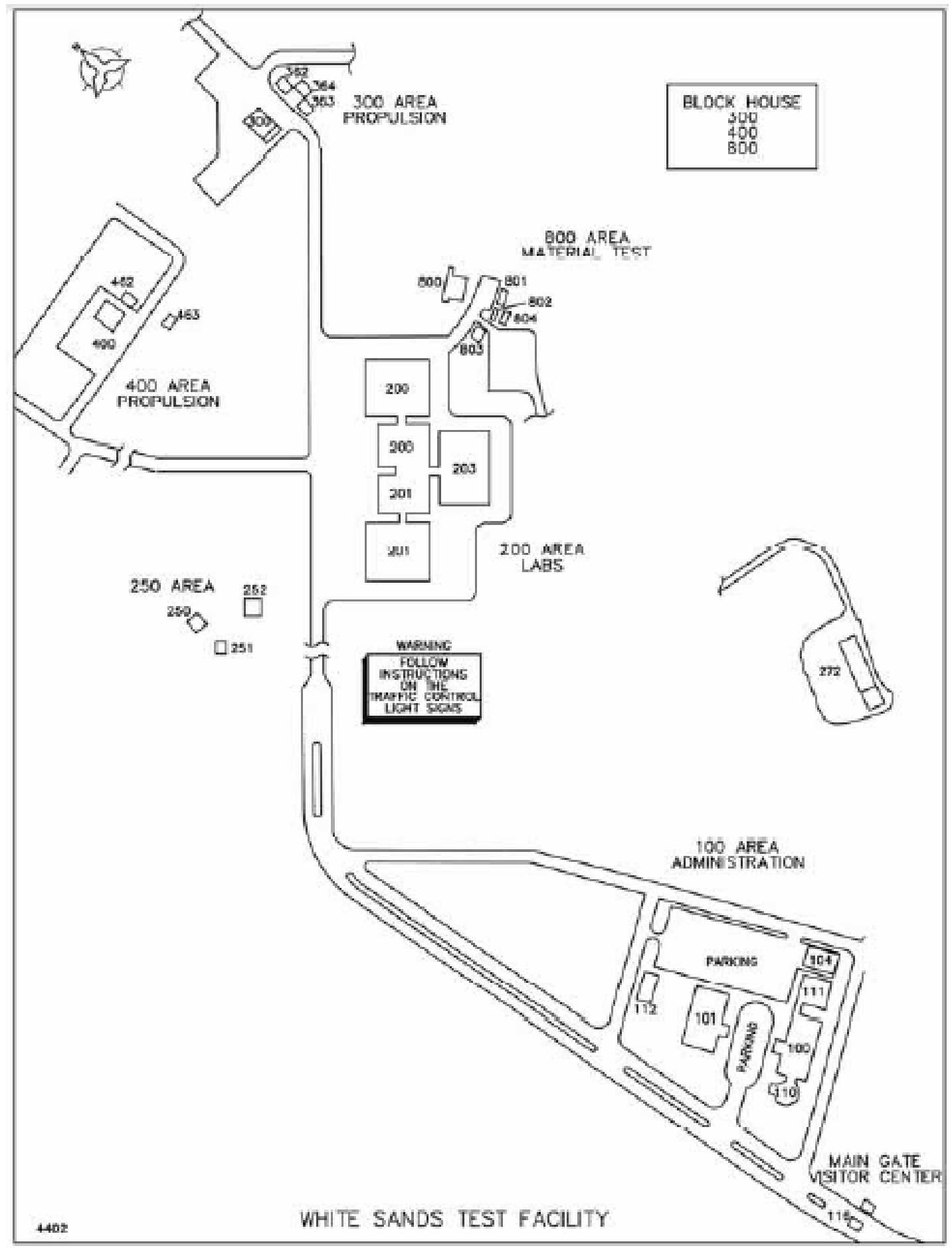

Figure 1. WSTF graphical representation. ${ }^{6}$

${ }^{6}$ http://www.nasa.gov/sites/default/files/files/wstfVisitorsGuide.pdf [accessed September 2, 2014]. 


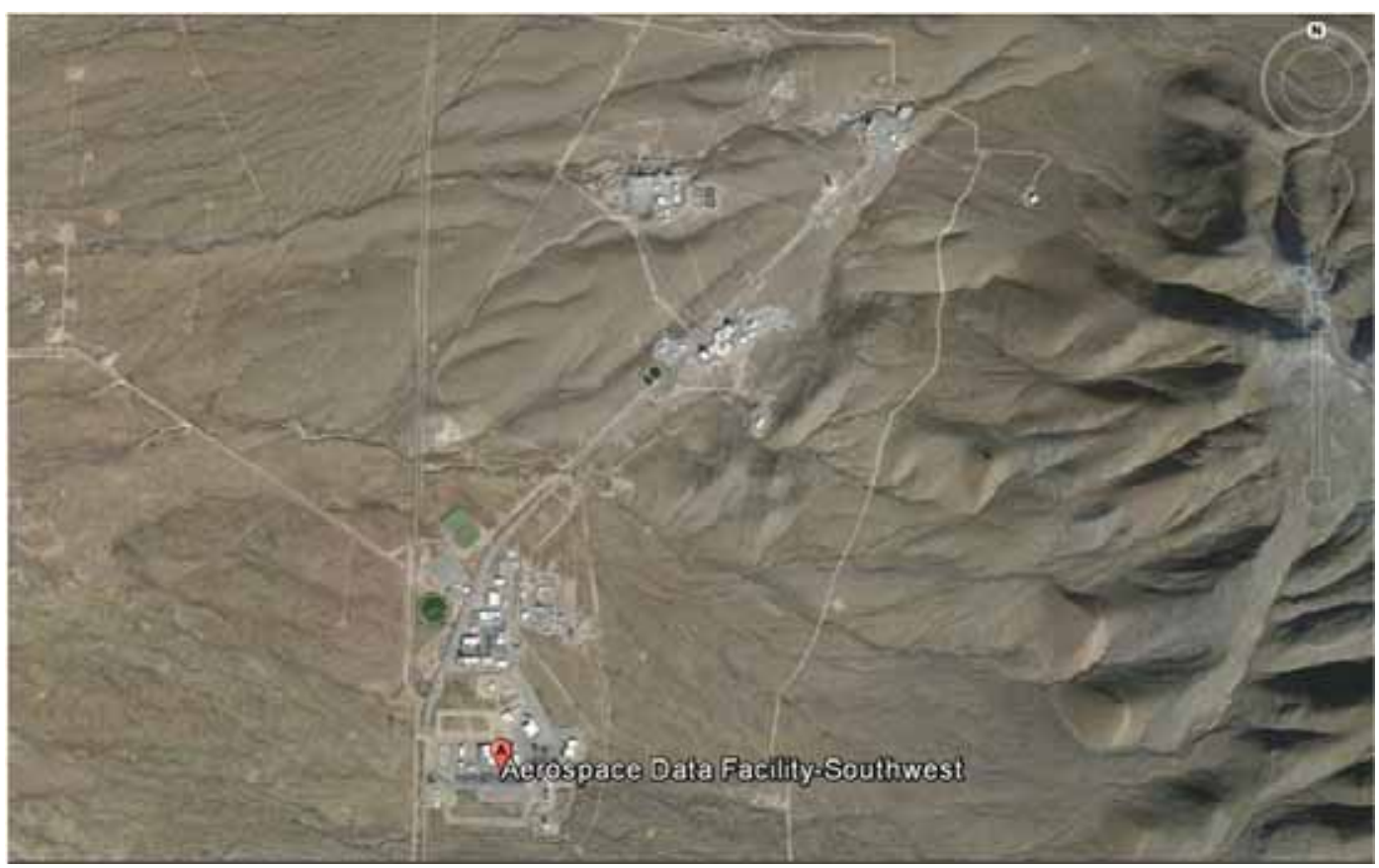

Figure 2. WSTF arial view. ${ }^{7}$

\section{PROJECT OBJECTIVE}

This study explores federal fleet vehicles and their usage characteristics, with a primary goal of supporting the goals of Presidential Executive Order 13514, which includes the following:

- Pursuing opportunities with vendors and contractors to address and incentivize GHG emission reductions and petroleum use reductions

- Implementing strategies and accommodations for transit, travel, training, and conferences that actively reduce carbon emissions associated with commuting and travel by agency staff

- Meeting GHG emissions reductions associated with other federal government sustainability goals

- Implementing innovative policies and practices that address agency-specific Scope 3 GHG emissions. ${ }^{8}$

Because of the large number of vehicles in the federal fleets, there is a substantial opportunity for PHEV and BEV adoption. Federal fleets offer an opportunity as a first market replacement for alternative fuels due to their scale, refueling patterns, and regular vehicle turnover. ${ }^{9}$

This project has the following four defined tasks:

1. Data collection: Coordinate with the fleet manager to collect data on agency fleet vehicles. This includes collecting information on the fleet vehicle and installing data loggers on a representative sample of the fleet vehicles to characterize their missions.

\footnotetext{
${ }^{7}$ Google earth [accessed September 2, 2014].

${ }^{8}$ http://energy.gov/sites/prod/files/2013/10/f3/eo13514.pdf [accessed February 5, 2014].

${ }^{9}$ Fleet Purchase Behavior: Decision Processes and Implications for New Vehicle Technologies and Fuel, Nesbitt, Sperling, University of California, Davis 2001.
} 
2. Data analysis and review: Examine the data collected by the loggers and fleet vehicle characteristics to describe typical fleet activity. Incorporate the fleet manager's input on introducing PEVs to the agency's fleet.

3. PEV implementation feedback: Provide feedback to fleet personnel and Battelle Energy Alliance, LLC on the selection criteria for replacement PEVs in their specific fleet vehicle missions.

4. Observations and recommendations: Provide actionable information to introduce PEVs into agency fleet operations and assess any related impacts for the facility.

Data collected from the vehicles include trip distance, idle time, time between uses, and stop locations. Data collection continues for 30 to 60 days using a non-intrusive data logger, which gathers and transmits information using global positioning satellites and cellular service. The loggers collect data at 1-minute intervals and transmit when an active signal is present.

Extrapolating the results of this analysis to the larger fleet provides estimates of potential savings in gasoline consumption and GHG emissions. This report also provides recommendations relating to fleet management of BEVs and PHEVs for additional consideration.

Fleet managers may use the information supplied in this report to help them to identify which vehicles are candidates for replacement by BEVs or PHEVs based on their use. BEVs are preferred because of the greater potential reduction of GHG emissions, fuel cost, and petroleum usage; however, they are not likely to be suitable for all vehicle missions.

The information in this report supports a final report to Battelle Energy Alliance, LLC/Idaho National Laboratory, and the U.S. Department of Energy. The aggregated results for all agencies' fleets will provide an overview of federal fleets, vehicle missions, vehicle uses, and agencies needs to plan and establish a more systematic method for the adoption of BEVs and PHEVs.

\section{METHODS}

\subsection{Fleet Vehicle Survey}

Agency fleet managers selected fleet vehicles for this study and provided basic information for each vehicle, including its managing agency, home base for the vehicle, contact information, primary vehicle mission, vehicle ownership, fuel type, and odometer reading.

WSTF identified 137 total fleet vehicles in their fleet. WSTF provided the vehicle missions as shown in Table 0. (Note that Section 4 provides descriptions of the vehicle mission types.) Intertek coordinated with the WSTF fleet manager to identify the specific vehicles for data collection for inclusion in the study. The fleet manager assessed their wide range of vehicles and made selections of high-interest, representative vehicles based on vehicle missions and vehicle type/class. Selection also favored vehicles used at least twice a week. Because data loggers rely on the vehicle's battery power, non-use of the vehicle can result in the vehicle having a depleted battery. Intertek received no reports of depleted batteries during the study at WSTF. Ten vehicles were selected, with eight vehicles having a support mission and two vehicles being enforcement vehicles.

Table 1. Fleet evaluation.

\begin{tabular}{cccc}
\hline Vehicle Mission & Study Vehicles & Total Fleet Reported & Percentage Studied \\
\hline Pool Vehicles & & 21 & 0 \\
Support Vehicles & 8 & 31 & 26 \\
Enforcement Vehicles & 2 & 14 & 14 \\
Specialty Vehicles & & 19 & 0 \\
Transport & & 52 & 0 \\
Total Fleet Vehicles & 10 & 137 & 7 \\
\hline
\end{tabular}




\subsection{Data Collection}

Individual privacy concerns exist when monitoring vehicle movement with data loggers. Data collection occurs through vehicle identification as identified by Intertek, data logger number, vehicle identification number (VIN), or agency-assigned vehicle number. Intertek receives no information related to the vehicle operator and provides no raw data to the fleet managers. In this manner, Intertek does not collect, analyze, or report on individual driving habits.

\subsubsection{Data Logger}

Non-intrusive data loggers, produced by InTouchMVC ${ }^{10}$ and depicted in Figure 3, were inserted into the vehicle's onboard diagnostic port to collect and transmit the relevant data. Installation of the data logger and manual recording of information about the vehicle that ties the logger and vehicle together in the data, typically takes less than 5 minutes. Once installed and activated (during vehicle use), the data loggers collect vehicle information once every minute during vehicle operation and transmit by cellular communication to the data center.

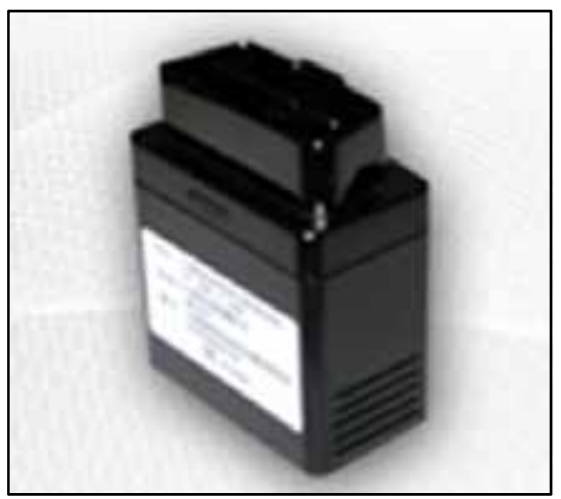

Figure 3. InTouchMVC data logger.

Intertek maintains the data logger's connectivity and verifies data transmission weekly. Missing data (reported as "null” values) are frequently the result of lost global positioning system reception, logger device removal, or extended periods in regions with insufficient cellular reception. Intertek filters the vehicle and data logger information if these null values present a significant impact on the data collected and no resolution is possible. This report also identifies the statistics on this validation process.

WSTF requested and installed ten data loggers into the selected fleet vehicles. The agency removed and shipped the data loggers to Intertek at the conclusion of the data collection period.

\subsubsection{Data Captured}

Data consist of key-on events, key-off events, and position updates logged every minute while the vehicle is keyed-on. InTouchMVC converted these data points into records of trip events, stop events, and idle events.

From these data points, the following information was available for evaluation:

- $\quad$ Trip start and stop time and location

- $\quad$ Trip distance and duration

${ }^{10}$ www.intouchmvc.com [accessed January 10, 2014]. 
- Idle start time, location, and duration

- Stop start time, location, and duration.

\subsection{Data Analysis}

\subsubsection{Definitions}

Figure 4 illustrates a vehicle outing, which is comprised of trips, stops, and idle events, that may occur during one day or over several days. The following list provides a definition of these terms:

1. Outing: An outing is the combination of trips and stops that begin at the home base and includes all travel until the vehicle returns home.

2. Trip: A trip begins with a key-on event and ends with the next key-off event.

3. Vehicle stop: A vehicle stop includes a key-off/key-on event pair.

4. Idle time: Idle time is the amount of time a vehicle spends stationary after a key-on event when the vehicle is not moving for a period of 3 minutes or longer.

5. Trip travel time: Trip travel time is the amount of time required to complete a trip, excluding stops but including idle time.

Definitions of additional analysis and survey terms are as follows:

1. Operating shift: Fleet manager-defined period worked.

2. Study days: Days during which the data loggers are connected.

3. Vehicle days: Study days during which a vehicle is used.

4. Null values: Data record unusable for analysis for various reasons.

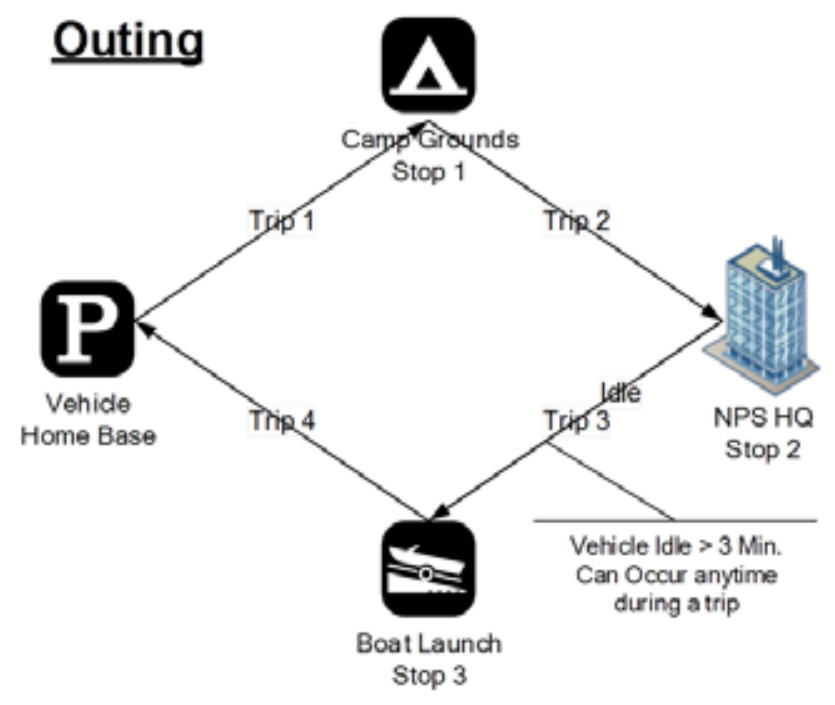

Figure 4. Vehicle outing.

\subsubsection{Data Evaluation}

Processing the data involves removal of null values and aggregation by different spatial and temporal scales. Aggregation was by day, by trip, and by outing to produce figures showing the patterns of use. Aggregation by vehicle mission followed to characterize use for the agency fleet. Section 5 presents these results. Data were extrapolated to provide the overall fleet usage and benefit analysis when fleet 
information was provided; Section 6 presents these benefits. Intertek observations are included in Section 7.

Statistical data analysis uses Microsoft ${ }^{\circledR}$ Excel and Tableau ${ }^{\circledR}$ software. Frequency distributions summarize the travel behavior of each vehicle and vehicle mission during the study period. Rounding of the tables and figures are to three significant digits.

\section{VEHICLES}

\subsection{Vehicle Missions}

The vehicle mission is an important characteristic in the fleet study. Information used to define the vehicle mission includes the vehicle's configuration, vehicle use, classification per 40 CFR Part 600.31582 and Environmental Protection Agency (EPA), the participating agency use, and generally assumed vehicle use. Based on fleet information gathered, Intertek has established the following seven mission/vehicle categories for analysis. They as follows and examples are depicted in Figure 5:

1. Pool vehicles: A pool vehicle is any automobile (other than the low-speed vehicles identified below) manufactured primarily for use in passenger transportation, with no more than 10 passengers.

2. Enforcement vehicles: Vehicles specifically approved in an agency's appropriation act for use in apprehension, surveillance, police, or other law enforcement work. This category also includes site security vehicles, parking enforcement, and general use, but the vehicles are capable of requirements to support enforcement activities. Appendix A provides further definition.

3. Support vehicles: Vehicles assigned to a specific work function or group to support the mission of that group. Vehicles are generally passenger vehicles or light-duty pickup trucks and may contain after-market modifications to support the mission.

4. Transport vehicles: Light, medium, or heavy-duty trucks used to transport an operator and tools or equipment of a non-specific design or nature. The vehicle's uses include repair, maintenance, or delivery.

5. Specialty vehicles: Vehicles designed to accommodate a specific purpose or mission (such as ambulances, mobile cranes, and handicap controls).

6. Shuttles/buses: Vehicles designed to carry more than 12 passengers and further outlined in 49 CFR 532.2.

7. Low-speed vehicle: Vehicles that are legally limited to roads with posted speed limits up to $45 \mathrm{mph}$ and that have a limited load-carrying capability.

\subsection{Alternative Fuel Vehicles}

As the operating agency, WSTF has a unique opportunity to plan for the adoption of BEVs and PHEVs, along with planning for the supporting infrastructure. The adoption of PHEVs and BEVs is a primary goal of the General Services Administration (GSA) and supports the directives previously referenced.

As GSA increases its certification of PHEVs and BEVs, agencies can plan for vehicle replacement through GSA for passenger vehicles and trucks. Table 2 presents the replacement requirements for fleet vehicles. Note that both of the age and mileage requirements need to be met in order for the vehicle to qualify for replacement, except where noted as "or." 


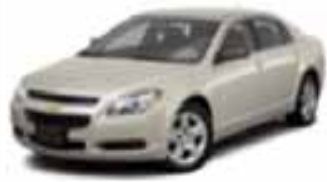

Pool Vehicle

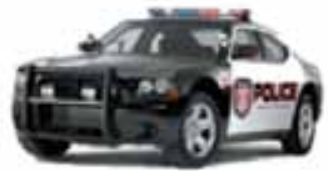

Enforcement Vehicle

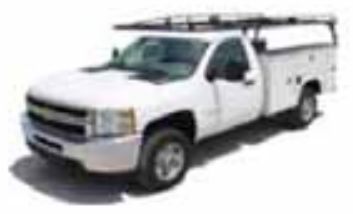

Support Vehicle

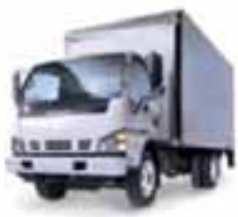

Transport Vehicle

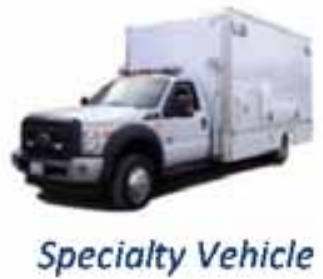

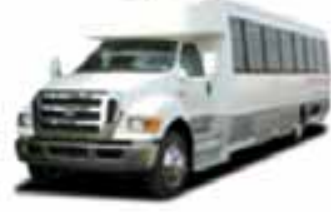

Shuttle / Bus

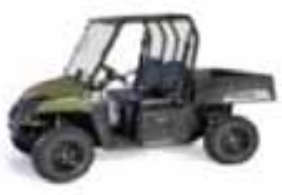

Low Speed

Vehicles

Figure 5. Vehicle missions.

Table 2. General Services Administration vehicle replacement requirements.

\begin{tabular}{lccc}
\hline & GSA Vehicle Replacement Requirements & \\
& Fuel Type & Years & Miles \\
\hline Passenger vehicles & Gasoline or & 3 & 36,000 \\
& alternative fuel & 4 & 24,000 \\
& vehicle & 5 & Any mileage \\
& Hybrid & Any age & 75,000 \\
& Low-speed BEV & 5 & Any miles \\
Light trucks 4 x 2 & Non-diesel & 6 & Any miles \\
& Diesel & 7 & 65,000 \\
Light trucks 4 x 4 & Hybrid & 8 or & 150,000 \\
& Non-diesel & 7 & Any mileage \\
& Diesel & 7 or & 60,000 \\
& Hybrid & 8 or & 150,000 \\
\hline
\end{tabular}

\subsection{Battery Electric Vehicle and Plug-In Hybrid Electric Vehicle Benefits/Challenges}

BEVs are fully powered by the battery energy storage system available onboard the vehicle. The Nissan Leaf is an example of a BEV. Because the BEV has no other energy source for propulsion, the range, power requirements, and mission of the needed vehicle factor greatly in purchasing decisions. Maximizing BEV capabilities typically requires batteries more than an order of magnitude larger in capacity than the batteries in hybrid electric vehicles.

\footnotetext{
${ }^{11}$ http://www.gsa.gov/graphics/fas/VehicleReplacementStandardsJune2011Redux.pdf [accessed January 10, 2014].
} 
PHEVs obtain their power from at least two energy sources. The typical PHEV configuration uses a battery and an ICE that is powered by either gasoline or diesel. PHEV designs differ between manufacturers. However, all PHEVs have a charge-depleting (CD) mode, in which the battery is depleted of its stored energy to propel the vehicle, and a charge-sustaining (CS) mode (or extended range mode) that is entered after CD mode is complete, in which the battery and the ICE work together to provide propulsion. The state of charge of the battery is maintained between set limits. Some PHEVs' operation in CD modes is purely electric, while others employ the engine to supplement the battery power during the initial battery depletion to a set state of charge (usually below 50\%).

\subsubsection{Battery Electric Vehicle Benefits/Challenges}

EPA identifies the following benefits of BEVs: ${ }^{12}$

- Energy efficient: Electric vehicles convert about 59 to $62 \%$ of the electrical energy from the grid to power at the wheels, whereas conventional gasoline vehicles only convert about 17 to $21 \%$ of the energy stored in gasoline to power at the wheels.

- Environmentally friendly: PEVs emit no tailpipe pollutants, although the power plant producing the electricity may emit them. Electricity from nuclear, hydro, solar, or wind-powered plants causes no air pollutants.

- Performance benefits: Electric motors provide quiet, smooth operation and exhibit maximum torque at zero and low speeds, while also requiring less maintenance than ICEs.

- Reduce energy dependence: Electricity is a domestic energy source.

EPA also identifies challenges associated with BEVs, including the following:

- Driving range: Most BEVs can only travel about 100 to 200 miles (or less) before recharging, whereas gasoline vehicles can often travel over 300 miles (and some much further) before refueling.

- Recharge time: Fully recharging the battery pack can take 4 to 8 hours. With a high-power direct current fast charger (DCFC), restoration from a depleted state to $80 \%$ capacity can take approximately 30 minutes.

- Battery cost: The large battery packs are expensive and may need to be replaced one or more times.

- Bulk and weight: Battery packs are heavy and take up considerable vehicle space.

\subsubsection{Plug-in Hybrid Electric Vehicle Benefits/Challenges}

EPA identifies the following benefits of PHEVs: ${ }^{13}$

- Less petroleum use: PHEVs are expected to use about 40 to $60 \%$ less petroleum than conventional vehicles. Because electricity is produced primarily from domestic resources, PHEVs reduce dependence on oil.

- Fewer emissions: PHEVs are expected to emit fewer GHG emissions than conventional vehicles, but as with BEVs, the difference depends largely on the type of power plant supplying the electricity.

- Higher vehicle costs, lower fuel costs: PHEVs will likely cost $\$ 1,000$ to $\$ 7,000$ more than comparable non-PHEVs. Fuel will cost less because electricity is much cheaper than gasoline, but the fuel savings depends on how much of the driving is done on the off-board electrical energy.

\footnotetext{
12 http://www.fueleconomy.gov/feg/evtech.shtml [accessed December 27, 2013].

${ }^{13}$ http://www.fueleconomy.gov/feg/phevtech.shtml [accessed July 19, 2013].
} 
- Recharging takes time: Recharging the battery typically takes several hours. However, PHEVs do not have to be plugged in to be driven. They can be fueled solely with gasoline, but will not achieve maximum range, fuel economy, or fuel savings without charging.

- Measuring fuel economy: Because a PHEV can operate on electricity alone, gasoline alone, or a mixture of the two, EPA provides a fuel economy estimate for gasoline-only operation (CS mode), electric-only operation (all-electric CD mode), or combined gasoline and electric operation (blended CD mode).

In most cases, the PEV retail cost is higher than a non-PEV model. This incremental purchase cost may be a fleet budget challenge; however, many original equipment manufacturers (OEMs) have offered incentives to encourage the use and adoption of BEVs and PHEVs. Some OEMs have recently reduced the vehicle cost, while also increasing vehicle range. Additionally, federal and state incentives have increased the attractiveness of purchasing a PEV. A common assumption is that increasing PEV sales will result in a reduction in this incremental purchase cost and a positive feedback loop will ensue.

\subsection{Plug-In Electric Vehicle Availability}

GSA provides a summary of light and medium-duty passenger vehicles available for lease or purchase through the GSA portal ${ }^{14}$; however, not all BEVs and PHEVs currently on the market are 'certified' to be GSA replacements. Vehicles not on the GSA list of 'certified' vehicles require an agency to self-certify a functional need or provide alternative measures for exemptions. Table 3 summarizes the vehicles that may be suitable replacements and are certified replacements through GSA. Note that the "CD/CS" column provides the EPA fuel economy values for CD and CS modes. The fuel economy of CD mode is provided in units of miles-per-gallon-of-gasoline-equivalent (MPGe). This metric allows for the electricity consumption during CD mode to be compared with fuel consumption during CS mode (or against conventional vehicles). The Nissan Leaf and Mitsubishi i-MiEV are not included in the alternative fuel guide for 2014, but they have appeared in previous guides.

Replacement is dependent on vehicle configuration characteristics and the vehicle mission. Further evaluation related to vehicle purpose and mission follows in Section 5.

Tables 4 through 7 provide summaries of the PHEVs and BEVs either currently available or near commercialization in both passenger cars and pickup trucks, but that do not appear on the GSA 'certified' vehicle list. These vehicles may qualify for use by the agency through demonstrating a functional need.

Table 3. GSA certified PEVs.

\begin{tabular}{lcccc}
\multicolumn{1}{c}{ Make/Model } & GSA Class & Type & CD/CS & GSA Incremental Price \\
\hline Chevrolet Volt & Sedan, Subcompact & PHEV & $98 \mathrm{MPGe} / 37 \mathrm{mpg}$ & $\$ 17,087.18$ \\
Ford C-MAX & Sedan, Subcompact & PHEV & $100 \mathrm{MPGe} / 38 \mathrm{mpg}$ & $\$ 14,899.52$ \\
Energi & & & \\
Ford Focus Electric & Sedan, Subcompact & BEV & $110 \mathrm{MPGe} / 99 \mathrm{mpg}$ & $\$ 16,573.09$ \\
Ford Fusion Energi & Sedan, Compact & PHEV & $100 \mathrm{MPGe} / 38 \mathrm{mpg}$ & $\$ 19,289.99$ \\
\hline
\end{tabular}

Note that EPA differs in vehicle class. EPA identifies the Volt as a compact, the C_MAX Energi as a midsize, the Fusion Energi as a midsize, and the Focus as a compact. ${ }^{15}$

\footnotetext{
${ }^{14}$ http://www.gsa.gov/portal/content/104224 [accessed March 6, 2014].

${ }^{15}$ http://www.fueleconomy.gov/feg/Find.do?action=sbs\&id=34130 [accessed August 1, 2014].
} 
Table 4. OEM PHEV cars and availability.

\begin{tabular}{llc}
\multicolumn{1}{c}{ Make } & \multicolumn{1}{c}{ Model } & Model Year \\
\hline Audi & A3 eTron PHEV & 2015 (estimate) \\
Chevrolet & Volt & 2011 \\
Honda & Accord PHEV & 2014 \\
Toyota & Prius PHEV & 2012 \\
Volvo & V60 Plug-in & 2016 (estimate) \\
BMW & i3 with range extender & 2014 \\
\hline
\end{tabular}

Table 5. OEM BEV cars and availability.

\begin{tabular}{llc}
\multicolumn{1}{c}{ Make } & \multicolumn{1}{c}{ Model } & Model Year \\
\hline BMW & i3 & 2014 \\
Chevrolet & Spark EV & 2014 \\
Fiat & 500e & 2013(California only) \\
Ford & Focus Electric & 2012 \\
Honda & Fit EV & 2013 \\
Kia & Soul EV & 2014 (estimate) \\
Mercedes-Benz & B-Class ED & 2015 (estimate) \\
Nissan & Leaf & 2011 \\
smart & ED & 2014 \\
Tesla & Model S & 2012 \\
Tesla & Model X & 2015 (estimate) \\
Volkswagen & Golf & 2015 (estimate) \\
Volvo & C30 Electric & 2016 (estimate) \\
\hline
\end{tabular}

Table 6. OEM PHEV trucks, vans, and availability.

\begin{tabular}{llc}
\multicolumn{1}{c}{ Make } & \multicolumn{1}{c}{ Model } & Model Year \\
\hline Land Rover & Range Rover Sport & 2016 (estimate) \\
Mitsubishi & Outlander PHEV & 2015 (estimate) \\
Via & VTRUX VR300 & 2013 \\
\hline
\end{tabular}

Table 7. OEM BEV trucks, vans, and availability.

\begin{tabular}{llc}
\multicolumn{1}{c}{ Make } & \multicolumn{1}{c}{ Model } & Model Year \\
\hline Nissan & eNV200 & 2015 (estimate) \\
Toyota & RAV4 EV & 2013 (California only - \\
& & elsewhere 2015 estimate) \\
\hline
\end{tabular}

\subsection{Plug-In Electric Vehicle Charging}

Refueling electric vehicles presents some challenges and some opportunities not encountered when refueling petroleum-fueled vehicles. Recharging the battery of a PHEV follows the same methodology as that for BEVs. This section provides basic information on recharging PEVs. 


\subsubsection{Electric Vehicle Supply Equipment Design}

4.5.1.1 Charging Components. Electric vehicle supply equipment (EVSE) stations deliver electric power from the utility to the applicable charge port on the vehicle. Figure 6 illustrates the primary components of a typical EVSE unit (the EVSE in Figure 6 is an alternating current [AC] Level 2).

The electric utility delivers AC current to the charging location. The conversion from AC to the DC electricity necessary for battery charging can occur either on or off board the vehicle. Section 4.5.1.2 provides further explanation of the different EVSE configurations. For onboard conversion, AC current flows through the PEV inlet to the onboard charger. The charger converts AC to the DC current required to charge the battery. A connector attached to the EVSE inserts into a PEV inlet to establish an electrical connection to the PEV for charging and information/data exchange. Off-board conversion, also known as DC charging, proceeds in a similar manner except that the AC to DC conversion occurs in a charger that is off board the vehicle and, thus, bypasses any onboard charger. For both AC and DC charging, the PEV's battery management system on board the vehicle controls the battery rate of charge, among other functions. All current PEVs have an onboard charger; some BEVs (but no PHEVs currently) accommodate DC charging.

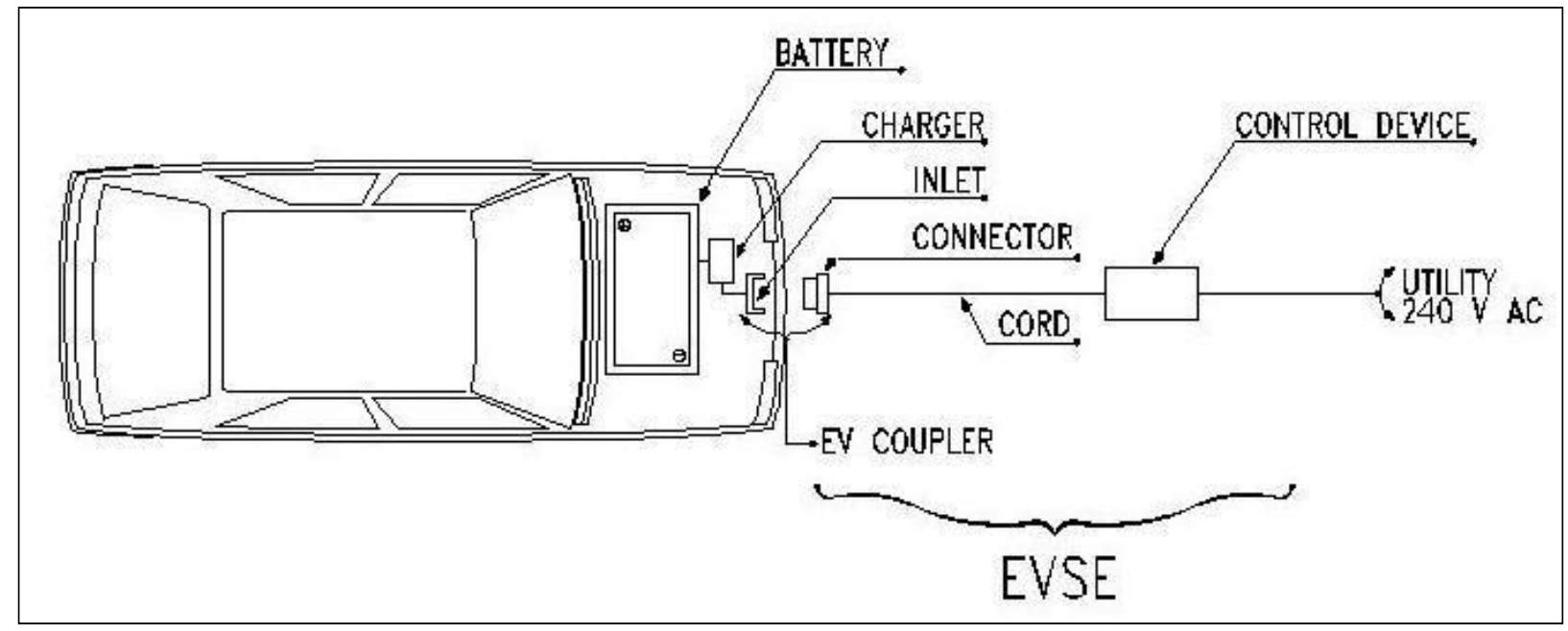

Figure 6. AC Level 2 charging diagram. ${ }^{16}$

4.5.1.2 Charging Configurations and Ratings. The Society of Automotive Engineers standardized the requirements, configurations, and equipment followed by most PEV suppliers in the United States in the J1772 standard. Figure 7 summarizes these attributes and the estimated recharge times. Actual recharge times depend on the onboard equipment, including the charger, battery, and battery management system.

Most PEV manufacturers supply an AC Level 1 cord-set with the vehicle, which provides sufficient capabilities for some drivers, but often provides an emergency backup capability because of the long recharge times. AC recharging capabilities found in the public arena more typically are AC Level 2. Figure 8 depicts a typical J1772-compliant inlet and connector for both AC Levels 1 and 2.

\footnotetext{
${ }^{16}$ http://www.theevproject.com/downloads/documents/Electric\%20Vehicle\%20Charging\%20Infrastructure\%20Deployment\%20 Guidelines\%20for\%20the\%20Greater\%20Phoenix\%20Area\%20Ver\%203.2.pdf [accessed January 15, 2014].
} 


\begin{tabular}{|c|c|c|c|}
\hline \multicolumn{4}{|c|}{ 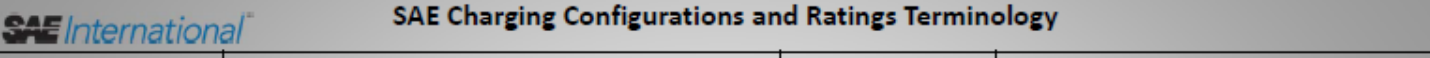 } \\
\hline \multirow{5}{*}{$\begin{array}{l}\text { AC level } 1 \\
\text { (SAE J1772 }\end{array}$} & PEV includes on-board charger & \multirow[t]{5}{*}{ *DC Level 1} & EVSE includes an off-board charger \\
\hline & $\begin{array}{l}120 \mathrm{~V}, 1.4 \mathrm{~kW} @ 12 \mathrm{amp} \\
120 \mathrm{~V}, 1.9 \mathrm{~kW} @ 16 \mathrm{amp}\end{array}$ & & $200-450 \mathrm{~V} \mathrm{DC}$, up to $36 \mathrm{~kW}(80 \mathrm{~A})$ \\
\hline & Est. charge time: & & Est. charge time ( $20 \mathrm{~kW}$ off-board charger): \\
\hline & PHEV: 7 hrs (SOC* $-0 \%$ to full) & & PHEV: $22 \mathrm{~min}$. (SOC* - 0\% to $80 \%$ ) \\
\hline & BEV: $17 \mathrm{hrs}$ (SOC $-20 \%$ to full) & & BEV: $1.2 \mathrm{hrs}$. (SOC $-20 \%$ to $100 \%)$ \\
\hline \multirow[t]{11}{*}{$\begin{array}{l}\text { AC level } 2 \\
\left(\text { SAE } J 1772^{\mathrm{ma}}\right)\end{array}$} & $\begin{array}{l}\text { PEV includes on-board charger (see below for different } \\
\text { types) }\end{array}$ & \multirow[t]{6}{*}{ *DC Level 2} & EVSE includes an off-board charger \\
\hline & $240 \mathrm{~V}$, up to $19.2 \mathrm{~kW}(80 \mathrm{~A})$ & & $200-450 \mathrm{~V} \mathrm{DC}$, up to $90 \mathrm{~kW}(200 \mathrm{~A})$ \\
\hline & Est. charge time for $3.3 \mathrm{~kW}$ on-board charger & & Est. charge time ( $45 \mathrm{~kW}$ off-board charger): \\
\hline & PEV: 3 hrs (SOC* - 0\% to full) & & PHEV: $10 \mathrm{~min}$. (SOC* $-0 \%$ to $80 \%$ ) \\
\hline & BEV: $7 \mathrm{hrs}$ (SOC $-20 \%$ to full) & & BEV: $20 \mathrm{~min}$. (SOC $-20 \%$ to $80 \%$ ) \\
\hline & Est. charge time for $7 \mathrm{~kW}$ on-board charger & & \\
\hline & PEV: 1.5 hrs (SOC* $-0 \%$ to full) & \multirow[t]{6}{*}{ *DC Level 3 (TBD) } & EVSE includes an off-board charger \\
\hline & BEV: 3.5 hrs (SOC $-20 \%$ to full) & & 200-600V DC (proposed) up to $240 \mathrm{~kW}(400 \mathrm{~A})$ \\
\hline & Est. charge time for $20 \mathrm{~kW}$ on-board charger & & Est. charge time ( $45 \mathrm{~kW}$ off-board charger): \\
\hline & PEV: 22 min. (SOC* $-0 \%$ to full) & & BEV (only): $<10 \mathrm{~min}$. (SOC* $-0 \%$ to $80 \%$ ) \\
\hline & BEV: $1.2 \mathrm{hrs}$ (SOC $-20 \%$ to full) & & \\
\hline •AC Level 3 (TBD) & $>20 \mathrm{~kW}$, single phase and 3 phase & & \\
\hline \multicolumn{4}{|c|}{$\begin{array}{l}\text { "Not finalized } \\
\text { Voltages are nominal configuration voltages, not coupler ratings } \\
\text { Rated Power is at nominal configuration operating voltage and coupler rated current } \\
\text { Ideal charge times assume } 90 \% \text { efficient chargers, } 150 \mathrm{~W} \text { to } 12 \mathrm{~V} \text { loads and no balancing of Traction Battery Pack }\end{array}$} \\
\hline \multicolumn{4}{|c|}{$\begin{array}{l}\text { 1) BEV ( } 25 \mathrm{kWh} \text { usable pack size) charging always starts at } 20 \% \mathrm{SOC} \text {, faster than a } 1 \mathrm{C} \text { rate (total capacity charged in one hour) will also stop at } 80 \% \text { SOC instead of } \\
100 \%\end{array}$} \\
\hline
\end{tabular}

Figure 7. Society of Automotive Engineers charging configurations and ratings terminology. ${ }^{17}$

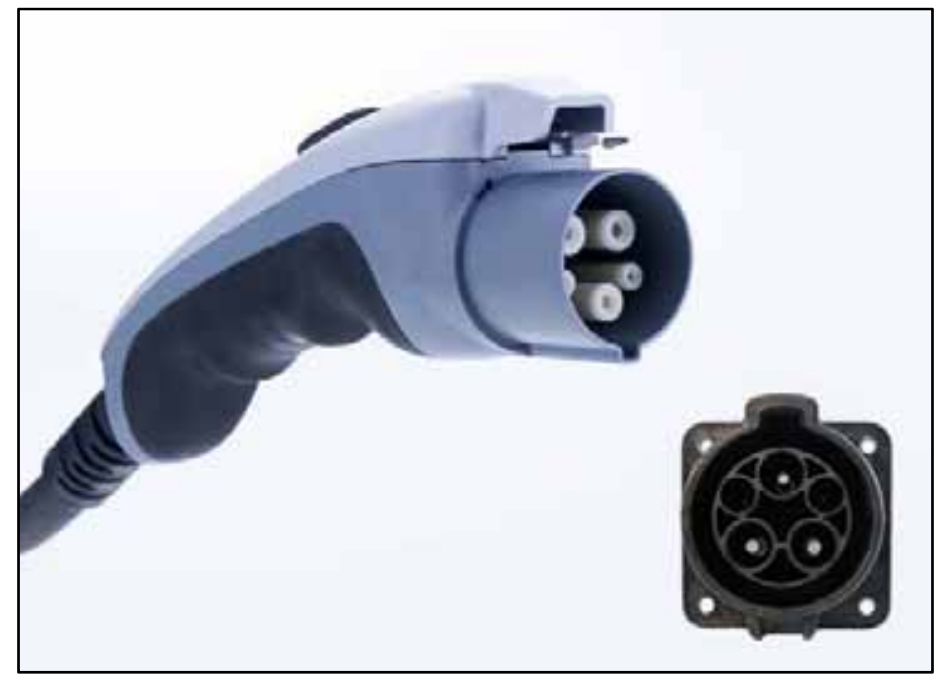

Figure 8. J1772 connector and inlet. ${ }^{18}$

${ }^{17}$ http://www.sae.org/smartgrid/chargingspeeds.pdf [accessed January 15, 2014].

${ }^{18}$ http://carstations.com/types/j09 [accessed January 15, 2014]. 
The J1772 standard also identifies requirements for DC charging. For PEVs that accept both AC and DC inputs, the Society of Automotive Engineers approved a single connector and inlet design. Figure 9 shows this connector, which is colloquially known as the J1772 "combo connector."
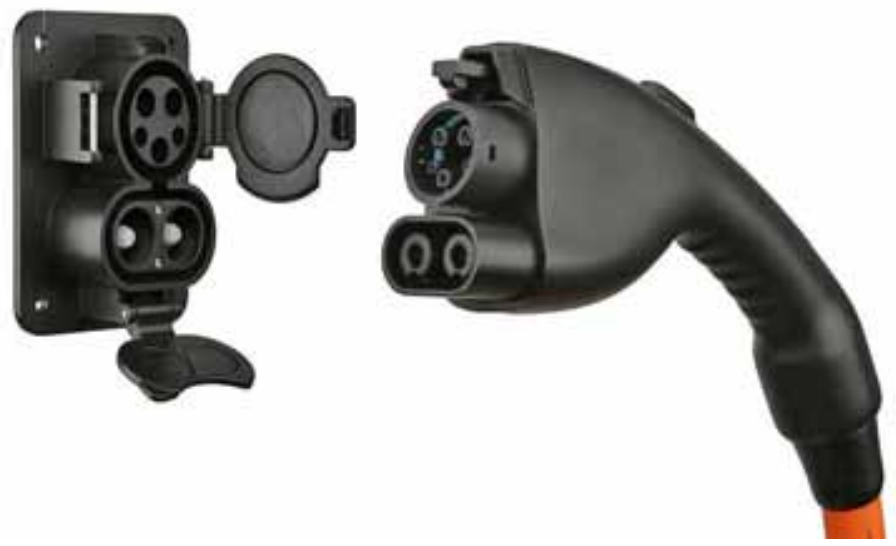

Figure 9. J1772-compliant combo connector. ${ }^{19}$

Some BEVs introduced in the United States prior to the approval of the J1772 standard for DC charging employ the CHAdeMO (designed in Japan) standard for connector and inlet design. Figure 10 shows this connector. EVSE units that are either J1772-compliant or CHAdeMO-compliant are both known as DCFCs.

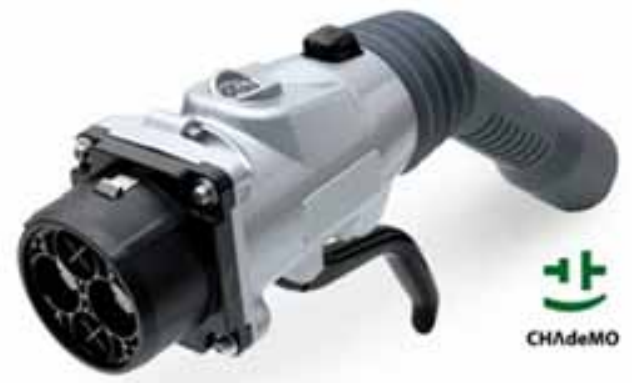

Figure 10. CHAdeMO-compliant connector. ${ }^{20}$

The presence of the two separate standards for DC charging presents challenges for vehicle owners to ensure the EVSE accessed provides the appropriate connector for their vehicle inlet. Not all PEV suppliers include DC charging options. BEV suppliers have provided DC inlets where PHEV suppliers have not, because the rapid recharging provides opportunities for expanded vehicle range with minimal operator wait times. PHEV operators can rely on the gasoline drive in the event they deplete the vehicle's battery. At present, no PHEV on the market or near commercialization has DC charging capability (although the Mitsubishi Outlander PHEV is rumored to be offering DC charging capability as an option). It is noted that DC Level 1 and DC Level 2 charging are commonly combined and labeled DCFC.

Because the battery of a BEV is typically much larger than that of a PHEV, recharge times are longer (see Figure 7). BEVs that see daily mileage near the limits of the advertised range do better when

\footnotetext{
${ }^{19}$ http://www.zemotoring.com/news/2012/10/sae-standardizes-j1772-fast-dc-charging-up-to-100-kw [accessed January 15, 2014].

${ }^{20}$ https://radio.azpm.org/p/azspot/2012/5/10/1632-electric-cars/ [accessed January 15, 2014].
} 
recharged using AC Level 2 EVSE or DCFC, because AC Level 1 recharge times are usually extensive. PHEVs, on the other hand, generally can use AC Level 1 EVSE for overnight charging to ensure a fully charged battery at the start of daily use. AC Level 2 EVSE units provide greater range in the shortest amount of time when intermediate or opportunity charging. DCFC provides the fastest recharge capability for those vehicles equipped with DCFC inlets.

\subsubsection{Electric Vehicle Supply Equipment Stations}

AC Level 2 charging is the predominant rating of publicly accessible EVSE because of its wide acceptance by auto manufacturers and recharge times that are faster than AC Level 1 charging. Purchase and installation costs are more manageable than DCFCs and less space is required. There are several manufacturers of AC Level 2 equipment and the agency should review brands for comparison purposes. Figure 10 provides an example of a public AC Level 2 EVSE unit. ${ }^{21}$

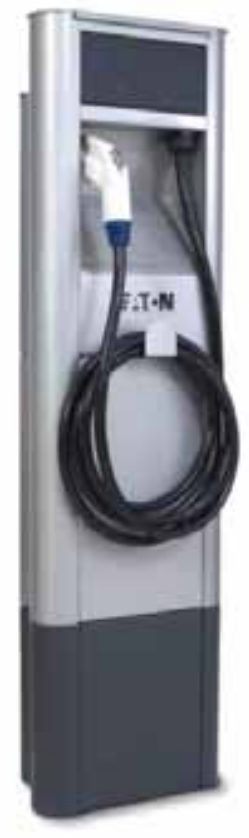

Figure 11. Public AC Level 2 EVSE.

DCFCs also are available from several manufacturers. Figure 12 illustrates one such charger. ${ }^{22}$ This particular charger uses the CHAdeMO connector standard.

In general, installation costs are higher for the DCFC because of the higher voltage requirements and inclusion of the AC to DC converter and other safety and design features. Costs for both types are highly dependent on site characteristics such as distance to the nearest power source, asphalt or concrete cutting and repair, conduit requirements, and payment systems, if any.

Payment and equipment control systems included by some suppliers provide the potential for use by privately owned vehicles for a fee, but can allow agency fleet vehicle use without direct payment. These systems also allow for accurate record keeping of vehicle charging requirements.

\footnotetext{
${ }^{21}$ www.eaton.com/ [accessed January 29, 2014].

${ }^{22}$ http://evsolutions.avinc.com/products/public_charging/public_charging_b [Accessed April 16, 2014].
} 


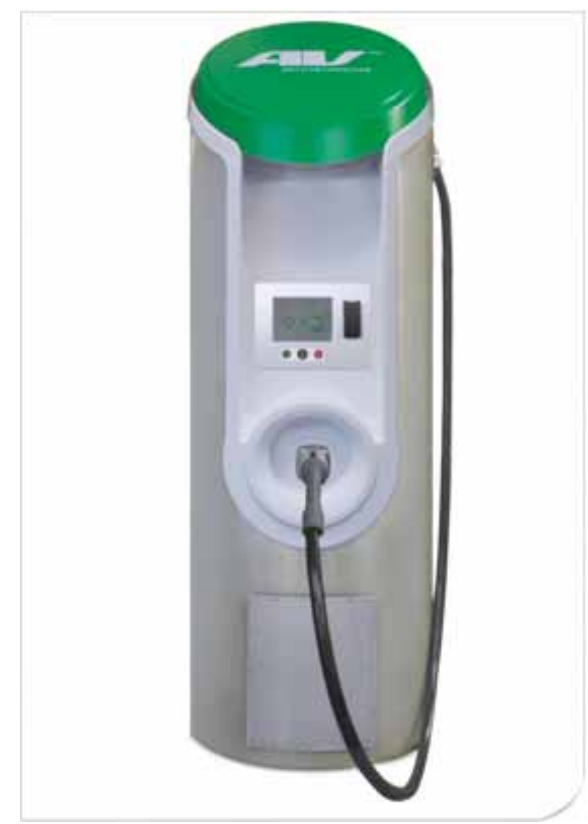

Figure 12. Public DCFC unit.

\section{NATIONAL AERONAUTICE AND SPACE ADMINISTRATION WHITE SANDS TEST FACILITY ANALYSIS \\ 5.1 White Sands Test Facility Fleet}

WSTF reports 137 NASA and GSA vehicle in their complete fleet. Table 8 shows the breakdown of EPA vehicle class by NASA department.

Table 8. WSTF fleet vehicles.

\begin{tabular}{|c|c|c|c|c|c|c|c|c|c|c|c|}
\hline Department & $\begin{array}{c}\text { Sedan } \\
\text { Compact } \\
\text { Midsize } \\
\end{array}$ & $\begin{array}{l}\text { Sedan } \\
\text { Large } \\
\end{array}$ & SUV & $\begin{array}{c}\text { Mini } \\
\text { Van } \\
\end{array}$ & $\begin{array}{c}\text { Cargo } \\
\text { Van } \\
\end{array}$ & $\begin{array}{l}\text { Pass } \\
\text { Van } \\
\end{array}$ & $\begin{array}{c}\text { Pickup or } \\
\text { Light- } \\
\text { Duty } \\
\text { Truck } \\
\end{array}$ & $\begin{array}{c}\text { Heavy- } \\
\text { Duty } \\
\text { Truck } \\
\end{array}$ & Specialty & Bus & Total \\
\hline Environmental & & & & 1 & & & 19 & & & & 20 \\
\hline $\begin{array}{l}\text { Facility } \\
\text { Engineering }\end{array}$ & & & 4 & 1 & 2 & 1 & 31 & 1 & 9 & & 49 \\
\hline $\begin{array}{l}\text { Mission } \\
\text { Services }\end{array}$ & 1 & & 1 & & 2 & & 6 & 1 & & 1 & 12 \\
\hline Labs & & & & 2 & & & 4 & & & & 6 \\
\hline NASA-RC/A/E & & & 3 & & & & 2 & & & & 5 \\
\hline Propulsion & & & 1 & 4 & & & 13 & & & & 18 \\
\hline NS3 & & & 5 & & & & 2 & & 6 & & 13 \\
\hline Security & & & 2 & & & & 12 & & & & 14 \\
\hline Total & 1 & & 16 & 8 & 4 & 1 & 89 & 2 & 15 & 1 & 137 \\
\hline
\end{tabular}

Based on WSTF input on fleet vehicles, the mission category by vehicle type was completed. Table 9 shows the results. 
Table 9. WSTF fleet mission assessment.

\begin{tabular}{|c|c|c|c|c|c|c|c|c|c|c|c|}
\hline Mission & $\begin{array}{c}\text { Sedan } \\
\text { Compact } \\
\text { Midsize } \\
\end{array}$ & $\begin{array}{l}\text { Sedan } \\
\text { Large }\end{array}$ & SUV & $\begin{array}{c}\text { Mini } \\
\text { Van } \\
\end{array}$ & $\begin{array}{c}\text { Cargo } \\
\text { Van } \\
\end{array}$ & $\begin{array}{l}\text { Pass } \\
\text { Van }\end{array}$ & $\begin{array}{c}\text { Pickup or } \\
\text { Light-Duty } \\
\text { Truck }\end{array}$ & $\begin{array}{c}\text { Heavy- } \\
\text { Duty } \\
\text { Truck }\end{array}$ & Specialty & Bus & Total \\
\hline Pool & & & 8 & 8 & & & 5 & & & & 21 \\
\hline Support & 1 & & 4 & & 3 & & 22 & 1 & & & 31 \\
\hline Enforcement & & & 2 & & & & 12 & & & & 14 \\
\hline Transport & & & 1 & & 1 & 1 & 47 & 1 & & 1 & 52 \\
\hline Specialty & & & 1 & & & & 3 & & 15 & & 19 \\
\hline Total & 1 & & 16 & 8 & 4 & 1 & 89 & 2 & 15 & 1 & 137 \\
\hline
\end{tabular}

\subsection{Survey Results}

Ten vehicles were included in the study at WSTF. Eight vehicles have support missions and two are law enforcement. Table 10 presents a summary of these vehicles and Table 11 provides details about the monitored vehicles.

Table 10. Vehicle study summary.

\begin{tabular}{lccccccc} 
& & & & & \multicolumn{3}{c}{ Truck } \\
\multicolumn{1}{c}{ Mission } & Sedan - & Sedan - & & Van- & Pickup & Heavy- \\
Compact & Midsize & Minivan & SUV & Cargo & Truck & Duty & Total \\
\hline Support & & & 2 & 2 & & 4 & 8 \\
Law Enforcement & & & & & 2 & 2 \\
\hline Total & & 2 & 2 & & 6 & 10 \\
\hline
\end{tabular}

Table 11. Detailed WSTF vehicle index.

\begin{tabular}{ccccccc}
\hline Log & Fleet Vehicle Id & Make & Model & Year & EPA Class & Mission \\
\hline 9 & G62-2618B & Chevrolet & Tahoe & 2005 & SUV & Support \\
10 & G63-2246L & Ford & F-250 & 2011 & Pickup & Support \\
11 & G41-2586D & Dodge & Caravan & 2006 & Minivan & Support \\
12 & G62-3553K & Chevrolet & Tahoe & 2010 & SUV & Support \\
13 & G63-3464H & Chevrolet & Silverado & 2010 & Pickup & Law Enforcement \\
14 & G63-0404D & Chevrolet & Silverado & 2006 & Pickup & Support \\
15 & G63-1990L & Ford & F-250 & 2011 & Pickup & Law Enforcement \\
16 & G62-1017D & Ford & F-150 & 2006 & Pickup & Support \\
17 & G41-5523H & Dodge & Grd Caravan & 2009 & Minivan & Support \\
18 & G63-1722B & Chevrolet & Silverado - 2500 & 2005 & Pickup & Support \\
\hline
\end{tabular}

Specific vehicle references may be made to the vehicle ID or logger ID in this report.

Appendix B provides the analysis of each individual vehicle included in this study. Grouping the vehicles by mission creates an aggregated view of mission requirements to provide observations related to PEV replacement. The missions of these two categories vary considerably; therefore, these missions were evaluated separately. 


\subsection{Data Validity}

WSTF data collection took place from September 21 through December 22, 2011. Vehicle data sheets (presented in Appendix B) detail the collected data for each vehicle, including specific dates the logger provided data.

Of the data collected, validation occurred for $99.2 \%$, while null values exist for the balance. Table 12 shows this information by mission type.

Table 12. Vehicle data logger reporting summary.

\begin{tabular}{cccc}
\hline \multicolumn{4}{c}{ Vehicle Data Logger Reporting Summary } \\
Mission & \% Collected & \% Null Values & Total \\
\hline Support & 99.1 & 0.9 & $100 \%$ \\
Law Enforcement & 99.8 & 0.2 & $100 \%$ \\
All Vehicles & 99.2 & 0.8 & $100 \%$ \\
\hline
\end{tabular}

\subsection{White Sands Test Facility Support Vehicles Evaluation}

\subsubsection{Survey and Site Information}

Support vehicles provide a specific work function, facilitating the mission of a particular group. The vehicles are generally passenger or light-duty pickup trucks and may contain after-market modifications to support the mission. While assigned to maintenance and service areas, missions may vary depending on agency needs.

Incorporation of BEVs and/or PHEVs into the support mission is a definite possibility. Support vehicles used for shorter trips or outings qualify for BEV or PHEV replacement, while other support vehicle activities that are associated with longer trips may require PHEV capabilities.

\subsubsection{Summary for Support Vehicles}

Appendix B provides the vehicle data sheets for each of the support vehicles monitored. This section aggregates data for all support vehicles for WSTF. Table 13 summarizes support vehicle travel during the study period for those days in which the vehicle was driven. Vehicle use occurred primarily between 0500 and 1400 hours daily. The vehicles were driven 10,020 miles, logged 572 hours, and idled 94 hours during the 92-day study period.

Table 13. WSTF support vehicles travel summary.

\begin{tabular}{|c|c|c|c|c|}
\hline \multicolumn{5}{|c|}{ Support Vehicles Travel Summary } \\
\hline & $\begin{array}{c}\text { Per Day } \\
\text { Average/Peak }\end{array}$ & $\begin{array}{c}\text { Per Outing } \\
\text { Average/Peak }\end{array}$ & $\begin{array}{c}\text { Per Trip } \\
\text { Average/Peak }\end{array}$ & Total \\
\hline Travel Distance (Miles) & $27.7 / 215.2$ & $10.6 / 214.7$ & $2.4 / 88.7$ & 10,020 \\
\hline Travel Time (Minutes) & $94.9 / 389.0$ & $36.3 / 813.0$ & $8.4 / 292.0$ & 34,365 \\
\hline Idle Time (Minutes) & 15.7/NA & 6.0/NA & $1.4 / \mathrm{NA}$ & 5,669 \\
\hline
\end{tabular}

\subsubsection{Support Vehicles Daily Summary}

Figure 13 identifies daily travel distance and time for all support vehicles. The green line and bars indicate the typical electric range on a single charge for a PHEV, while the blue line and bars (including the green bars) indicate the same for a BEV. Figures 14 and 15 show the composite history in distance and time traveled for the support vehicles. In the stacked bar charts of Figures 14 and 15, the contribution of each vehicle is indicated by a different color. 
When driven, the average travel distance per day for support vehicles was 27.7 miles. On $95 \%$ of the vehicle days, the daily travel was less than the 70 miles considered to be within the BEV safe range (i.e., while BEV range can vary based on several factors, most BEVs provide at least 70 miles of vehicle range on a single battery charge). Five percent of the support vehicles' daily travel was greater than 70 miles. Further, $71 \%$ of vehicle travel days were less than the 40 miles considered to be within the CD range of a PHEV.

Figures 14 and 15 show that the vehicles were not used every day, although there were many days when many of the vehicles were in use. Vehicles G63-1722B and G41-2586D had the highest number of travel days, while vehicles G62-1017D and G41-5523H had the least.

Figure 16 displays the summary of vehicle use by time of day for all support vehicles.
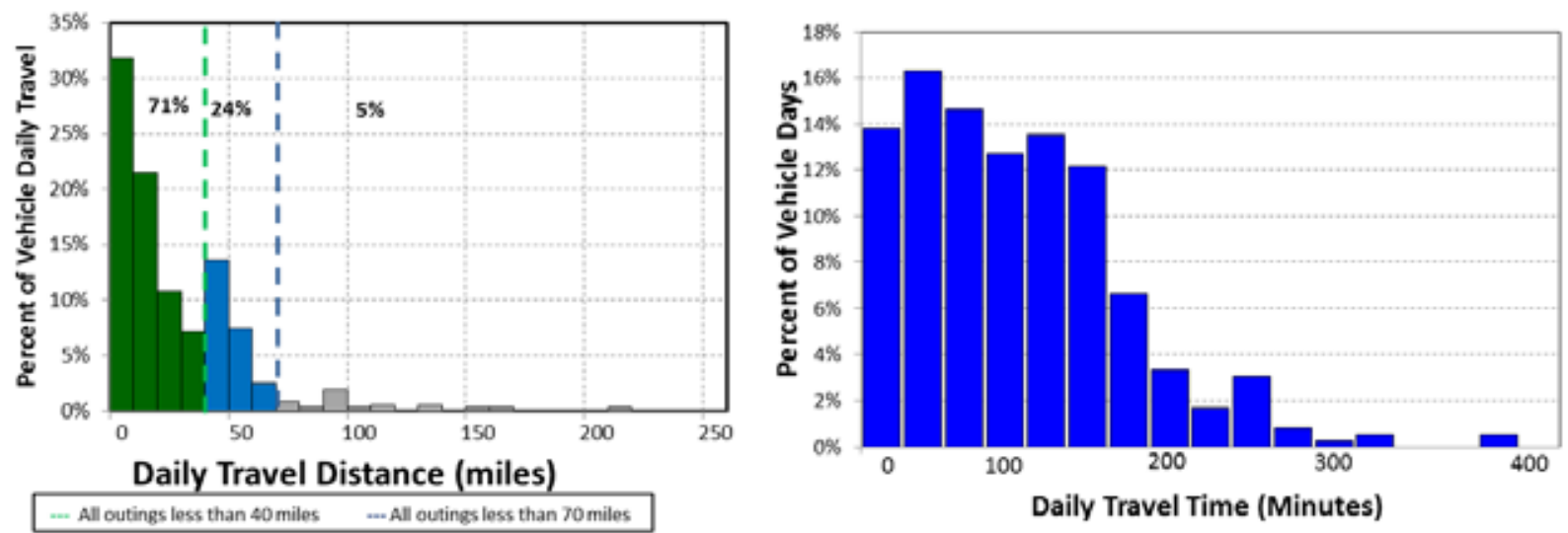

Figure 13. WSTF support vehicle daily travel miles and time (all vehicles).

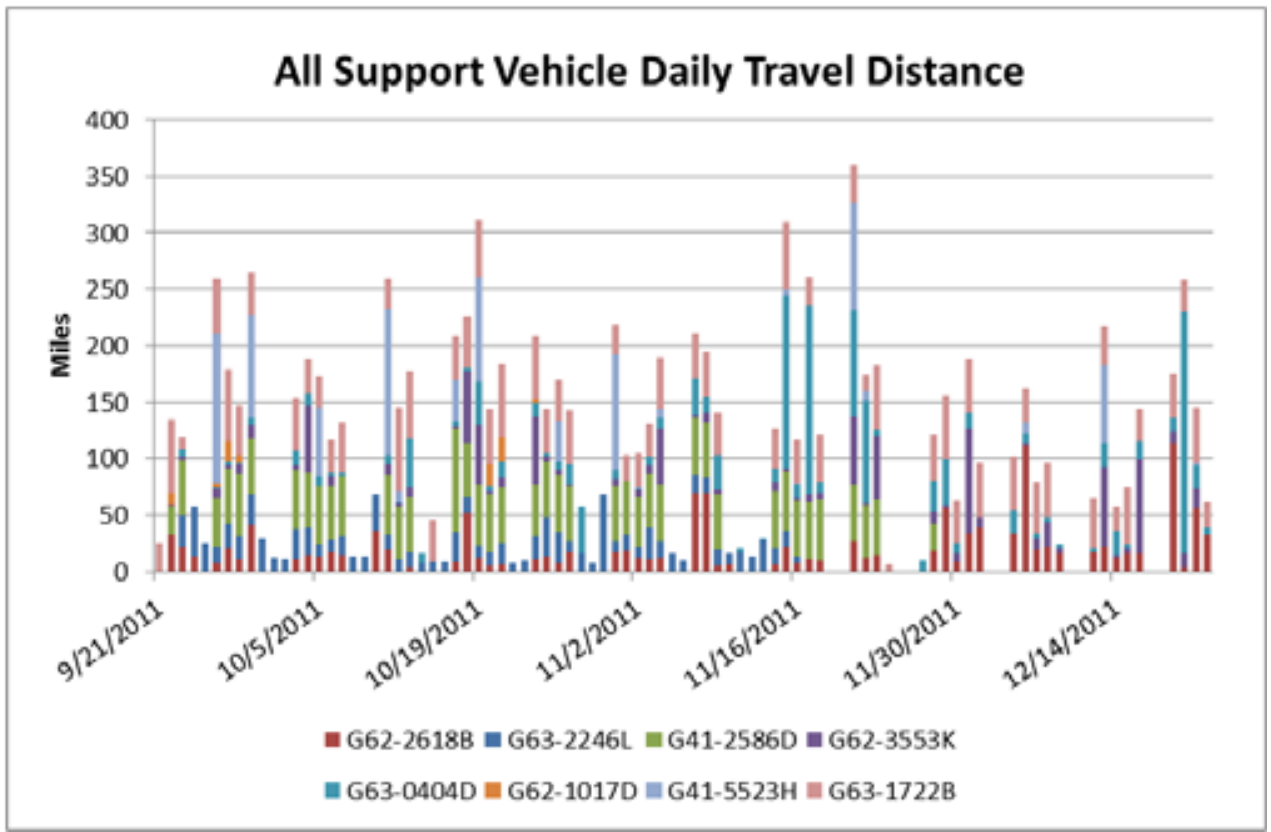

Figure 14. WSTF support vehicle daily travel history (all vehicles). 


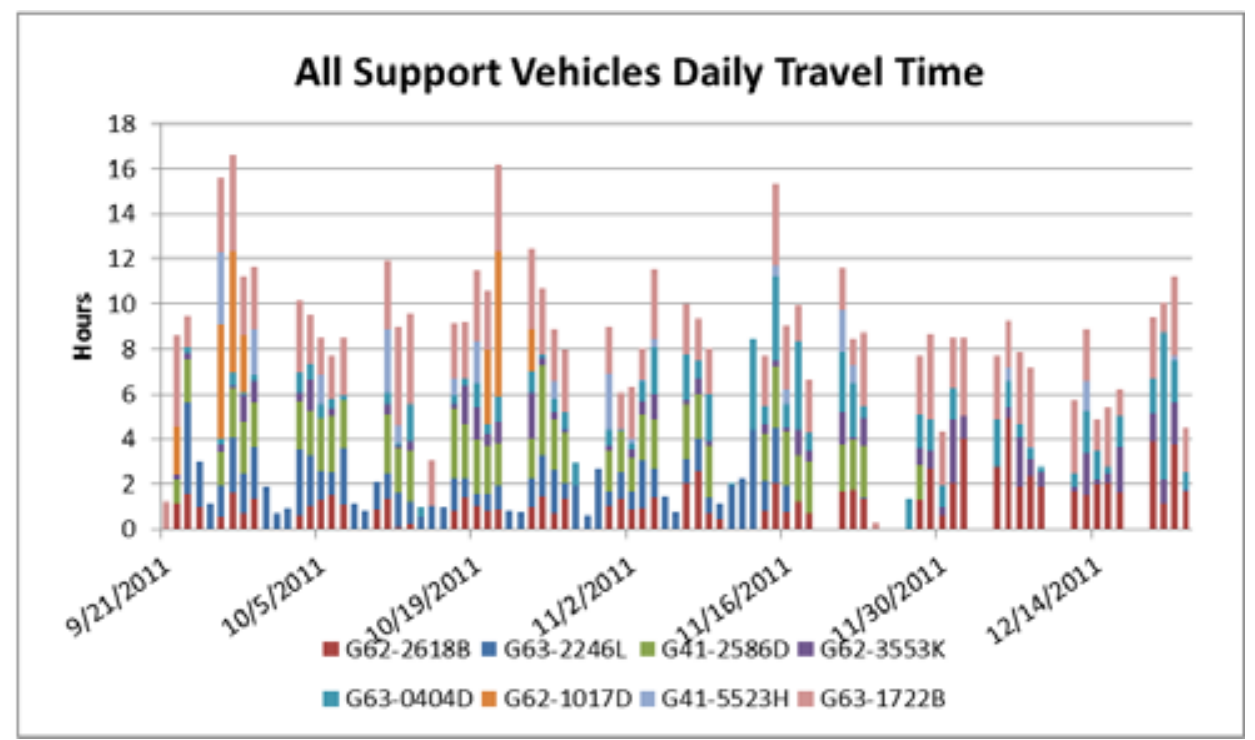

Figure 15. WSTF support vehicles travel time (all vehicles).

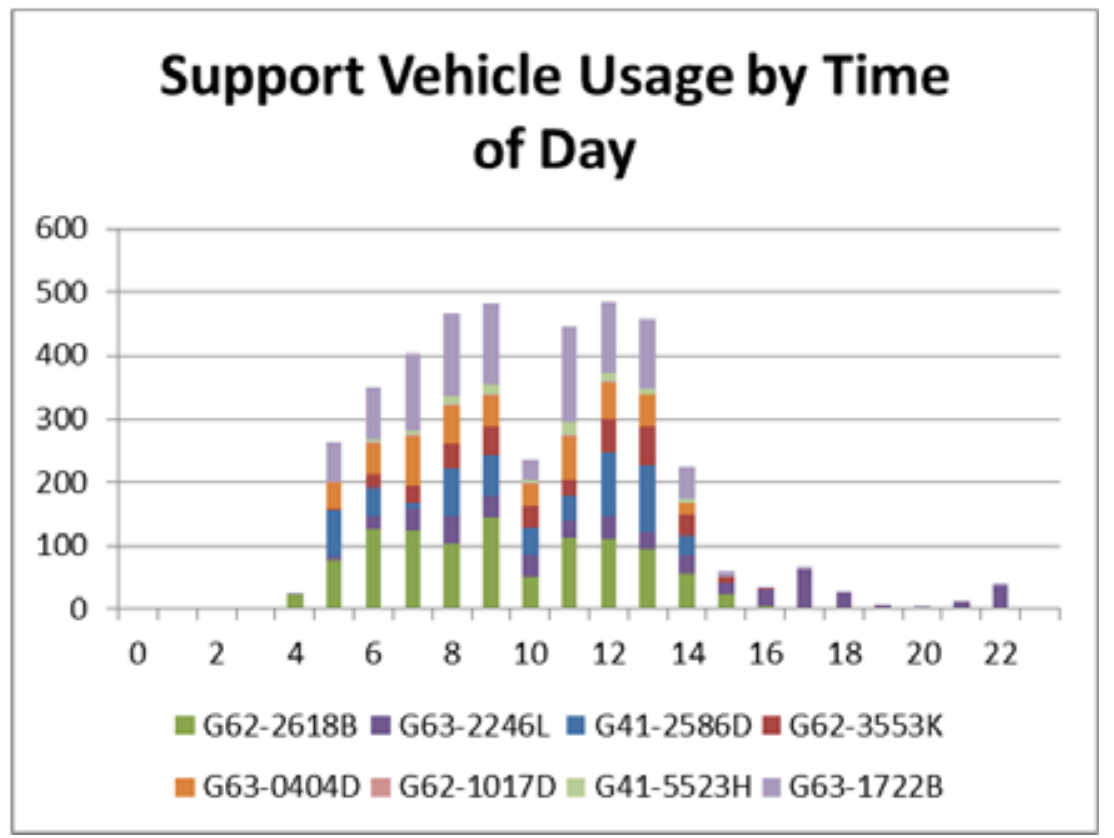

Figure 16. WSTF support vehicles hourly usage.

Figure 17 shows the outing distances traveled, including data for all support vehicles.

Appendix B provides the details of each of the support vehicle's outing travel.

The average travel outing for support vehicles was 10.6 miles. On $98 \%$ of these vehicle outings, the distance traveled was less than the 70 miles considered to be within the BEV safe range. Only $2 \%$ percent of support outing travel was greater than 70 miles. Further, $94 \%$ of vehicle travel outings were less than 40 miles considered to be within the CD range of a PHEV. In summary, these vehicles can be characterized by fairly low daily travel and outing distances (i.e., the average numbers are quite low), with a few days of travel that exceeded the typical BEV range. 


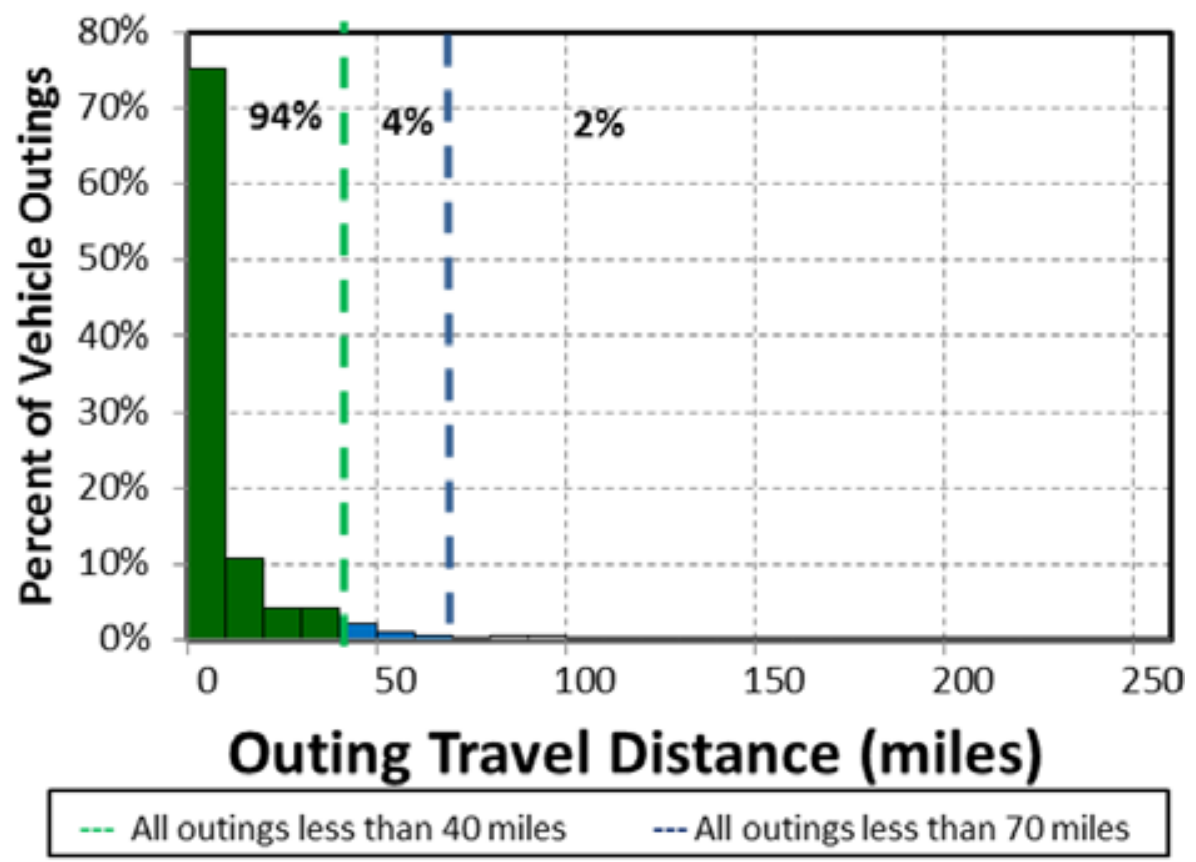

Figure 17. WSTF support vehicle outings.

\subsubsection{White Sands Test Facility Support Vehicle Observations/Summary}

There appears to be three choices for WSTF in implementing PEVs into the support fleet. It should be noted that the objective would be to incorporate as many BEVs as possible to realize the advantages of reduced petroleum usage and reduced emissions of GHGs.

1. All BEV fleet: While some BEV manufacturers report vehicle range exceeding 70 miles, Intertek recommends careful evaluation of experienced range to ensure vehicle missions are accomplished. Nevertheless, assuming the 70-mile safe range for a BEV, an all-BEV fleet does not appear to be possible due to the length of some of the daily travel.

2. Mixed BEV/PHEV fleet: Certainly, PHEVs can accomplish the same mission as the current fleet when only considering travel times and distances, because the PHEV's gasoline engine can provide motive power when the battery has been depleted. Figure 13 shows that on $71 \%$ of all vehicle travel days, the total daily travel was less than 40 miles, which typically is the maximum distance a PHEV will travel in CD mode. This represents a significant operating cost savings opportunity, while retaining the ability to go longer distances when needed. In addition, $94 \%$ of the outings are less than 40 miles and could be completed in CD mode for certain PHEVs if the battery is fully charged prior to the outing.

Meanwhile, $98 \%$ of the outings are within the typical capability of a BEV; this meant that EVSE at the home base could provide recharge energy for another outing. A mixed fleet requires fleet manager attention to assign vehicles appropriately for the anticipated use on that day.

Figure 13 also shows $95 \%$ of daily travel was within the typical range of a BEV. This would suggest that $5 \%$ of the fleet could be PHEVs to handle the travel greater than 70 miles per day without requiring additional opportunity charging during daytime stops and $95 \%$ of the fleet could be BEVs. However, this does not allow for use of several vehicles at the same time and would require a greater level of fleet management, with the daily assignment of vehicles based on anticipated driving distance. Allowing more conservatism in assigning vehicles, two PHEVs and six BEVs could conservatively meet the demand for these eight support vehicles. All monitored support vehicles were 
pickup trucks, minivans, or SUVs and replacement PEVs are currently available for these vehicle types.

3. All PHEV fleet: As noted above, PHEVs can accomplish the same mission as the current fleet when only considering travel times and distances. Replacing all current vehicles with PHEVs only requires an evaluation of the individual vehicle capabilities of currently available PHEVs to meet current support requirements. These eight support vehicles have replacement PEVs available. Data show that for a significant number of days, the PHEV will operate in a CD mode. The first 40 miles of longer travel days would also be powered by (at least mostly) electricity; therefore, $71 \%$ of all support vehicle travel would be (again, at least mostly) battery powered with only one charge per day. As above, this represents an opportunity for significant operating cost savings, while retaining the ability to go longer distances when needed. Intermediate charging opportunities provide additional benefit, enhancing the CD mode. Data show significant charging opportunities throughout the day during stop times.

The vehicle summary shows sufficient time for charging at the base location during the course of the day and additional opportunities at intermediate charging stations are not required. Given the availability of daytime changing, with experience, WSTF may find that a greater fraction of BEVs within the support vehicle fleet may meet their needs.

Considering a full complement of 31 support vehicles in the total fleet, Intertek notes that one is a heavy-duty truck for which no PEV is currently available as a potential replacement. However, for the balance of the vehicles, Intertek suggests that a mixed fleet may be possible. Even though the remaining vehicles were not monitored, using the same ratio as above suggests a fleet of 22 BEVs and eight PHEVs will conservatively meet vehicle travel requirements. Typically, additional EVSE at frequently visited locations will provide recharging for both the BEV and PHEV that may be of benefit.

\subsubsection{White Sands Test Facility Support Vehicle Charging Needs}

Upon review of these data, Intertek suggests replacement of the studied support fleet with six BEVs and two PHEVs. No available PHEVs at this writing provide for DCFC nor do the data suggest that this would be a significant benefit for PHEVs in the support fleet. A DCFC at the home base will provide a more rapid recharge for BEVs; however, it appears to be unnecessary, given that the data show that $98 \%$ of outings are less than a typical BEV's driving range.

As noted above, AC Level 2 overnight charging of BEVs is typical, whereas overnight charging of PHEVs can usually be accomplished with AC Level 1 charging.

Intertek's experience suggests that each vehicle should have an assigned charging parking space at its home base. Assigned stations require less management attention to ensure completion of overnight charging. BEVs and PHEVs not assigned to these stations also benefit during visits to the location as part of their normal operation. For the entire fleet of support vehicles, the 22 BEVs require 22 AC Level 2 EVSE units for overnight charging and the eight PHEVs require eight AC Level 1 outlets at each vehicle's overnight parking location. Intertek recommends a minimum of two EVSE at each location to maximize charge capability without a significant increase in installation costs. The PHEVs can utilize the AC Level 2 EVSE at the home base during the day to increase the amount of vehicle miles traveled in CD mode. For the monitored vehicles, Intertek suggests BEVs could replace all support vehicles except G62-3553K and G41-5523H.

At times, fleet vehicles obtain benefit from using public charging infrastructure. Figure 18 displays the availability of public charging for the WSTF area at the time of this writing. The one indicated station provides AC Level 2 EVSE. It may be of use to vehicles traveling to Las Cruces from WSTF. 


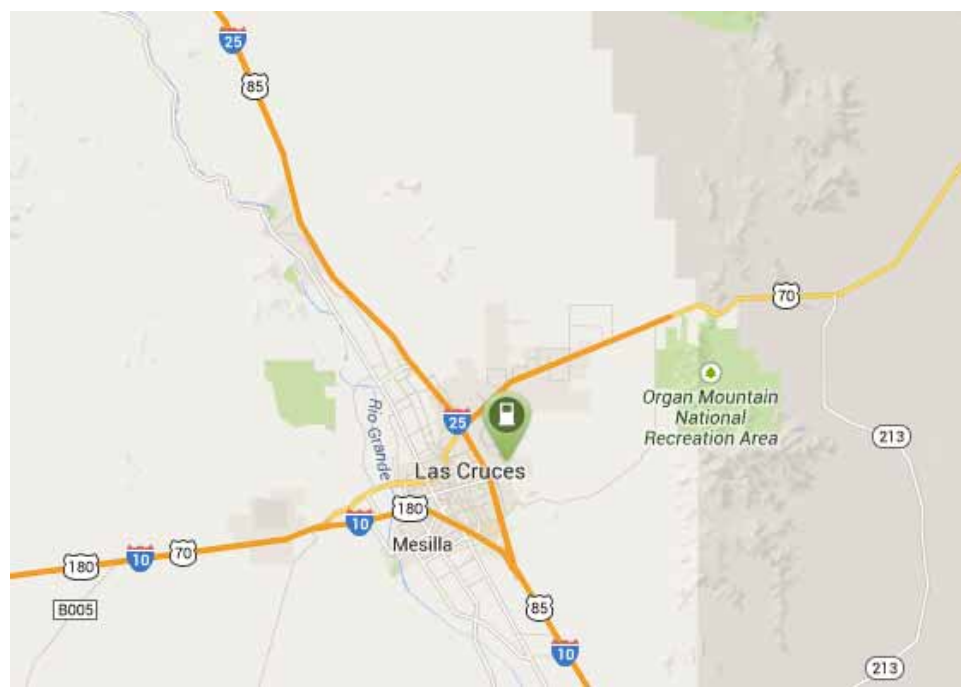

Figure 18. Public EVSE in WSTF region. ${ }^{23}$

\subsection{Law Enforcement Vehicles Evaluation}

Enforcement vehicles typically are light-duty motor vehicles that are specifically approved in an agency's appropriation act for use in apprehension, surveillance, police, or other law enforcement work. Enforcement missions can vary by agency, location, and jurisdiction; however, they typically utilize sedans, minivans, vans, or small pickup trucks and typically do not carry specific cargo or equipment.

Incorporation of BEVs and/or PHEVs into the enforcement mission is a definite possibility. Enforcement vehicles used to patrol small areas and for parking enforcement activities qualify for BEV or PHEV replacement, while other law enforcement vehicle activities associated with longer trips may require PHEV capabilities.

\subsubsection{Summary for Enforcement Vehicles}

Appendix B provides the vehicle data sheets for the enforcement vehicles that were monitored.

Table 14 summarizes enforcement vehicle travel during the study period. Vehicle use occurred primarily during extended day shift hours. Enforcement vehicles traveled 11,477 miles, logged 960 hours, and idled 246 hours during the 92-day study period.

Table 14. Support vehicle travel summary.

\begin{tabular}{lcccc}
\hline \multicolumn{4}{c}{ Enforcement Vehicle Travel Summary } & \\
& Per Day & Per Outing & Per Trip & \\
& Average/Peak & Average/Peak & Average/Peak & Total \\
\hline Travel Distance (Miles) & $117.1 / 249.8$ & $61.4 / 413.1$ & $6.3 / 52.6$ & 11,477 \\
Travel Time (Minutes) & $587.5 / 1,167.0$ & $307.9 / 2,304.0$ & $31.8 / 404.0$ & 57,580 \\
Idle Time (Minutes) & $150.7 / \mathrm{NA}$ & $79.0 / \mathrm{NA}$ & $8.2 / \mathrm{NA}$ & 14,773 \\
\hline
\end{tabular}

\footnotetext{
${ }^{23}$ http://www.plugshare.com/ [accessed September 6, 2014].
} 


\subsubsection{Enforcement Vehicle Daily Summary}

Figure 19 identifies daily travel distance and time for the enforcement vehicles. The green line and bars indicate typical electric range on a single charge for a PHEV, while the blue line and bars indicate the same for a BEV. Figures 20 and 21 show the composite history in distance and time traveled for the enforcement vehicles.
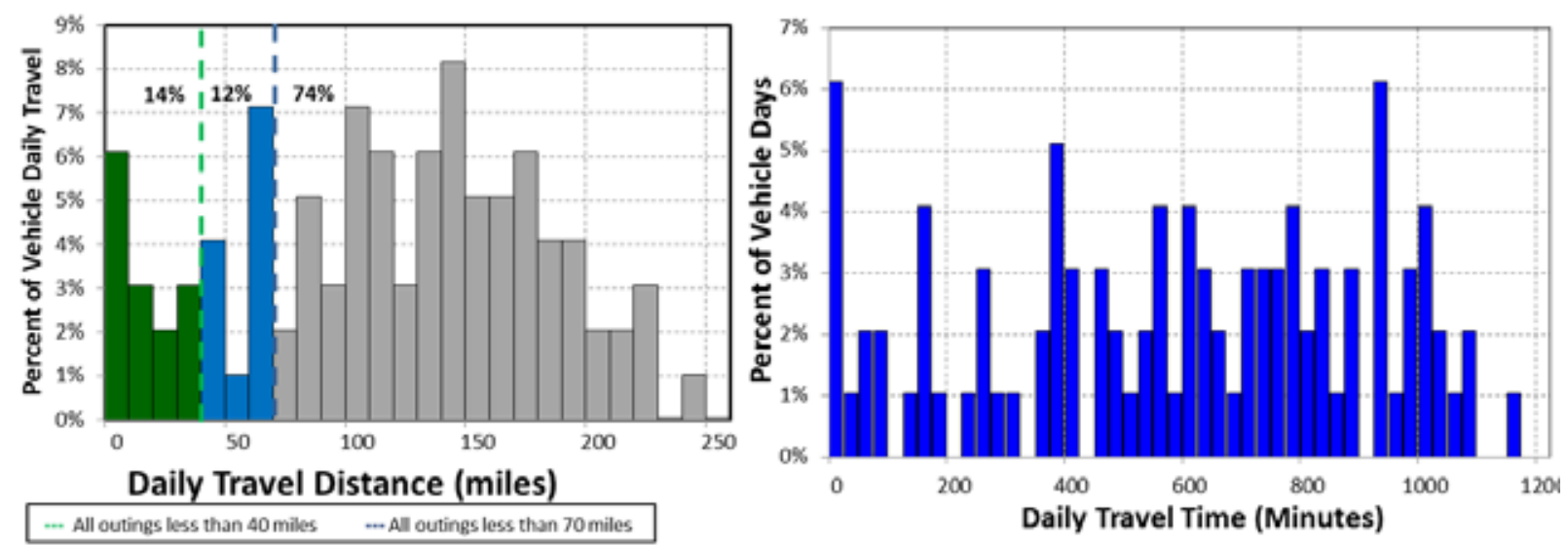

Figure 19. Enforcement vehicle percentage of daily use versus daily travel miles and time (all vehicles).

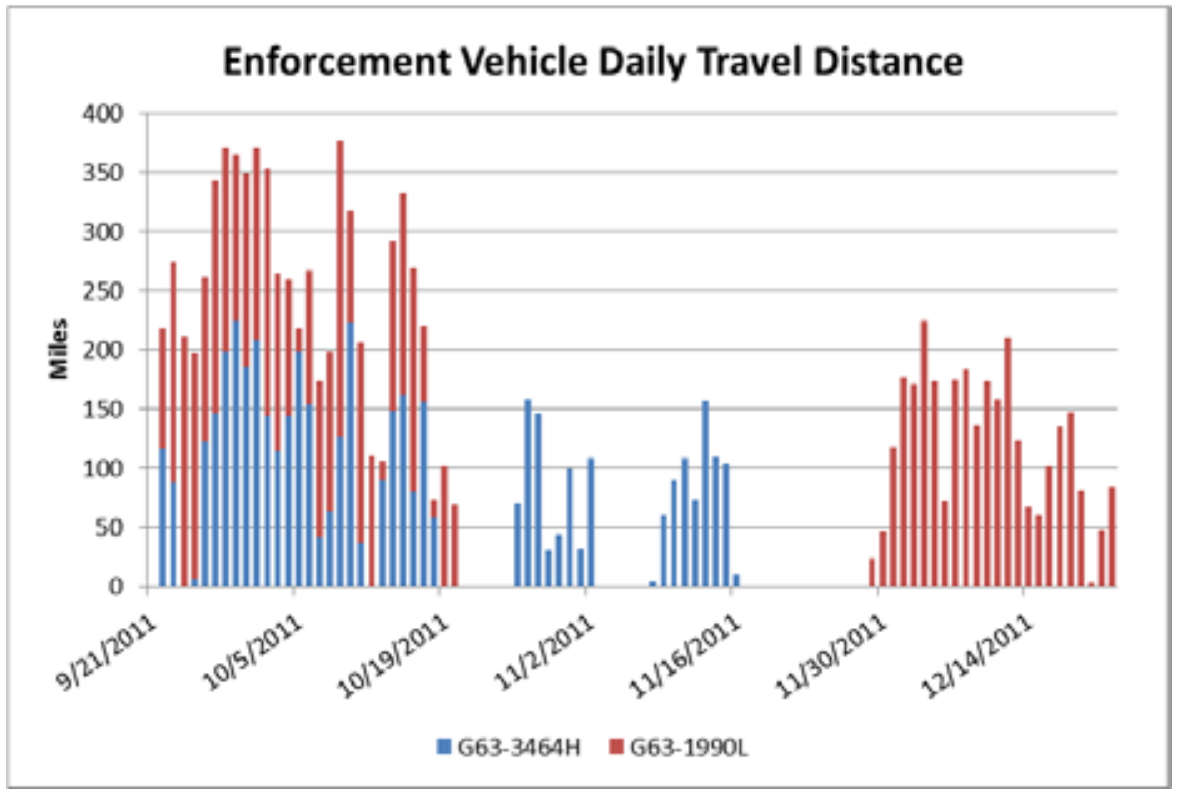

Figure 20. Enforcement vehicle daily travel miles (all vehicles). driven.

The history graphs identify when both vehicles may be in use at the same time and the total miles

During the study period, the average travel distance per day, when driven, by the enforcement vehicles was 117.1 miles. On $26 \%$ of these vehicle days, the daily travel was less than the 70 miles considered to be within the BEV safe range. Seventy-four percent of enforcement vehicle daily travel was greater than 70 miles and $14 \%$ of vehicle travel days were less than the 40 miles considered to be within the CD mode range of a PHEV. 
Figures 20 and 21 show that the vehicles were not used every day, although frequent usage was indicated. as well as usage of both vehicles at the same time. Figure 22 displays a summary of use by time of day for the combined enforcement vehicles.

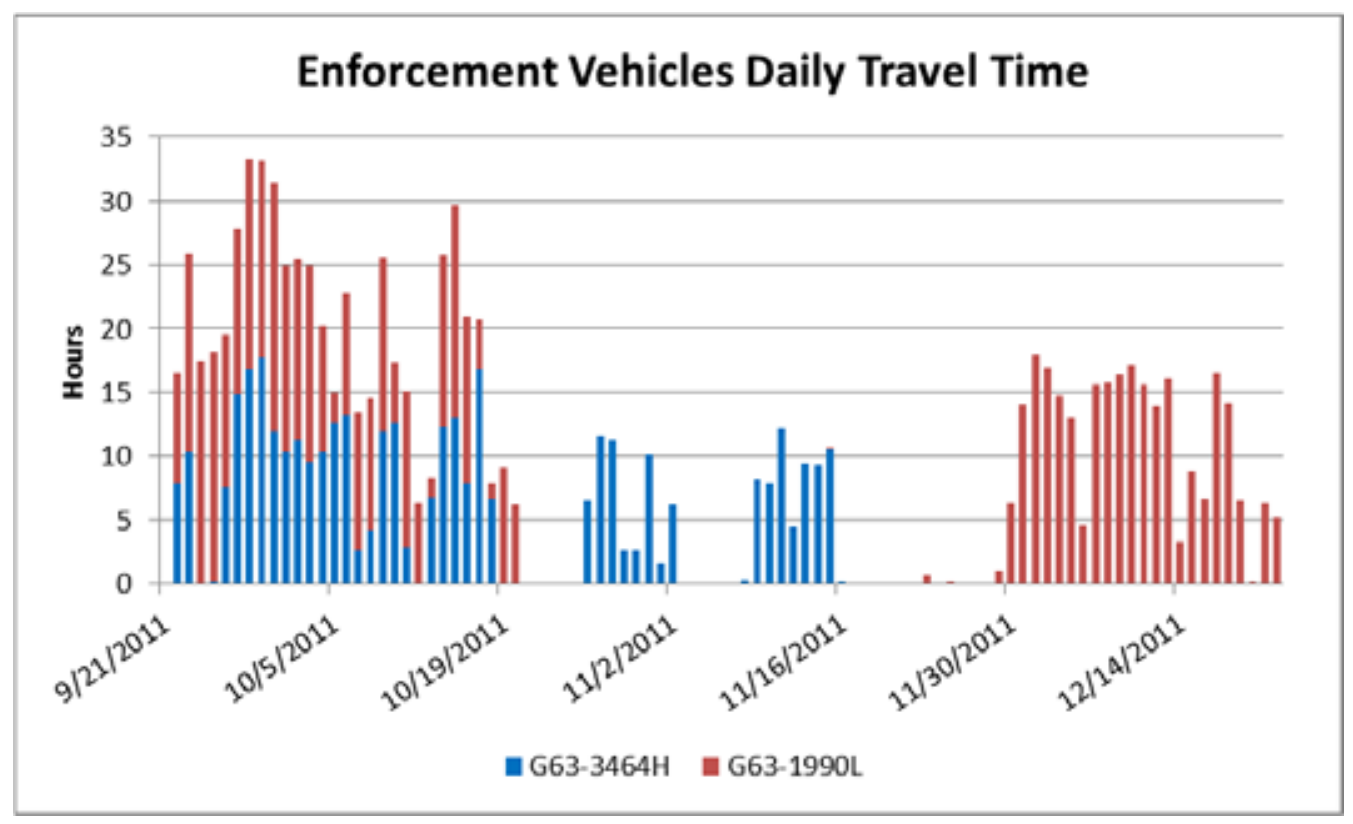

Figure 21. Enforcement vehicle daily travel time (all vehicles).

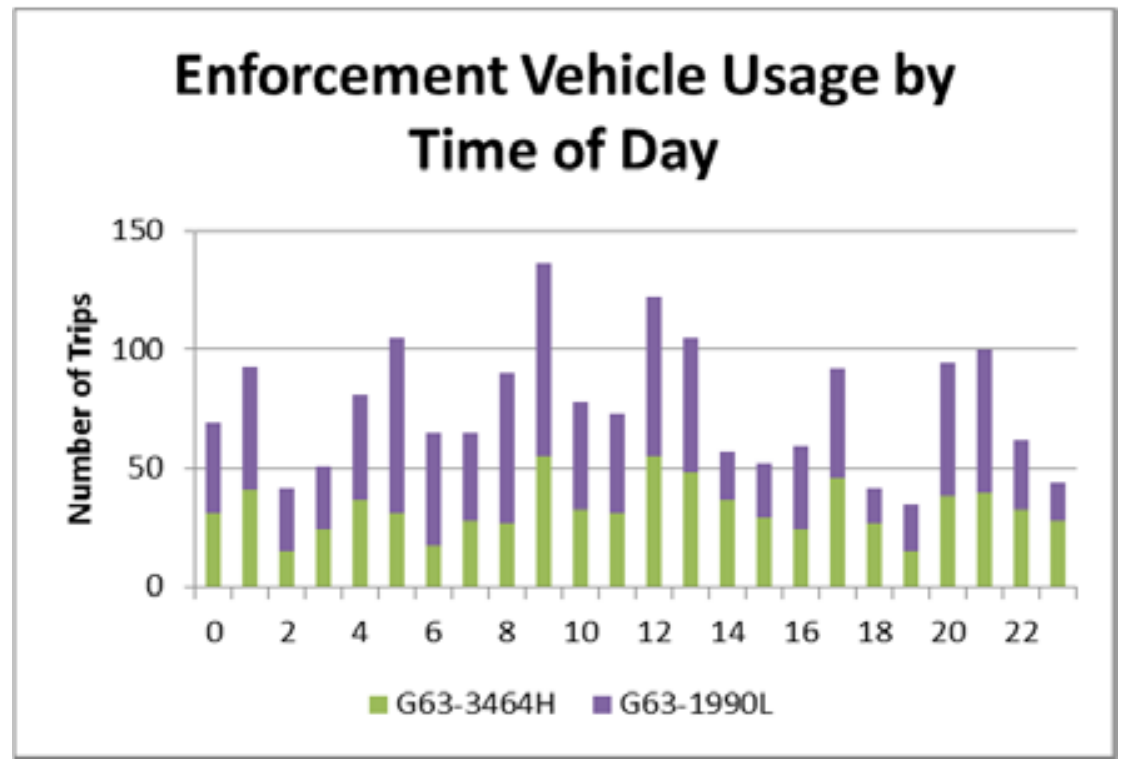

Figure 22. Enforcement vehicle hourly usage.

Figure 23 shows the outing distances for the enforcement vehicles.

Appendix B provides the details of the enforcement vehicles' daily travel.

The average travel outing for the enforcement vehicles was 61.4 miles, with $51 \%$ of vehicle travel outings being less than 40 miles and considered to be within the CD mode range of a PHEV.

In summary, these vehicles can be characterized by high daily travel, with widely varying outage distances. 


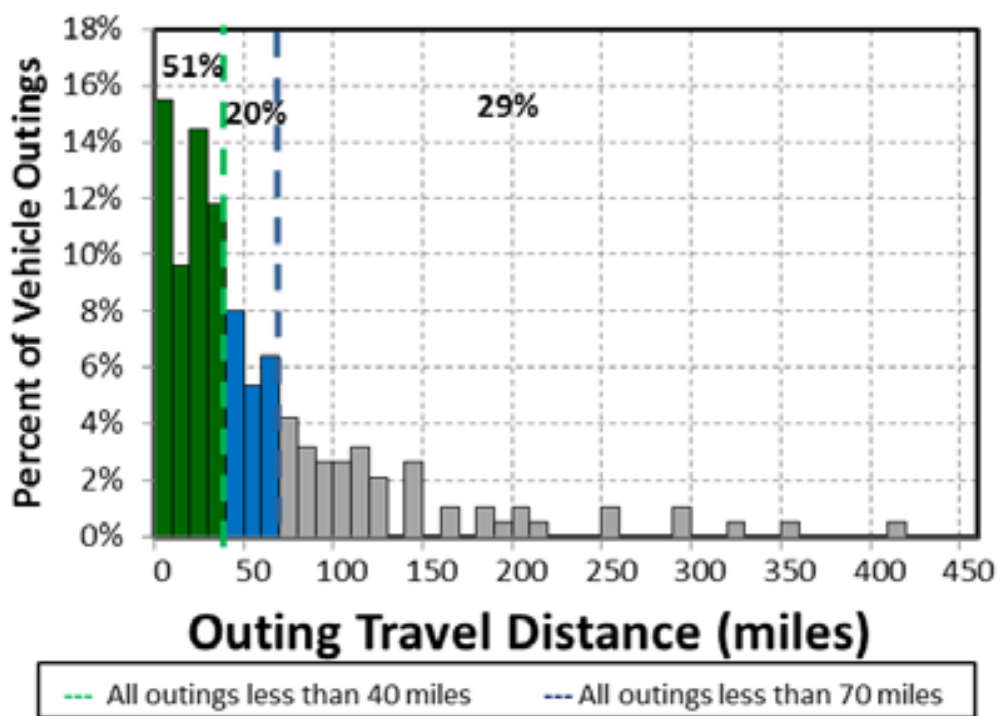

Figure 23. Enforcement vehicles’ outings.

\subsubsection{Enforcement Vehicle Observations/Summary}

The enforcement vehicles are two pickup trucks. These are a popular choice for enforcement vehicles because they are versatile to support the various types of enforcement activities needed.

Three possible options for WSTF in introducing PEVs into the enforcement vehicle fleet are evaluated. It should be noted that the objective would be to incorporate as many BEVs as possible to realize the advantages of reduced petroleum usage and reduced emissions of GHGs.

1. All BEV fleet: While some BEV manufacturers report vehicle ranges exceeding 70 miles, Intertek recommends careful evaluation of experienced range to ensure vehicle missions are accomplished. Nevertheless, assuming the 70-mile safe range for a BEV, an all-BEV fleet is not possible for enforcement vehicles due to the frequent long distances experienced by the vehicles. In addition, the mission of enforcement vehicles does not typically lend itself to range limitations.

2. Mixed BEV/PHEV fleet: Certainly, PHEVs can accomplish the same mission as the current fleet when only considering travel times and distances because the PEV's gasoline engine can provide motive power when the battery has been depleted. Figure 19 shows that on $14 \%$ of all vehicle travel days, the total daily travel was less than 40 miles, which typically is the maximum distance a PHEV will travel in CD mode. This represents a significant operating cost savings opportunity, while retaining the ability to go longer distances when needed. In addition, $51 \%$ of the outings were less than 40 miles and could be completed in CD mode for certain PHEVs if the battery was fully charged prior to the outing.

Seventy-one percent of the outings were within the typical capability of a BEV; therefore, EVSE at the home base could provide recharge energy for another outing. A mixed fleet requires fleet manager attention to assign vehicles appropriately for the anticipated use on that day.

The data suggest that $74 \%$ of the fleet could be PHEVs to handle travel greater than 70 miles per day, without requiring additional opportunity charging during daytime stops, and $26 \%$ of the fleet could be BEVs. A more conservative approach for enforcement vehicles, for which range limitations may not be desirable, is to replace these two vehicles with two PHEVs.

3. All PHEV fleet: As noted above, PHEVs can accomplish the same mission as the current fleet when only considering travel times and distances. Replacing all current vehicles with PHEVs only requires 
an evaluation of the individual vehicle capabilities of currently available PHEVs to meet current support vehicle requirements.

The vehicle summary shows sufficient time for charging at the base location during the course of the day. These stations also provide charging opportunities for the visiting public, whose fees may assist in offsetting operating costs; however, it is recognized that visitation by the public is limited because of WSTF operations.

Considering a full complement of 14 enforcement vehicles in the total fleet, Intertek notes that all are pickup trucks or SUVs for which PEVs are currently available as potential replacements. Intertek suggests that a mixed fleet may be possible. While the remaining vehicles were not monitored and, considering range limitations, do not typically support all enforcement activities, it is still assumed that BEVs could replace some of the enforcement vehicles. Intertek suggests a fleet of two BEVs and 12 PHEVs conservatively meets vehicle travel requirements. Typically, additional EVSE at frequently visited locations provide recharging for both the BEV and PHEV that may be of benefit.

\subsubsection{Enforcement Vehicle Charging Needs}

As noted above, overnight charging of PHEVs can usually be accomplished with AC Level 1 charging. Opportunity charging at intermediate stops obtains the greater benefits from AC Level 2 EVSE. However, remote intermediate stop locations were not identified in the data.

For the entire fleet of enforcement vehicles, two BEVs require two AC Level 2 EVSE and 12 PHEVs require 12 AC Level 1 outlets for home base charging. Intertek recommends a minimum of two EVSE at each location to maximize charge capability without a significant increase in installation costs. As noted above, there is one publicly accessible EVSE in the vicinity that may provide backup charging resources.

This analysis does assume a fully recharged battery at the start of each day. WSTF will gain experience in management as the PEV fleet grows.

\subsection{Pool Vehicles Evaluation}

Pool vehicles are typically light-duty motor vehicles for use in passenger transportation, with not more than 10 passengers. Pool missions can vary by agency, location, and jurisdiction; however, they typically utilize sedans, minivans, SUVs, vans, or small pickup trucks and typically do not carry specific cargo or equipment.

No pool vehicles were monitored as part of this study. However, pool mission vehicles have potential PEV replacement models. Assuming that pool vehicles operate in a manner similar to the support vehicles, Intertek suggests 16 BEVs and five PHEVs could conservatively replace the entire fleet of 21 pool vehicles.

\subsection{Transport Vehicles Evaluation}

Transport vehicles are typically light or heavy-duty motor vehicles for use in passenger and cargo transportation. PEV replacements are not currently available for heavy-duty trucks and passenger vans. A PEV bus may be available for replacement, but that is beyond the scope of this study.

No transport vehicles were monitored as part of this study. However, 49 of the 52 vehicles with the transport mission have potential PEV replacement models. Assuming that the transport vehicles operate in a manner similar to the support vehicles, Intertek conservatively suggests 12 ICE vehicles, $30 \mathrm{BEVs}$, and 10 PHEVs could conservatively replace the 52 transport vehicles.

\subsection{Balance of Fleet Vehicles}

The balance of the WSTF fleet consists of specialty vehicles. Certain select PEVs are being demonstrated for various specialty applications, but none is listed in the GSA schedule. 


\section{GREENHOUSE GAS EMISSIONS AVOIDED AND FUEL COST REDUCTION ANALYSIS}

PEV substitution for an existing conventional vehicle avoids GHG emissions and reduces fuel costs. The GHG emissions avoided occur due to the difference in emissions associated with power plant electricity generation versus fuel combustion that occurs in the engine of a conventional vehicle. This analysis does not account for life-cycle emissions that occur outside of electricity generation and fuel combustion phases (i.e., materials and resource extraction, production supply-chains, and decommissioning are not accounted for). These phases are beyond the scope of this report due to the significant effort required to conduct an accurate environmental life-cycle assessment for a transportation system in a very specific setting. The analysis used is known as a "tank-to-wheel” analysis, rather than a "well-to-wheel" analysis that would include the aforementioned phases. Cost reduction also occurs because the cost of electricity is comparable to the cost of gasoline on a unit of energy basis, but PEVs are more efficient than conventional ICE vehicles. Because fuel logs were not kept, the mileage accumulated by each vehicle and the extrapolation to annual miles provide one source of annual miles estimates. WSTF also provided information related to anticipated annual miles. These are compared to that calculated during the study to identify the source of fuel consumption estimates for the study vehicles.

In order to perform the analysis, EPA fuel economy ratings are used. ${ }^{24}$ Tables 15 and 16 provide these ratings. Ratings for the PHEVs in Table 16 include CD operation. Because these data are estimates, assumptions include the following:

1. PHEVs operate in CD mode only for the percentage of travel less than 40 miles per day. This is reasonable for most daily operations, as described in Section 5. This is conservative because there exists additional charge time between most outings. It is also conservative in that the replacement PEV typically will have greater fuel economy when operating in CS mode. BEVs operate in electric mode for $100 \%$ of travel.

2. The energy consumption for the Mitsubishi Outlander is assigned the same value as the RAV4 EV and the Via Motors VTRUX PU is estimated because the EPA has not yet created ratings for these vehicles.

3. Table 16 suggests the PEVs for replacing existing monitored vehicles. See Section 4.4 for vehicle availability.

4. Annual miles are calculated from the actual miles identified in the study and extrapolated to a full 365-day year, which is compared to the annual miles reported by WSTF for information. The WSTF annual miles are used for the reduction calculations, if available. Miles in CD mode are the WSTF annual miles times the percent of daily travel less than 40 miles for the PHEV replacement and full annual miles for the BEV replacement.

Table 17 provides a pictorial view of potential replacement PEVs.

Calculations provided for GHG emissions and fuel savings include both a total U.S. perspective and for the local area. The electricity generation mix of power plants for the total United States is different from the local mix of generation in the WSTF area. Likewise, the national average cost for petroleum fuel is different from the local cost for fuel. This analysis includes both approaches in order to allow for local evaluation and to provide the potential benefit for fleet vehicles in other locations of the United States that may be of interest. The final report summarizing results from all sites studied across the United States from Intertek to Idaho National Laboratory primarily will consider the national figures. For clarity, only the local figures are shown here. The national figures are included in Appendix C.

\footnotetext{
${ }^{24}$ http://www.fueleconomy.gov/feg/Find.do?action=sbs\&id=33558 [accessed August 27, 2014].
} 
Table 15. U.S. EPA fuel economy ratings of current fleet vehicles.

\begin{tabular}{lccccc}
\multicolumn{1}{c}{ Vehicle } & Logger & Mission & Make and Model & Model Year & $\begin{array}{c}\text { Fuel Economy-Combined } \\
\text { (miles/gallon) }\end{array}$ \\
\hline G62-2618B & 9 & Support & Chevrolet Tahoe & 2005 & 15 \\
G63-2246L & 10 & Support & Ford F-250 & 2011 & 18 \\
G41-2586D & 11 & Support & Dodge Caravan & 2006 & 20 \\
G62-3553K & 12 & Support & Chevrolet Tahoe & 2010 & 17 \\
G63-3464H & 13 & Law Enforcement & Chevrolet Silverado & 2010 & 17 \\
G63-0404D & 14 & Support & Chevrolet Silverado & 2006 & 17 \\
G63-1990L & 15 & Law Enforcement & Ford F-250 & 2011 & 19 \\
G62-1017D & 16 & Support & Ford F-150 & 2006 & 14 \\
G41-5523H & 17 & Support & Dodge Grand Caravan & 2009 & 19 \\
G63-1722B & 18 & Support & Chev. Silverado - 2500 & 2005 & 11 \\
\hline
\end{tabular}

Table 16. U.S. EPA PEV energy consumption assumptions.

\begin{tabular}{ccc}
\hline Mission & Replacement PEV & Wh/mile \\
\hline Support & Rav4 & 440 \\
Support & Rav4 & 440 \\
Support & Rav4 & 440 \\
Support & VTRUX PU & 475 \\
Law Enforcement & Outlander & 440 \\
Support & eNV200 & 400 \\
Law Enforcement & Outlander & 440 \\
Support & eNV200 & 400 \\
Support & VTRUX PU & 475 \\
Support & Rav4 & 440 \\
\hline
\end{tabular}

For the GHG emissions avoided portion of the analysis, the GHG emissions (in pounds of carbon dioxide equivalent (which also accounts for other GHGs such as methane and nitrous oxide in $l b-\mathrm{CO}_{2} e$ ) from combustion of gasoline is $20.1 \mathrm{lb}-\mathrm{CO}_{2} \mathrm{e} /$ gallon. ${ }^{25}$ The United States average GHG emissions for the production of electricity is $1.53 \mathrm{lb}-\mathrm{CO}_{2} \mathrm{e} / \mathrm{kWh}^{26}$.

El Paso Electric provides electric power to WSTF. El Paso Electric reports generation from several power plants, including coal, gas, nuclear, and wind/solar generation. ${ }^{27}$ EPA reports GHG emissions from the production of electricity. The annual report is available in the Emissions and Generation Resource Integrated Database. The most recent publication is for $2010^{28}$. Using the information provided for the El Paso Electric Company Power Control Area, emissions for 2010 for the production of electricity were $1.298 \mathrm{lb}-\mathrm{CO}_{2} \mathrm{e} / \mathrm{kWh}$. This emission rate is slightly lower than the national average due to significant usage of nuclear as the generation fuel.

\footnotetext{
${ }^{25}$ http://www.theevproject.com/cms-assets/documents/106077-891082.ghg.pdf [accessed 19 July 2013].

${ }^{26}$ http://www.theevproject.com/cms-assets/documents/106077-891082.ghg.pdf [accessed July 19, 2013].

${ }^{27}$ http://www.epelectric.com/files/html_pages_content193.pdf [accessed September 8, 2014].

${ }^{28}$ http://www.epa.gov/cleanenergy/energy-resources/egrid/ [accessed September 8, 2014].
} 
Table 17. PEV substitutions for current vehicles.

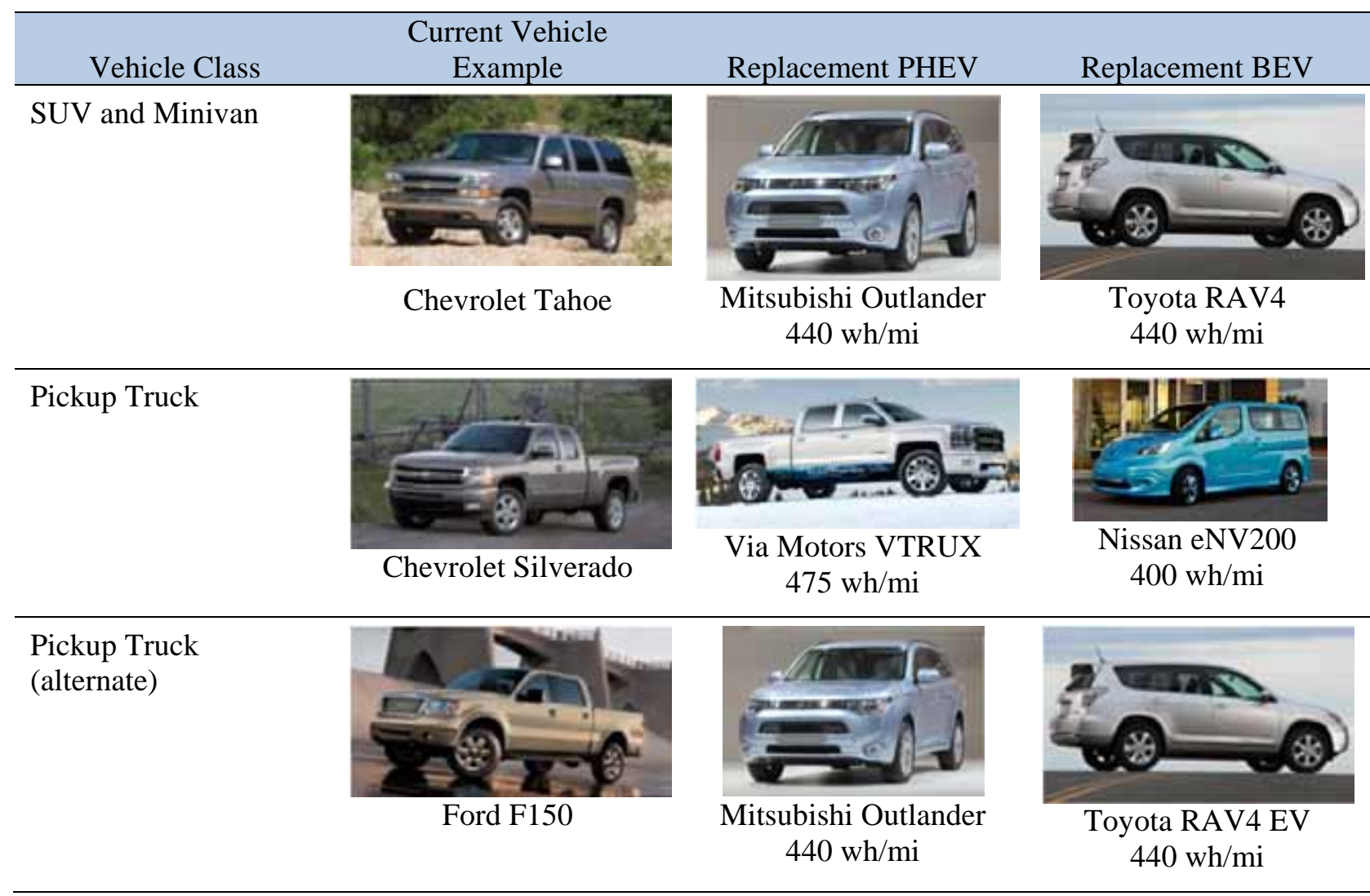

GHG emissions avoided are the GHGs emitted by the current vehicle (total annual gallons gasoline $\times$ GHG emissions/gallon) minus the annual GHG emitted by the replacement PEV (total annual $\mathrm{kWh} \times$ GHG emissions/kWh). For PHEVs, the percentages of outings less than 40 miles are counted for the annual miles saved in CD mode, with the balance of the miles accounted as fueled with gasoline.

For the cost-avoided piece of the analysis, fuel cost assumptions are \$3.436/gallon of regular gasoline for the United States and \$3.318/gallon in the Las Cruces area. Electrical cost are 0.0984 \$/kWh for the United States and $0.088 \$ / \mathrm{kWh}$ in New Mexico. Therefore, fuel costs savings are the current vehicle's calculated annual gasoline cost (total annual gallons gasoline $\times$ cost/gallon) minus the electricity cost (total annual $\mathrm{kWh} \times \operatorname{cost} / \mathrm{kWh}$ ) of the replacement PEV traveling the same distance.

The miles calculated above for CD mode yields estimates for yearly GHG emissions avoided and fuel cost reductions. The results of this analysis (shown in Table 19) demonstrate that the substitution of a conventional ICE vehicle with a PEV can reduce the GHG emissions and fuel costs dramatically. Table 19 also shows the percentage reduction in GHG emissions and fuel costs for ease of comparison. For example, if the Mitsubishi Outlander replaces LAW ENFORCEMENT vehicle G63-3464H, a 52\% reduction in GHG emissions in New Mexico occurs. The Chevrolet Silverado produces 5,929 lb$\mathrm{CO}_{2} \mathrm{e} /$ year for the distance traveled, whereas the Outlander produces 2,864 lb- $\mathrm{CO}_{2} \mathrm{e} /$ year for that same distance for a reduction of 3,065 lb- $\mathrm{CO}_{2} \mathrm{e} /$ year.

Table 18 shows the calculation of annual miles based on the recorded and extrapolated miles in this study. The WSTF reported annual miles are shown for comparison. The replacement vehicle is identified for each vehicle. It is important to note that the analysis conducted above suggests replacement vehicles for the fleet of vehicles rather than necessarily replacing the exact vehicle monitored. The percent of miles in CD mode is $100 \%$ for BEVs because all travel is battery powered. The percent of miles in CD 
mode for PHEVs is obtained from the daily travel shown in Appendix B. Miles in CD mode is the percentage of WSTF reported annual miles.

For the cost-avoided piece of the analysis, fuel cost assumptions are \$3.436/gallon of regular gasoline for the United States and \$3.318/gallon in the Las Cruces area. ${ }^{29}$ Electrical cost are $0.0984 \$ / \mathrm{kWh}$ for the United States and $0.088 \$ / \mathrm{kWh}$ in New Mexico. ${ }^{30}$ Therefore, fuel costs savings are the current vehicle's calculated annual gasoline cost (total annual gallons gasoline $\times$ cost/gallon) minus the electricity cost (total annual $\mathrm{kWh} \times \operatorname{cost} / \mathrm{kWh}$ ) of the replacement PEV traveling the same distance.

The miles calculated above for CD mode yields estimates for yearly GHG emissions avoided and fuel cost reductions. The results of this analysis (shown in Table 19) demonstrate that the substitution of a conventional ICE vehicle with a PEV can reduce the GHG emissions and fuel costs dramatically.

Table 19 also shows the percentage reduction in GHG emissions and fuel costs for ease of comparison. For example, if the Mitsubishi Outlander replaces LAW ENFORCEMENT vehicle G63-3464H, a 52\% reduction in GHG emissions in New Mexico occurs. The Chevrolet Silverado produces 5,929 lb$\mathrm{CO}_{2} \mathrm{e} /$ year for the distance traveled, whereas the Outlander produces 2,864 lb- $\mathrm{CO}_{2} \mathrm{e} /$ year for that same distance for a reduction of 3,065 lb- $\mathrm{CO}_{2} \mathrm{e} /$ year.

Table 18. CD mode miles calculations.

\begin{tabular}{llcccc}
\hline \multicolumn{1}{c}{ Vehicle } & $\begin{array}{c}\text { Replacement } \\
\text { Vehicle }\end{array}$ & $\begin{array}{c}\text { Study } \\
\text { Calculated } \\
\text { Annual Miles }\end{array}$ & $\begin{array}{c}\text { WSTF Reported } \\
\text { Annual Miles }\end{array}$ & $\begin{array}{c}\text { Percent of } \\
\text { Miles CD } \\
\text { Mode }\end{array}$ & $\begin{array}{c}\text { CD Mode } \\
\text { Miles }\end{array}$ \\
\hline Tahoe & Rav4 & 5,517 & 8,352 & $100 \%$ & 8,352 \\
F-250 & Rav4 & 3,866 & 8,160 & $100 \%$ & 8,160 \\
Caravan & Rav4 & 7,831 & 12,108 & $100 \%$ & 12,108 \\
Tahoe & VTRUX PU & 3,658 & 4,128 & $81 \%$ & 3,344 \\
Silverado & Outlander & 18,449 & 35,820 & $14 \%$ & 5,015 \\
Silverado & eNV200 & 5,457 & 10,440 & $100 \%$ & 10,440 \\
F-250 & Outlander & 27,086 & 34,212 & $14 \%$ & 4,790 \\
F-150 & eNV200 & 950 & 4,308 & $100 \%$ & 4,308 \\
Grand Caravan & VTRUX PU & 3,536 & 5,280 & $64 \%$ & 3,379 \\
Silverado - 2500 & Rav4 & 9,548 & 9,108 & $100 \%$ & 9,108 \\
\hline
\end{tabular}

Table 19. Greenhouse gas emissions avoidance and fuel cost reduction analysis summary

\begin{tabular}{cccccc}
\hline & \multicolumn{3}{c}{$\begin{array}{c}\text { Extrapolated } \\
\text { Local. Yearly }\end{array}$} & \multicolumn{3}{c}{$\begin{array}{c}\text { Extrapolated } \\
\text { Local Yearly } \\
\text { Replacement } \\
\text { Model }\end{array}$} & $\begin{array}{c}\mathrm{CO}_{2} \mathrm{e} \text { Avoided } \\
\left({\left.\mathrm{lb}-\mathrm{CO}_{2} \mathrm{e} / \text { year }\right)}\right.\end{array}$ & $\begin{array}{c}\text { \% reduction } \\
\text { Reduction }\end{array}$ & $\%$ reduction \\
\hline Sission & Rav4 & 6,422 & $57 \%$ & $\$ 1,523$ & $82 \%$ \\
Support & Rav4 & 4,452 & $49 \%$ & $\$ 1,187$ & $79 \%$ \\
Support & Rav4 & 5,253 & $43 \%$ & $\$ 1,538$ & $77 \%$ \\
Support & VTRUX PU & 1,892 & $48 \%$ & $\$ 512$ & $79 \%$ \\
Law Enforcement & Outlander & 3,065 & $52 \%$ & $\$ 784$ & $80 \%$ \\
Support & eNV200 & 6,923 & $56 \%$ & $\$ 1,669$ & $82 \%$ \\
\hline
\end{tabular}

${ }^{29}$ http://www.newmexicogasprices.com/Las Cruces/index.aspx [accessed September 8, 2014].

${ }^{30}$ http://www.eia.gov/electricity/state/ [Accessed September 8, 2014]. 


\begin{tabular}{|c|c|c|c|c|c|}
\hline Mission & $\begin{array}{c}\text { Replacement } \\
\text { Model }\end{array}$ & $\begin{array}{l}\text { Extrapolated } \\
\text { Local. Yearly } \\
\mathrm{CO}_{2} \mathrm{e} \mathrm{Avoided} \\
\text { (lb-CO } \mathrm{CO}_{2} \mathrm{e} / \text { year) }\end{array}$ & $\%$ reduction & $\begin{array}{c}\text { Extrapolated } \\
\text { Local Yearly } \\
\text { Fuel Cost } \\
\text { Reduction } \\
\end{array}$ & $\%$ reduction \\
\hline Law Enforcement & Outlander & 2,331 & $46 \%$ & $\$ 650$ & $78 \%$ \\
\hline Support & eNV200 & 3,948 & $64 \%$ & $\$ 869$ & $85 \%$ \\
\hline Support & VTRUX PU & 1,491 & $42 \%$ & $\$ 448$ & $76 \%$ \\
\hline Support & Rav4 & 11,441 & $69 \%$ & $\$ 2,393$ & $87 \%$ \\
\hline Total & & 47,219 & $55 \%$ & $\$ 11,575$ & $81 \%$ \\
\hline Total Support & & 41,823 & $56 \%$ & $\$ 10,322$ & $82 \%$ \\
\hline Total Enforcement & & 5,397 & $49 \%$ & $\$ 1,455$ & $79 \%$ \\
\hline
\end{tabular}

Table 19 shows the high potential benefit in the reduction of GHG emissions in the local WSTF area. In addition, the fuel cost reduction potential benefit is also significant due to the low cost of power.

As presented in Section 5, 16 BEVs and 5 PHEVs could replace the pool fleet of 21 vehicles. The support fleet of 31 vehicles would retain one heavy-duty pickup and replace the balance with 22 BEVs and eight PHEVs. Two BEVs and 12 PHEVs are assumed to replace the enforcement fleet of 14 vehicles. The transport fleet is assumed to consist of 12 ICE vehicles, $30 \mathrm{BEVs}$, and 10 PHEVs and all specialty fleet vehicles are assumed to be retained as ICE vehicles. Using an average savings per vehicle, Table 20 provides the avoided GHG and fuel cost savings should these replacements occur. The table also shows the percentage reduction in GHG emissions and fuel costs for ease of comparison. Only local New Mexico savings are projected in this table, while national figures are presented in Appendix C.

Table 20. Extrapolated greenhouse gas emissions avoided and fuel cost savings for the entire fleet.

\begin{tabular}{ccccc} 
& $\begin{array}{c}\text { Extrapolated Local } \\
\text { Yearly } \mathrm{CO}_{2} \mathrm{e} \\
\text { Avoided }\end{array}$ & \% reduction & $\begin{array}{c}\text { Extrapolated } \\
\text { Local Yearly Fuel } \\
\text { Cost Reduction } \\
\text { (\$/year }\end{array}$ & \% reduction \\
Mission & 151,707 & $57 \%$ & $\$ 36,100$ & $82 \%$ \\
Support & 41,131 & $50 \%$ & $\$ 10,743$ & $79 \%$ \\
Enforcement & 78,247 & $55 \%$ & $\$ 18,544$ & $80 \%$ \\
Pool & 201,770 & $56 \%$ & $\$ 48,269$ & $82 \%$ \\
Transport & 472,855 & $56 \%$ & $\$ 113,656$ & $81 \%$ \\
Total & & & & \\
\hline
\end{tabular}

\section{OBSERVATIONS}

Intertek appreciates the opportunity to present the results of this evaluation. Observations for possible follow-up action include the following:

\section{Observation \#1:}

Implementation: WSTF can move forward in the near future with the replacement of support and enforcement vehicles with PEVs as current budget and vehicle replacement schedules allow. Certainly, most of the vehicle types studied in this report are candidates for immediate replacement.

\section{Observation \#2:}

Fleet Inventory: A more thorough examination of the quantities and types of fleet vehicles within each usage category may be beneficial to quantify the potential for replacement by PEVs. While Intertek 
suggests a mix of BEVs and PHEVs, a more refined look may be possible. In addition, this study did not monitor the other fleet vehicle categories such as specialty, transport, and pool vehicles.

\section{Observation \#3:}

Vehicle Replacement Plan: The development of a detailed vehicle replacement plan could be beneficial. Such a plan would include cost and schedule for vehicle replacement. A more detailed survey and calculation of the use of the fleet vehicles (such as vehicle parking locations, age of vehicle, expected replacement time, expected replacement costs, GSA vehicle costs, EVSE cost, total life costs, and EVSE installation costs) provide support to this replacement plan. A more refined estimate for reduced GHG emissions, petroleum usage reduction, and fuel cost savings flow from this detailed plan.

\section{Observation \#4:}

Infrastructure Planning: In conjunction with the replacement plan, evaluation of the WSTF sites for the placement of PEV charging infrastructure could be beneficial. Intertek has significant experience in this area and such plans will consider not only fleet vehicle charging needs, but also the convenience that charging infrastructure provides employees and visitors. This planning also considers the existing facility electrical distribution system. Vehicle home base considerations factor into the ratio of PEVs to EVSE units to maintain all vehicles at operational readiness.

Charging stations located at various destination points may provide additional infrastructure for PEV charging of the WSTF fleet. Charging stations at WSTF may also provide an opportunity for charging by employees and the general public, although it is recognized that access to the WSTF is controlled. 


\section{Appendix A Definitions}

Alternative fuel

City fuel economy

(MPG)

Conventional fuel

Daily travel

Diesel fuel

E85

Electric vehicle

Ethanol-fueled vehicle

Federal vehicle standards

Government motor vehicle

Gross vehicle weight rating

GSA fleet
An alternative fuel means any fuel other than gasoline and diesel fuels, such as methanol, ethanol, and gaseous fuels (40 CFR 86.1803-01). A fuel type other than petroleum-based gasoline or diesel as defined by the Energy Policy Act (examples include ethanol, methanol, compressed natural gas, propane, and electrical energy).

City fuel economy means the city fuel economy determined by operating a vehicle (or vehicles) over the driving schedule in the federal emission test procedure or determined according to the vehicle-specific 5-cycle or derived 5-cycle procedures (40 CFR 600.001).

A petroleum-based fuel (examples include gasoline and diesel fuel).

The sum of daily trips and stops in one day.

Diesel means a type of engine with operating characteristics significantly similar to the theoretical diesel combustion cycle. The non-use of a throttle during normal operation is indicative of a diesel engine (49 CFR 86-1803).

Ethanol fuel blend of up to $85 \%$ denatured ethanol fuel and gasoline or other hydrocarbons by volume.

Electric vehicle means a motor vehicle that is powered solely by an electric motor drawing current from a rechargeable energy storage system, such as from storage batteries or other portable electrical energy storage devices, including hydrogen fuel cells, provided that

(1) The vehicle is capable of drawing recharge energy from a source off the vehicle, such as residential electric service

(2) The vehicle must be certified to the emission standards of Bin \#1 of Table S04-1 in § 86.1811-09(c)(6)

(3) The vehicle does not have an onboard combustion engine/generator system as a means of providing electrical energy (40 CFR 86-1803).

Ethanol-fueled vehicle-means any motor vehicle or motor vehicle engine that is engineered and designed to be operated using ethanol fuel (i.e., a fuel that contains at least $50 \%$ ethanol $\left(\mathrm{C}_{2} \mathrm{H}_{5} \mathrm{OH}\right.$ ) by volume) as fuel (40 CFR 86.1803-01).

The document that establishes classifications for various types and sizes of vehicles, general requirements, and equipment options. It is issued annually by the GSA Vehicle Acquisition and Leasing Service's Automotive Division.

Any motor vehicle that the government owns or leases. This includes motor vehicles obtained through purchase, excess, forfeiture, commercial lease, or GSA fleet lease.

Gross vehicle weight rating (GVWR) means the value specified by the vehicle manufacturer as the maximum design loaded weight of a single vehicle (e.g., vocational vehicle) (US Government Printing Office 2009)

GSA fleet lease means obtaining a motor vehicle from the General Services Administration fleet (GSA fleet) (41 CFR 102-34). 
Heavy light-duty truck

Highway fuel economy (Hwy MPG)

Hybrid electric vehicle

Idle time

Law enforcement

Light-duty motor vehicle

Light-duty truck
Heavy light-duty truck means any light-duty truck rated greater than 6,000 lb GVWR. The light-duty truck 3 (LDT3) and LDT4 classifications comprise the heavy light-duty truck category (40 CFR 86.1803-01).

Highway fuel economy means the highway fuel economy determined either by operating a vehicle (or vehicles) over the driving schedule in the federal highway fuel economy test procedure or determined according to either the vehicle-specific, 5-cycle equation, or the derived 5-cycle equation for highway fuel economy (40 CFR 600.001).

Hybrid electric vehicle means a motor vehicle that draws propulsion energy from onboard sources of stored energy that are both an internal combustion engine or heat engine using consumable fuel and a rechargeable energy storage system (such as a battery, capacitor, hydraulic accumulator, or flywheel), where recharge energy for the energy storage system comes solely from sources on board the vehicle.

Idle time is logged whenever a vehicle idles with the engine running for 3 minutes or longer.

Law enforcement motor vehicle means a light-duty motor vehicle that is specifically approved in an agency-s appropriation act for use in apprehension, surveillance, police, or other law enforcement work or specifically designed for use in law enforcement. If not identified in an agency's appropriation language, a motor vehicle qualifies as a law enforcement motor vehicle only in the following cases:

(1) A passenger automobile having heavy-duty components for electrical, cooling, and suspension systems and at least the next higher cubic inch displacement or more powerful engine than is standard for the automobile concerned

(2) A light truck having emergency warning lights and identified with markings such as "police"

(3) An unmarked motor vehicle certified by the agency head as essential for the safe and efficient performance of intelligence, counterintelligence, protective, or other law enforcement duties

(4) A forfeited motor vehicle seized by a federal agency that subsequently is used for performing law enforcement activities (41 CFR Part 102-34.35).

Any motor vehicle with a GVWR of 8,500 pounds or less (41 CFR 102-34). Light-duty truck means any motor vehicle rated at 8,500 pounds GVWR or less, which has a curb weight of 6,000 pounds or less and, which has a basic vehicle frontal area of 45 square feet or less, which is as follows:

(1) Designed primarily for purposes of transportation of property or is a derivation of such a vehicle

(2) Designed primarily for transportation of persons and has a capacity of more than 12 persons

(3) Available with special features, enabling off-street or off-highway operation and use.

LDT1 means any light light-duty truck up through 3,750-lb loaded vehicle weight.

LDT2 means any light light-duty truck greater than 3,750-lb loaded vehicle weight. 


\section{Light-duty vehicle \\ Low-speed vehicle \\ Light-duty vehicle means a passenger car or passenger car derivative capable of seating 12 passengers or less. \\ Low-speed vehicle means a motor vehicle \\ (1) That is 4-wheeled \\ (2) Whose speed attainable in $1.6 \mathrm{~km}$ (1 mile) is more than 32 kilometers per hour (20 miles per hour) and not more than 40 kilometers per hour (25 miles per hour) on a paved level surface \\ (3) Whose GVWR is less than 1,361 kilograms (3,000 pounds) (49 CFR 571.3 - Definitions).}

Medium-duty passenger vehicle

Model year

MPG

MPGe

Non-passenger automobile
LDT3 means any heavy light-duty truck up through 5,750-lb adjusted loaded vehicle weight.

LDT4 means any heavy light-duty truck greater than 5,750-lb adjusted loaded vehicle weight (US Government Printing Office 2009)

Medium-duty passenger vehicle means any heavy-duty vehicle (as defined in this subpart) with a GVWR of less than 10,000 pounds that is designed primarily for transportation of persons. The medium-duty passenger vehicle definition does not include any vehicle which

(1) Is an "incomplete truck" as defined in this subpart

(2) Has a seating capacity of more than 12 persons

(3) Is designed for more than 9 persons in seating rearward of the driver's seat

(4) Is equipped with an open cargo area (for example, a pick-up truck box or bed) of 72.0 inches in interior length or more. A covered box not readily accessible from the passenger compartment will be considered an open cargo area for purposes of this definition (US Government Printing Office 2009)

Model year means the manufacturer's annual production period (as determined by the administrator), which includes January 1 of such calendar year; provided that if the manufacturer has no annual production period, the term "model year" shall mean the calendar year (40 CFR 86-1803.01).

"MPG" or "mpg" means miles per gallon. This generally may be used to describe fuel economy as a quantity or it may be used as the units associated with a particular value.

MPGe means miles per gallon equivalent. This generally is used to quantify a fuel economy value for vehicles that use a fuel other than gasoline. The value represents miles the vehicle can drive with the energy equivalent of one gallon of gasoline:

(c) SCF means standard cubic feet

(d) SUV means sport utility vehicle

(e) CREE means carbon-related exhaust emissions [76 FR 39527, July 6, 2011].

A non-passenger automobile means an automobile that is not a passenger automobile or a work truck and includes vehicles described in paragraphs (a) and (b) of 49 CFR 523.5. 


\author{
Owning agency \\ Passenger automobile \\ Pickup truck \\ Plug-in hybrid electric \\ vehicle
}

Vehicle class

Vehicle configuration

Vehicle days

Vehicle home base

Vehicle study period
Owning agency means the executive agency that holds the vehicle title, manufacturer's Certificate of Origin or is the lessee of a commercial lease. This term does not apply to agencies that lease motor vehicles from the GSA fleet (41 CFR Part 102-34.35).

A passenger automobile is any automobile (other than an automobile capable of off-highway operation) manufactured primarily for use in the transportation of not more than 10 individuals (49 CFR 523.4 - Passenger automobile). A sedan or station wagon designed primarily to transport people (41 CFR 102-34).

Pickup truck means a non-passenger automobile, which has a passenger compartment and an open cargo bed (49 CFR 523.2).

PHEV means a hybrid electric vehicle that has the capability to charge the battery from an off-vehicle electric source, such that the off-vehicle source cannot be connected to the vehicle while the vehicle is in motion (40 CFR 86.1803).

The designation of motor vehicle types that include sedans, station wagons, ambulances, buses, and trucks, or different categories of vehicles according to Federal vehicle standards and further defined in 49 CFR 600.315-82.

Vehicle configuration means a unique combination of basic engine, engine code, inertia weight class, transmission configuration, and axle ratio.

The number of days a vehicle was driven or utilized during the (vehicle) study period.

The primary assigned outing beginning and ending parking location for the vehicle.

The time period the vehicle, within the study, has been equipped with a data logger. 


\section{Appendix B WSTF Vehicle Data Sheets}

Table B-1. WSTF vehicle index.

\begin{tabular}{ccccccc}
\hline \multicolumn{1}{c}{ Log } & Fleet Vehicle Id & Make & Model & Year & EPA Class & Mission \\
\hline 9 & G62-2618B & Chevrolet & Tahoe & 2005 & SUV & Support \\
10 & G63-2246L & Ford & F-250 & 2011 & Pickup & Support \\
11 & G41-2586D & Dodge & Caravan & 2006 & Minivan & Support \\
12 & G62-3553K & Chevrolet & Tahoe & 2010 & SUV & Support \\
13 & G63-3464H & Chevrolet & Silverado & 2010 & Pickup & Law Enforcement \\
14 & G63-0404D & Chevrolet & Silverado & 2006 & Pickup & Support \\
15 & G63-1990L & Ford & F-250 & 2011 & Pickup & Law Enforcement \\
16 & G62-1017D & Ford & F-150 & 2006 & Pickup & Support \\
17 & G41-5523H & Dodge & Grand Caravan & 2009 & Minivan & Support \\
18 & G63-1722B & Chevrolet & Silverado- 2500 & 2005 & Pickup & Support \\
\hline
\end{tabular}




\section{Vehicle G62-2618B}

\begin{tabular}{|l|l|c|}
\hline & Make/Model/Year & Chevrolet Tahoe/2005 \\
\cline { 2 - 3 } & EPA Class Size & SUV \\
\cline { 2 - 3 } & Mission & Support \\
\cline { 2 - 3 } & VIN & See Figure B-1 \\
\cline { 2 - 3 } & Parking Location & G62-2618B \\
\cline { 2 - 3 } & Fleet Vehicle ID & Gas/E85 \\
\hline Fuel Type & $14 / 18 / 1510 / 14 / 12$ \\
\cline { 2 - 3 } & EPA Label/MPG (City/Hwy/Combined) & $592 / 525$ \\
\hline & EPA GHG Emissions (Grams CO $/$ Mi) & 9 \\
\cline { 2 - 3 } & Study Logger ID & $61 / 92$ \\
\cline { 2 - 3 } & Total Vehicle Days/Total Study Days & . \\
\hline
\end{tabular}

\begin{tabular}{|l|c|c|c|c|}
\hline \multicolumn{5}{|c|}{ Vehicle G62-2618B Travel Summary } \\
\hline & $\begin{array}{c}\text { Per Day } \\
\text { Average/Peak }\end{array}$ & $\begin{array}{c}\text { Per Outing } \\
\text { Average/Peak }\end{array}$ & $\begin{array}{c}\text { Per Trip } \\
\text { Average/Peak }\end{array}$ & Total \\
\hline Travel Distance (Miles) & $22.8 / 113.9$ & $7.7 / 133.0$ & $1.3 / 64.9$ & 1,391 \\
\hline Travel Time (Minutes) & $90.0 / 298.0$ & $30.4 / 383.0$ & $5.2 / 155.0$ & 5,473 \\
\hline Idle Time (Minutes) & $17.2 / \mathrm{NA}$ & $5.8 / \mathrm{NA}$ & $1.0 / \mathrm{NA}$ & 1,049 \\
\hline
\end{tabular}

\begin{tabular}{|c|c|c|c|c|}
\hline \multicolumn{2}{|c|}{ Total Stops } & \multicolumn{2}{c|}{ Stop Duration } \\
\hline $\begin{array}{c}\text { Distance From Home } \\
\text { Base (Miles) }\end{array}$ & Stops & Percentages & $\begin{array}{c}\text { Stop Duration } \\
\text { (Hours) }\end{array}$ & Stops \\
\hline Less than 10 & 731 & $98.5 \%$ & Less than 2 & 663 \\
\hline 10 to 20 & 11 & $1.5 \%$ & 2 to 4 & 22 \\
\hline 20 to 40 & 0 & $0 \%$ & 4 to 8 & 4 \\
\hline Greater than 40 & 0 & $0 \%$ & Greater than 8 & 53 \\
\hline
\end{tabular}

Vehicle G62-2618B Stops > 2 Hours

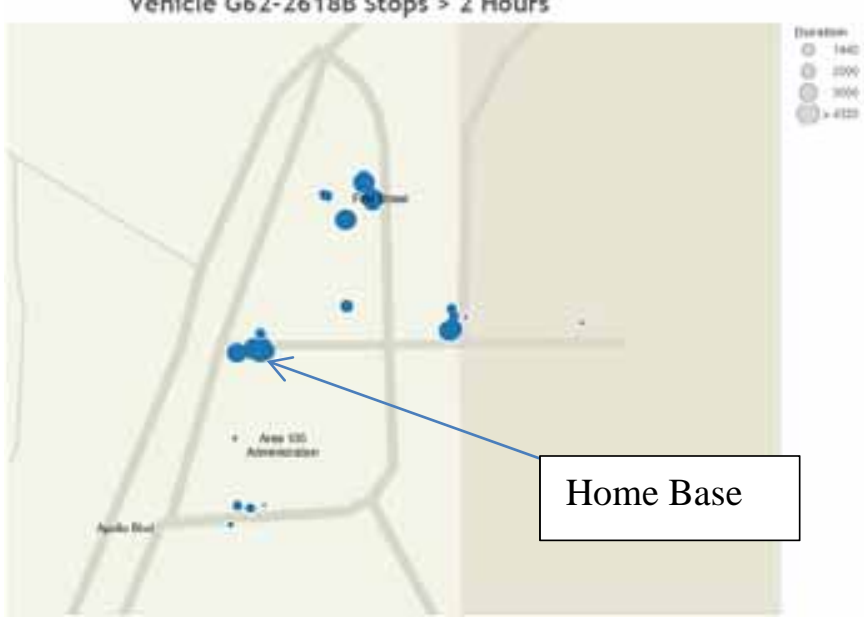

Figure B-1. Vehicle G62-2618B stops.

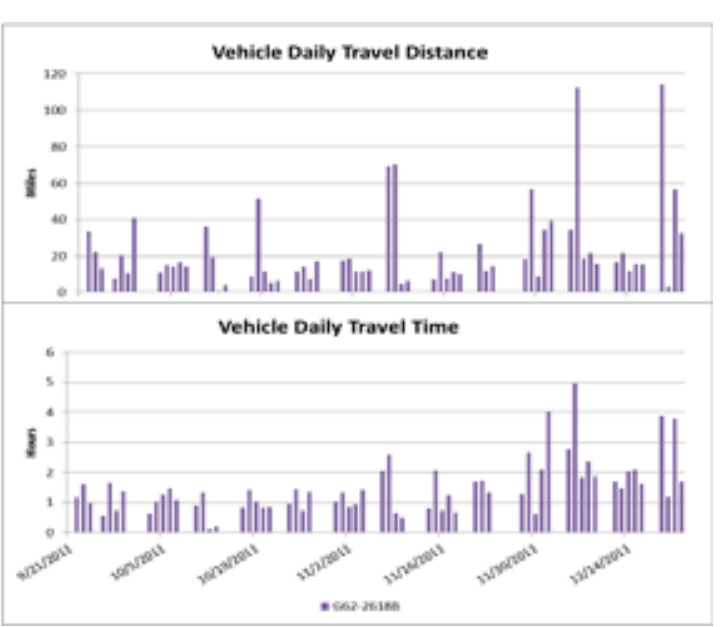

Figure B-2. Vehicle G62-2618B history. 


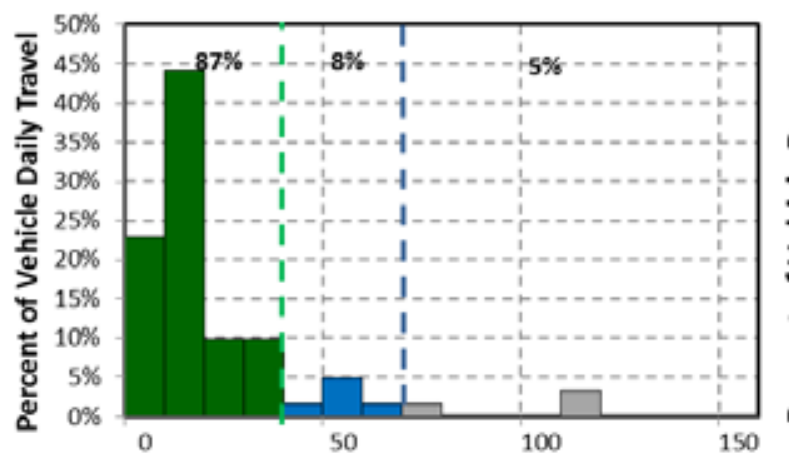

Daily Travel Distance (miles)
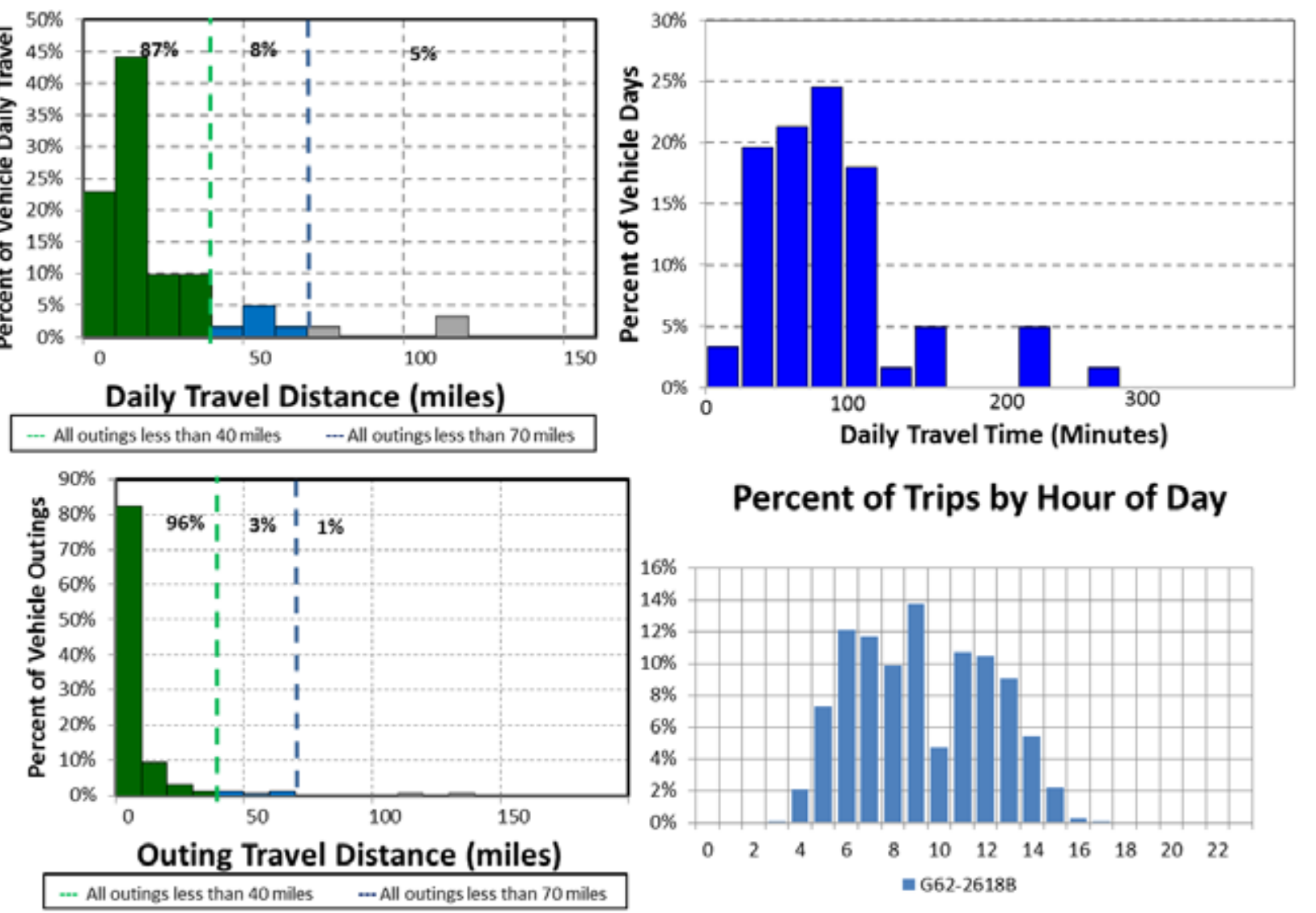

Figure B-3. Vehicle G62-2618B travel graphs.

\section{Vehicle G62-2618B Observations}

Logger 9 collected data on this vehicle for a period of 61 days of the 92-day study period. Validation occurred on $96.0 \%$ of the input data. Data recorded for this vehicle indicated that it has a support mission for maintenance and typically parks in Area 100, although it parks in most adjacent areas.

NASA reports the vehicle odometer indicated 48,874 miles during the study and it travels approximately 8,352 miles per year. The vehicle was used on $66 \%$ of the available days with an average daily usage of 1.5 hours and a peak daily usage of 5.0 hours on the days it was used. The vehicle was used during typical day shift hours.

Figure B-3 shows $95 \%$ of daily travel and $99 \%$ of all outings are within the typically advertised range of a BEV of approximately 70 miles, while $5 \%$ of daily travel exceeded this range. Further, $87 \%$ of daily travel and $96 \%$ of outings are within the typically advertised CD mode of 40 miles for PHEVs.

A BEV could meet $95 \%$ of the daily travel without additional charging opportunities. However, sufficient time exists daily for additional charging that could meet additional outing usage. A fleet of BEVs and PHEVs is more likely to allow daily travel without requiring additional charge times, providing the PEV meets other mission requirements. The survey information suggests no other special requirements exist for these support activities. 
Vehicle G63-2246L

\begin{tabular}{|l|l|c|}
\hline & Make/Model/Year & Ford F250/2011 \\
\cline { 2 - 3 } & EPA Class Size & Pickup Truck \\
\hline Mission & Support \\
\hline & VIN & 1ED7W2BT8BEC37868 \\
\cline { 2 - 3 } & Parking Location & See Figure B-4 \\
\cline { 2 - 3 } & Fleet Vehicle ID & G63-2246L \\
\hline & Fuel Type & Diesel \\
\hline & EPA Label/MPG (City/Hwy/Combined)* & $16 / 22 / 18$ \\
\cline { 2 - 3 } & EPA GHG Emissions (Grams CO $/$ Mi)* & 494 \\
\hline & Study Logger ID & 10 \\
\hline & Total Vehicle Days/Total Study Days & $57 / 92$ \\
\hline
\end{tabular}

\begin{tabular}{|l|c|c|c|c|}
\hline \multicolumn{5}{|c|}{ Vehicle G63-2246L Travel Summary } \\
& $\begin{array}{c}\text { Per Day } \\
\text { Average/Peak }\end{array}$ & $\begin{array}{c}\text { Per Outing } \\
\text { Average/Peak }\end{array}$ & $\begin{array}{c}\text { Per Trip } \\
\text { Average/Peak }\end{array}$ & Total \\
\hline Travel Distance (Miles) & $17.1 / 68.7$ & $5.8 / 50.2$ & $2.0 / 50.2$ & 975 \\
\hline Travel Time (Minutes) & $86.0 / 266.0$ & $29.0 / 137.0$ & $10.2 / 115.0$ & 4,875 \\
\hline Idle Time (Minutes) & $12.4 / \mathrm{NA}$ & $4.2 / \mathrm{NA}$ & $1.5 / \mathrm{NA}$ & 708 \\
\hline
\end{tabular}

\begin{tabular}{|c|c|c|c|c|}
\hline \multicolumn{2}{|c|}{ Total Stops } & \multicolumn{2}{c|}{ Stop Duration } \\
\hline $\begin{array}{c}\text { Distance From Home } \\
\text { Base (Miles) }\end{array}$ & Stops & Percentages & $\begin{array}{c}\text { Stop Duration } \\
\text { (Hours) }\end{array}$ & Stops \\
\hline Less than 10 & 422 & $100 \%$ & Less than 2 & 247 \\
\hline 10 to 20 & 0 & $0 \%$ & 2 to 4 & 57 \\
\hline 20 to 40 & 0 & $0 \%$ & 4 to 8 & 68 \\
\hline Greater than 40 & 0 & $0 \%$ & Greater than 8 & 50 \\
\hline
\end{tabular}

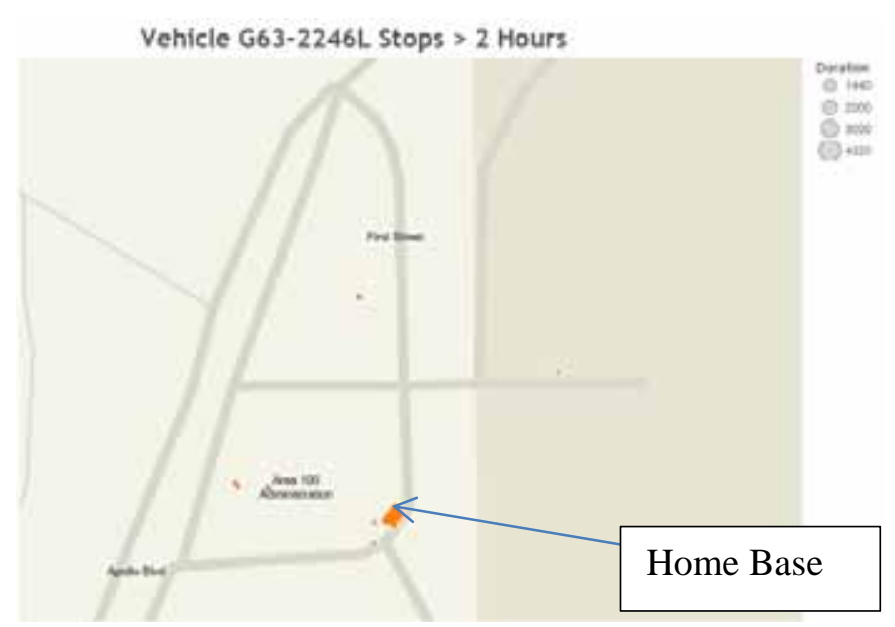

Figure B-4. Vehicle G63-2246L stops.

*Diesel economy is not available. Figures are for gasoline F150 model.

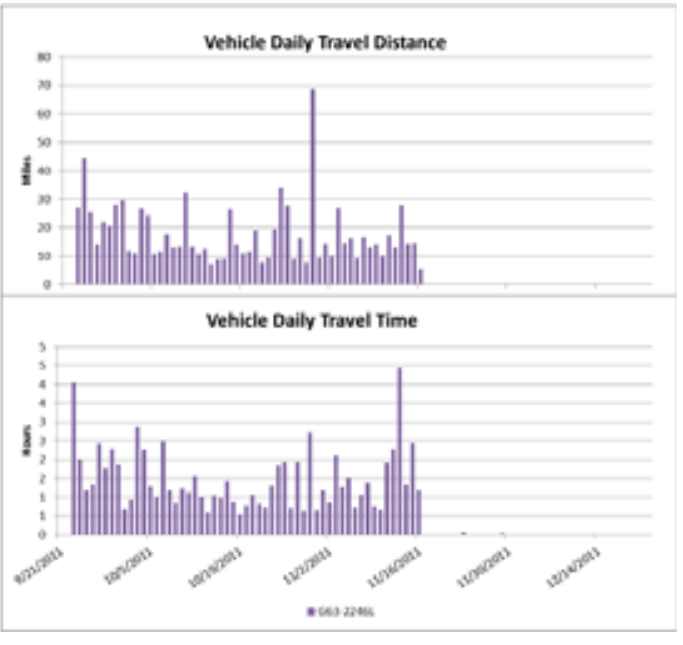

Figure B-5. Vehicle G63-2246L history. 

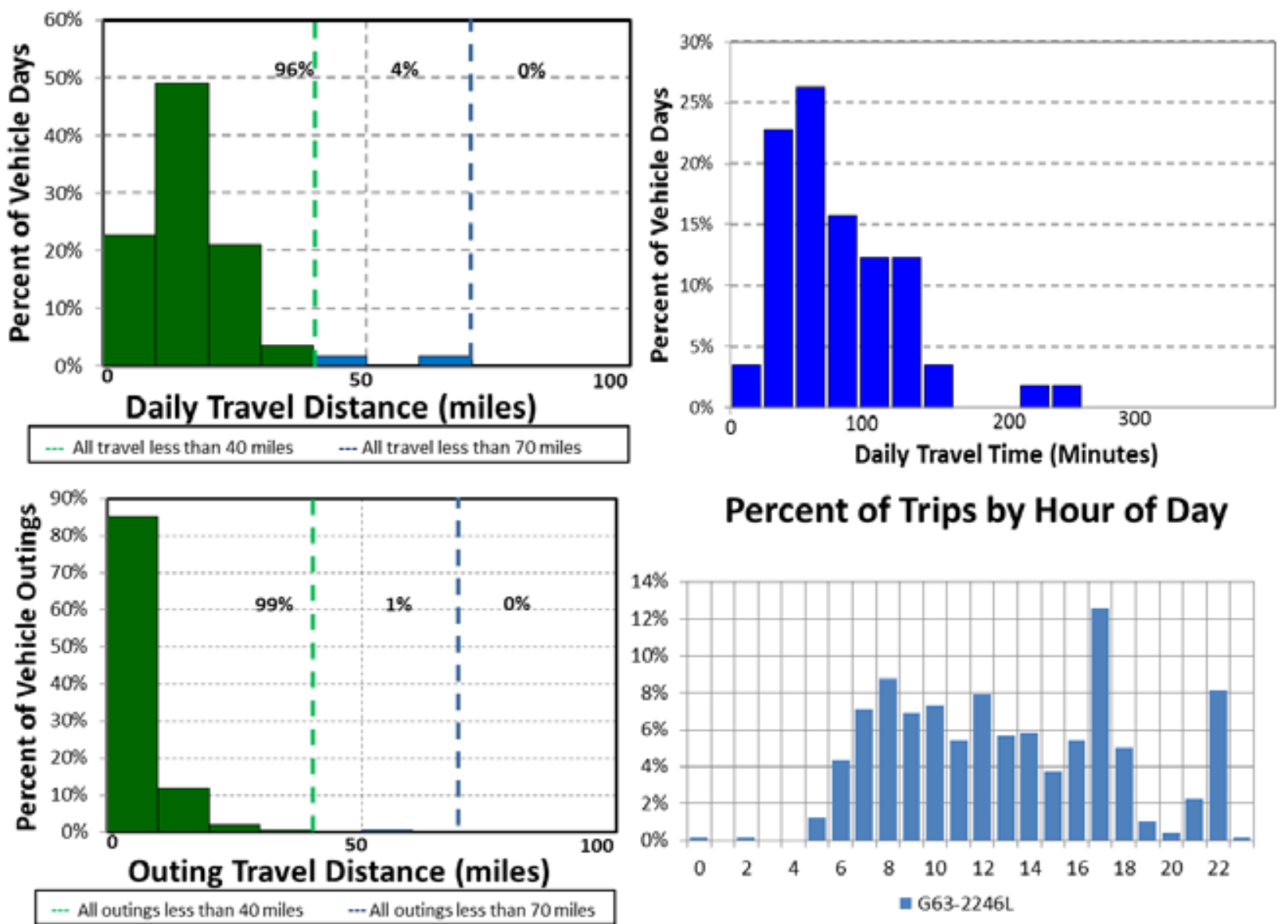

Figure B-4. Vehicle G63-2246L travel graphs.

\section{Vehicle G63-2246L Observations}

Logger 10 collected data on this vehicle for a period of 57 days of the 92-day study period. Validation occurred on $99.7 \%$ of the input data. Data recorded for this vehicle indicated that it has a support mission in emergency services and typically parks in Area 100, although it parks in other adjacent areas. Why data terminated early on November 29 is unknown.

NASA reports the vehicle odometer indicated 2,001 miles during the study and it travels approximately 8,160 miles per year. The vehicle was used on $62 \%$ of the available days with an average daily usage of 1.4 hours and a peak daily usage of 4.4 hours on the days it was used. The vehicle was used during extended day shift hours.

Figure B-6 shows $100 \%$ of daily travel and $100 \%$ of all outings are within the typically advertised range of a BEV of approximately 70 miles. Further, $96 \%$ of daily travel and $99 \%$ of outings are within the typically advertised CD mode of 40 miles for PHEVs.

A BEV could meet all daily travel without additional charging opportunities. A fleet of BEVs and PHEVs is likely to allow daily travel without requiring additional charge times, providing the PEVs

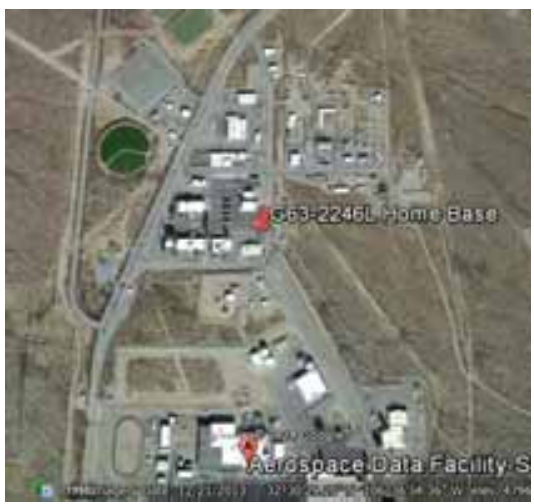
meet other mission requirements. The survey information suggests no other special requirements exist for these support activities. 


\begin{tabular}{|c|c|c|}
\hline & Make/Model/Year & Dodge Caravan/2006 \\
\hline$a$ & EPA Class Size & Minivan \\
\hline A & Mission & Support \\
\hline & VIN & 1D4GP24E96B649520 \\
\hline & Parking Location & See Figure B-7 \\
\hline & Fleet Vehicle ID & G41-2586D \\
\hline & Fuel Type & Gas/E85 \\
\hline & EPA Label/MPG (City/Hwy/Combined) & $17 / 24 / 20 \quad 11 / 16 / 13$ \\
\hline & EPA GHG Emissions (Grams $\mathrm{CO}_{2} / \mathrm{Mi}$ ) & $444 / 484$ \\
\hline & Study Logger ID & 11 \\
\hline & Total Vehicle Days/Total Study Days & $40 / 92$ \\
\hline
\end{tabular}

\begin{tabular}{|l|c|c|c|c|}
\hline \multicolumn{5}{|c|}{ Vehicle G41-2586D Travel Summary } \\
\hline & $\begin{array}{c}\text { Per Day } \\
\text { Average/Peak }\end{array}$ & $\begin{array}{c}\text { Per Outing } \\
\text { Average/Peak }\end{array}$ & $\begin{array}{c}\text { Per Trip } \\
\text { Average/Peak }\end{array}$ & Total \\
\hline Travel Distance (Miles) & $49.3 / 90.5$ & $15.0 / 82.5$ & $3.4 / 44.5$ & 1,974 \\
\hline Travel Time (Minutes) & $130.0 / 238.0$ & $39.5 / 128.0$ & $8.9 / 116.0$ & 5,216 \\
\hline Idle Time (Minutes) & $7.6 / \mathrm{NA}$ & $2.3 / \mathrm{NA}$ & $0.5 / \mathrm{NA}$ & 304 \\
\hline
\end{tabular}

\begin{tabular}{|c|c|c|c|c|}
\hline \multicolumn{2}{|c|}{ Total Stops } & \multicolumn{2}{c|}{ Stop Duration } \\
\hline $\begin{array}{c}\text { Distance From } \\
\text { Home Base (Miles) }\end{array}$ & Stops & Percentages & Stop Duration (Hours) & Stops \\
\hline Less than 10 & 374 & $89.3 \%$ & Less than 2 & 355 \\
\hline 10 to 20 & 45 & $10.7 \%$ & 2 to 4 & 24 \\
\hline 20 to 40 & 0 & $0 \%$ & 4 to 8 & 0 \\
\hline Greater than 40 & 0 & $0 \%$ & Greater than 8 & 40 \\
\hline
\end{tabular}

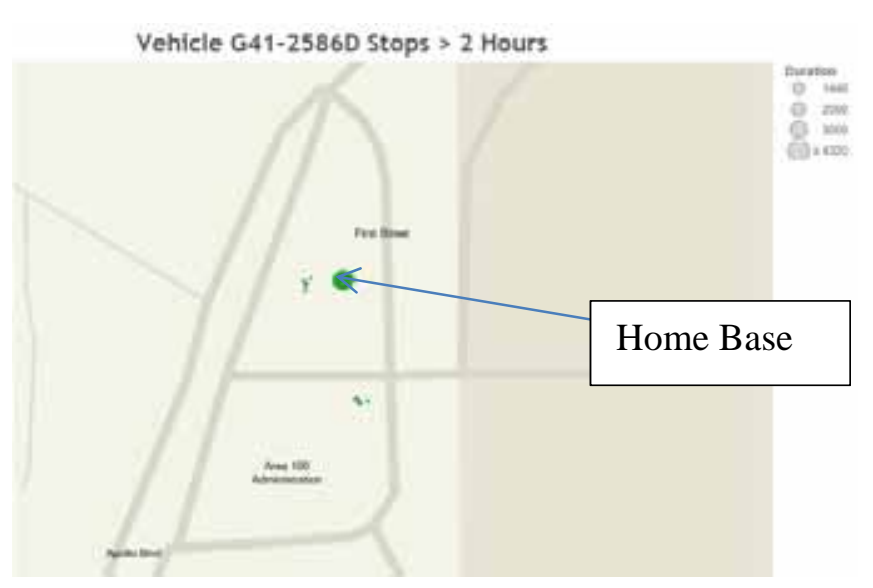

Figure B-7. Vehicle G41-2586D stops.

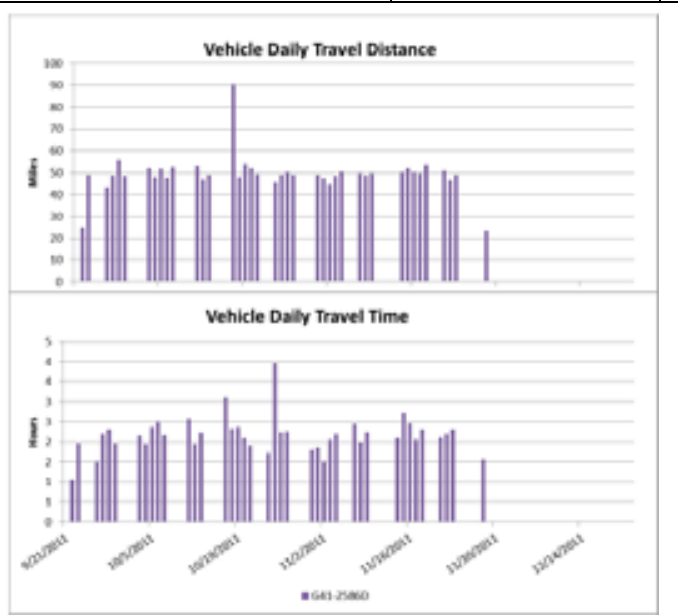

Figure B-8. Vehicle G41-2586D history. 

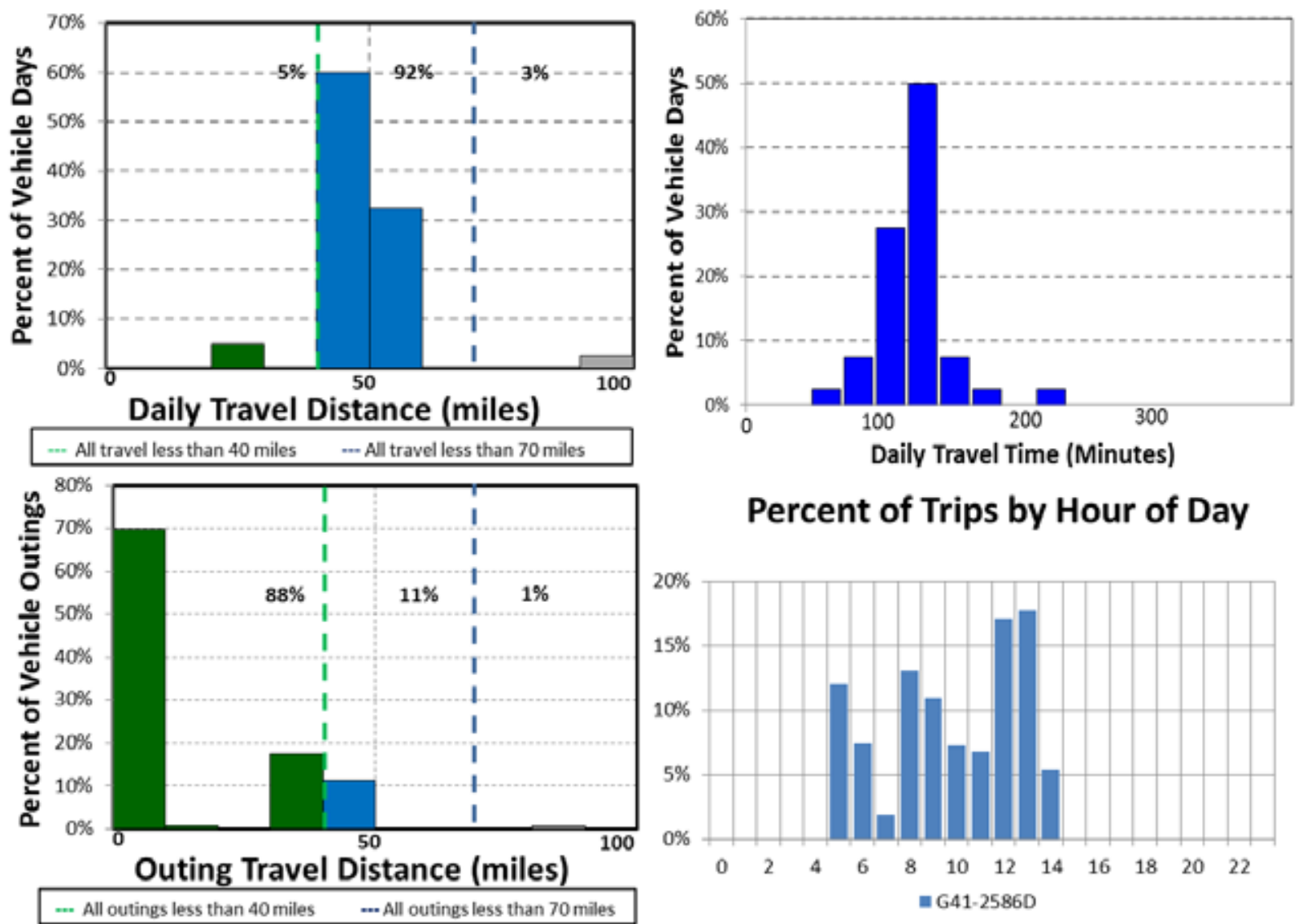

Figure B-5. Vehicle G41-2586D travel graphs.

\section{Vehicle G41-2586D Observations}

Logger 11 collected data on this vehicle for a period of 40 days of the 92-day study period. Validation occurred on $99.9 \%$ of the input data. Data recorded for this vehicle indicated that it has a support mission in mail delivery and typically parks north of Area 100, although it parks in other adjacent areas.

NASA reports that the vehicle odometer indicated 54,494 miles during the study and it travels approximately 12,108 miles per year. The vehicle was used on $43 \%$ of the available days, with an average daily usage of 2.2 hours and a peak daily usage of 4.0 hours on the days it was used. The vehicle was used during typical day shift hours.

Figure B-9 shows $97 \%$ of daily travel and $99 \%$ of all outings are within the typically advertised range of a BEV of approximately 70 miles. Further, $5 \%$ of daily travel and $88 \%$ of outings are within the typically advertised CD mode of 40 miles for PHEVs.

A BEV could meet $97 \%$ of the daily travel without additional charging opportunities. With $88 \%$ of outings within the capability of a PHEV, there exists sufficient charge

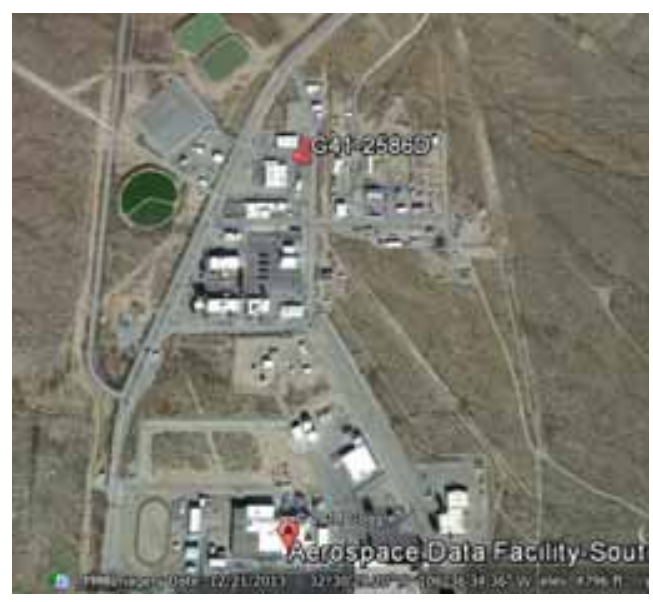
opportunities to include more daily travel in CD mode. A fleet of BEVs and PHEVs is likely to allow daily travel without requiring additional charge times, providing the PEVs meet other mission requirements. The survey information suggests no other special requirements exist for this support activity. 


\section{Vehicle G62-3553K}

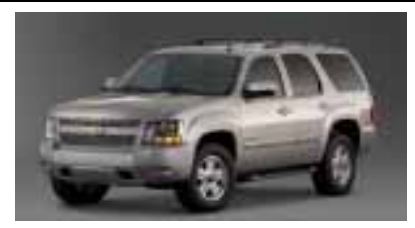

\begin{tabular}{|l|c|}
\hline Make/Model/Year & Chevrolet Tahoe/2010 \\
\hline EPA Class Size & SUV \\
\hline Mission & Support \\
\hline VIN & 1GNUKAE06AB278724 \\
\hline Parking Location & See Figure B-10 \\
\hline Fleet Vehicle ID & G62-3553K \\
\hline Fuel Type & Gas/E85 \\
\hline EPA Label/MPG (City/Hwy/Combined) & $15 / 21 / 1711 / 16 / 13$ \\
\hline EPA GHG Emissions (Grams CO $/$ Mi) & $523 / 484$ \\
\hline Study Logger ID & 12 \\
\hline Total Vehicle Days/Total Study Days & $54 / 92$ \\
\hline
\end{tabular}

\begin{tabular}{|l|c|c|c|c|}
\hline \multicolumn{5}{|c|}{ Vehicle G62-3553K Travel Summary } \\
& $\begin{array}{c}\text { Per Day } \\
\text { Average/Peak }\end{array}$ & $\begin{array}{c}\text { Per Outing } \\
\text { Average/Peak }\end{array}$ & $\begin{array}{c}\text { Per Trip } \\
\text { Average/Peak }\end{array}$ & Total \\
\hline Travel Distance (Miles) & $17.1 / 91.6$ & $11.0 / 99.3$ & $2.7 / 48.8$ & 922 \\
\hline Travel Time (Minutes) & $45.0 / 167.0$ & $29.1 / 213.0$ & $7.1 / 83.0$ & 2,448 \\
\hline Idle Time (Minutes) & $10.5 / \mathrm{NA}$ & $6.8 / \mathrm{NA}$ & $1.6 / \mathrm{NA}$ & 568 \\
\hline
\end{tabular}

\begin{tabular}{|c|c|c|c|c|}
\hline \multicolumn{2}{|c|}{ Total Stops } & \multicolumn{2}{c|}{ Stop Duration } \\
\hline $\begin{array}{c}\text { Distance From } \\
\text { Home Base (Miles) }\end{array}$ & Stops & Percentages & Stop Duration (Hours) & Stops \\
\hline Less than 10 & 282 & $95.6 \%$ & Less than 2 & 214 \\
\hline 10 to 20 & 11 & $3.7 \%$ & 2 to 4 & 20 \\
\hline 20 to 40 & 2 & $0.7 \%$ & 4 to 8 & 11 \\
\hline Greater than 40 & 0 & $0 \%$ & Greater than 8 & 50 \\
\hline
\end{tabular}

Vehicle G62-3553K Stops $>2$ Hours

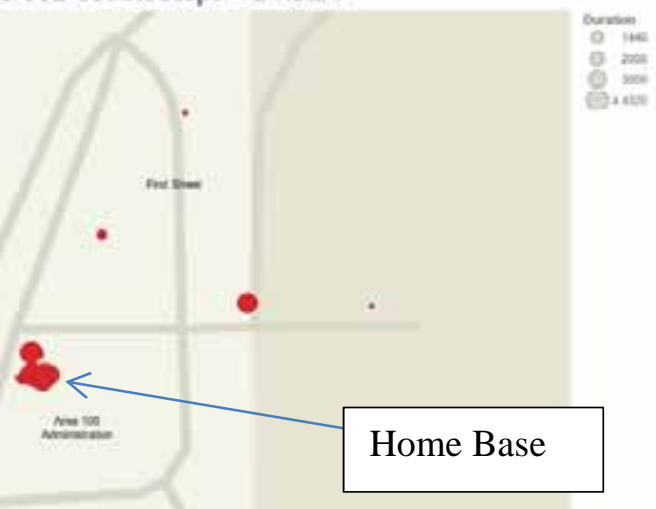

Figure B-10. Vehicle G62-3553K stops.

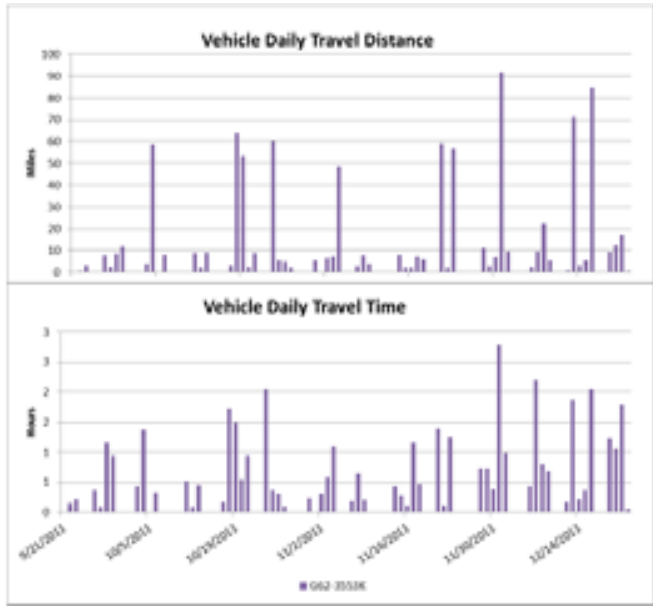

Figure B-11. Vehicle G62-3553K history. 


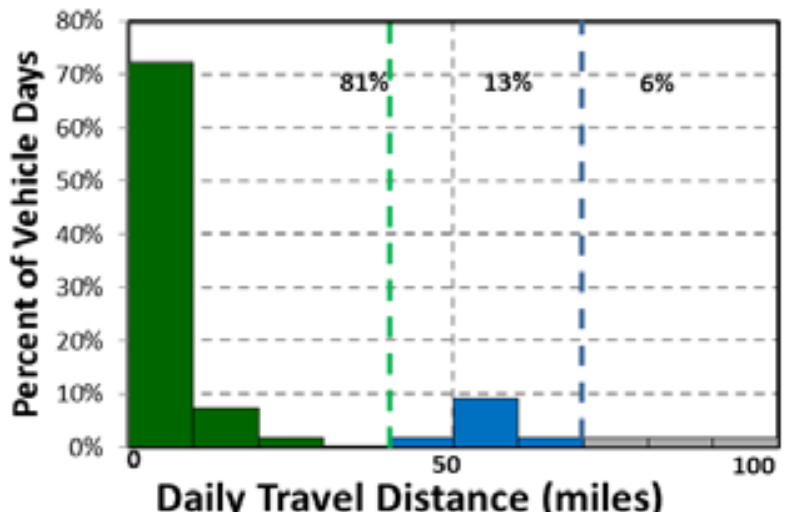

Daily Travel Distance (miles)

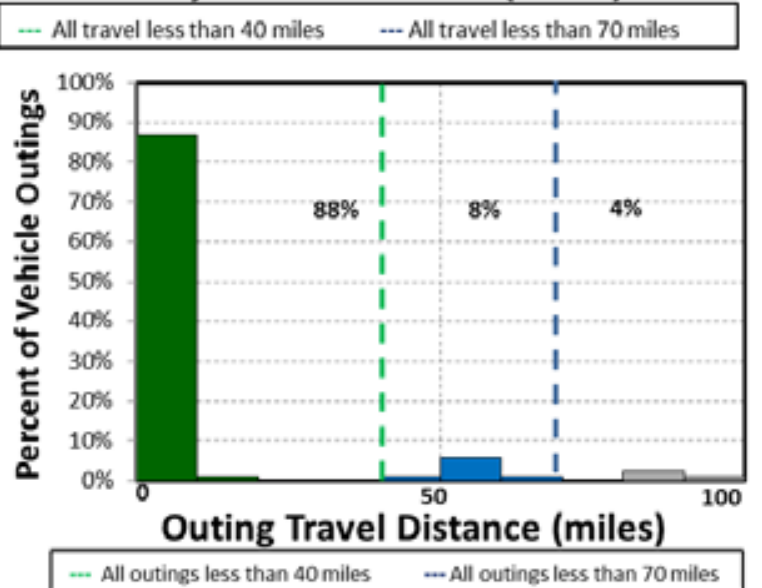

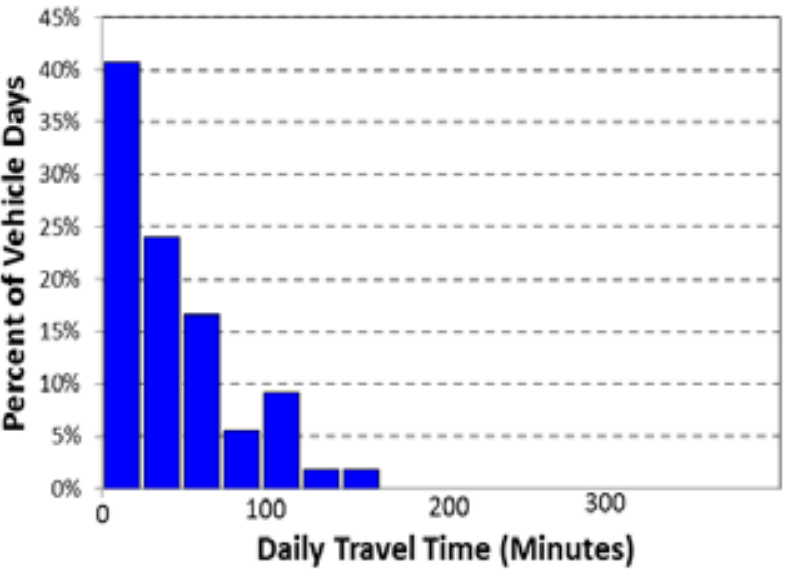

Percent of Trips by Hour of Day

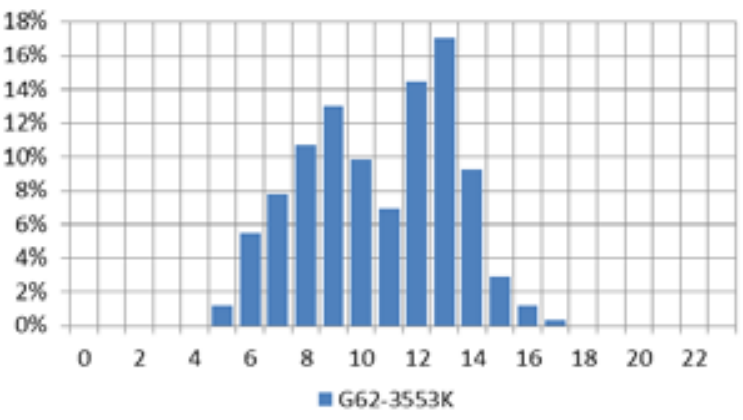

Figure B-6. Vehicle G62-3553K travel graphs.

\section{Vehicle G62-3553K Observations}

Logger 12 collected data on this vehicle for a period of 54 days of the 92-day study period. Validation occurred on $100 \%$ of the input data. Data recorded for this vehicle indicated that it has a support mission for information technology and typically parks in Area 100, although it parks in other adjacent areas.

NASA reports that the vehicle odometer indicated 5,431 miles during the study and it travels approximately 4,128 miles per year. The vehicle was used on $59 \%$ of the available days, with an average daily usage of 0.8 hours and a peak daily usage of 2.8 hours on the days it was used. The vehicle was used during typical day shift hours.

Figure B-12 shows $94 \%$ of daily travel and $96 \%$ of all outings are within the typically advertised range of a BEV of approximately 70 miles. Further, 81\% of daily travel and $88 \%$ of outings are within the typically advertised CD mode of 40 miles for PHEVs.

A BEV could meet $94 \%$ of the daily travel without additional charging opportunities. With $88 \%$ of outings within the capability of a PHEV, there exists sufficient charge

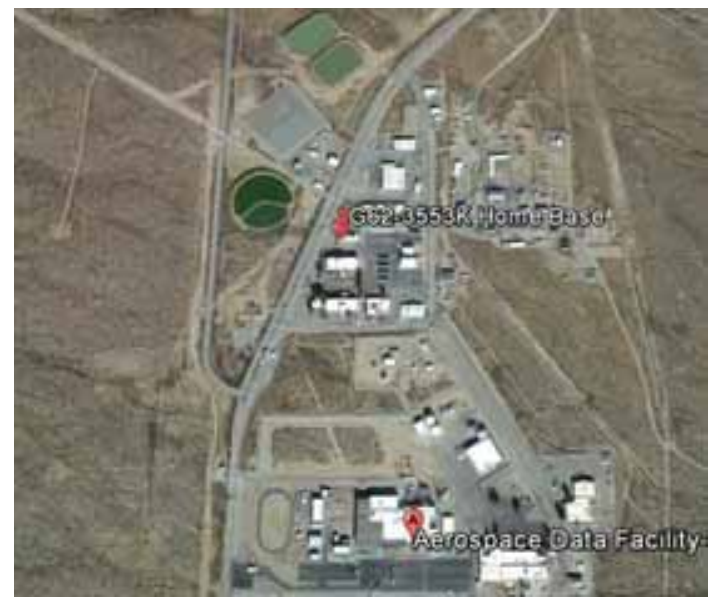
opportunities to include more daily travel in CD mode. A fleet of BEVs and PHEVs is likely to allow daily travel without requiring additional charge times, providing the PEVs meet other mission requirements. The survey information suggests no other special requirements exist for this support activity. 
Vehicle G63-3464H

\begin{tabular}{|c|c|c|}
\hline & Make/Model/Year & Chevrolet Silverado/2010 \\
\hline ah $=$ & EPA Class Size & Pickup Truck \\
\hline$=-8=-8$ & Mission & Law Enforcement \\
\hline & VIN & 1GC4KVBG1AF146957 \\
\hline & Parking Location & See Figure B-13 \\
\hline & Fleet Vehicle ID & G63-3464H \\
\hline & Fuel Type & Gas \\
\hline & EPA Label/MPG (City/Hwy) & $15 / 20 / 17$ \\
\hline & EPA GHG Emissions (Grams $\mathrm{CO}_{2} / \mathrm{Mi}$ ) & 523 \\
\hline & Study Logger ID & 13 \\
\hline & Total Vehicle Days/Total Study Days & $42 / 92$ \\
\hline
\end{tabular}

\begin{tabular}{|l|c|c|c|c|}
\hline \multicolumn{5}{|c|}{ Vehicle G63-3464H Travel Summary } \\
\hline & $\begin{array}{c}\text { Per Day } \\
\text { Average/Peak }\end{array}$ & $\begin{array}{c}\text { Per Outing } \\
\text { Average/Peak }\end{array}$ & $\begin{array}{c}\text { Per Trip } \\
\text { Average/Peak }\end{array}$ & Total \\
\hline Travel Distance (Miles) & $110.7 / 224.8$ & $52.2 / 292.6$ & $5.9 / 52.6$ & 4,650 \\
\hline Travel Time (Minutes) & $524.0 / 1,061.0$ & $247.2 / 1,376.0$ & $27.8 / 218.0$ & 21,998 \\
\hline Idle Time (Minutes) & $133.4 / \mathrm{NA}$ & $62.9 / \mathrm{NA}$ & $7.1 / \mathrm{NA}$ & 5,601 \\
\hline
\end{tabular}

\begin{tabular}{|c|c|c|c|c|}
\hline \multicolumn{2}{|c|}{ Total Stops } & \multicolumn{2}{c|}{ Stop Duration } \\
\hline $\begin{array}{c}\text { Distance From } \\
\text { Home Base (Miles) }\end{array}$ & Stops & Percentages & Stop Duration (Hours) & Stops \\
\hline Less than 10 & 697 & $100 \%$ & Less than 2 & 670 \\
\hline 10 to 20 & 0 & $0 \%$ & 2 to 4 & 8 \\
\hline 20 to 40 & 0 & $0 \%$ & 4 to 8 & 6 \\
\hline Greater than 40 & 0 & $0 \%$ & Greater than 8 & 13 \\
\hline
\end{tabular}

Vehicle G63-3464H Stops > 2 Hours

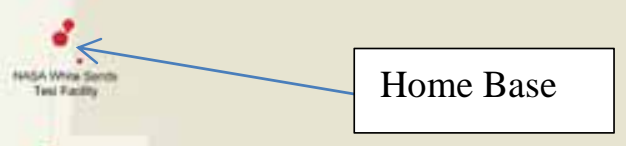

Figure B-13. Vehicle G63-3464H stops.

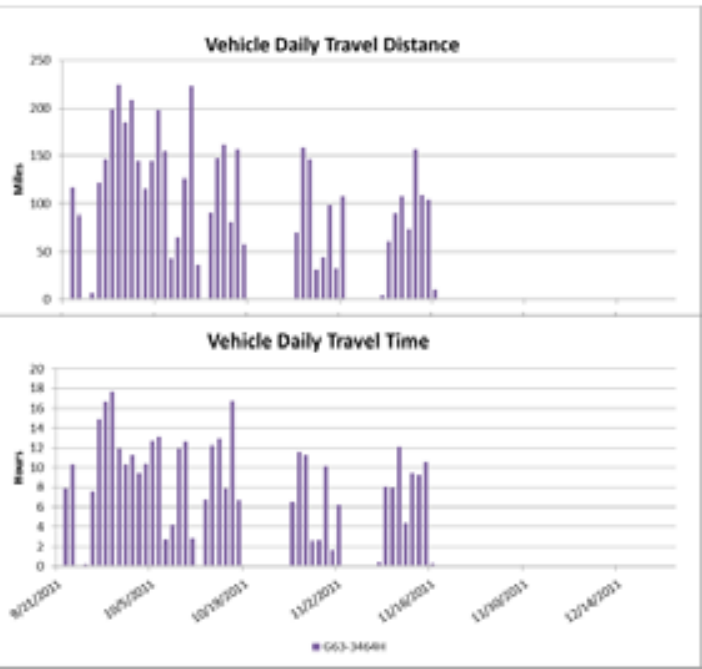

Figure B-14. Vehicle G63-3464H history. 


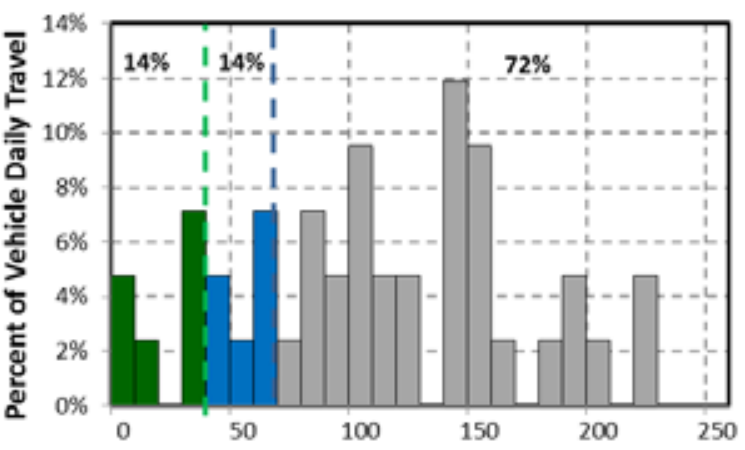

Daily Travel Distance (miles)

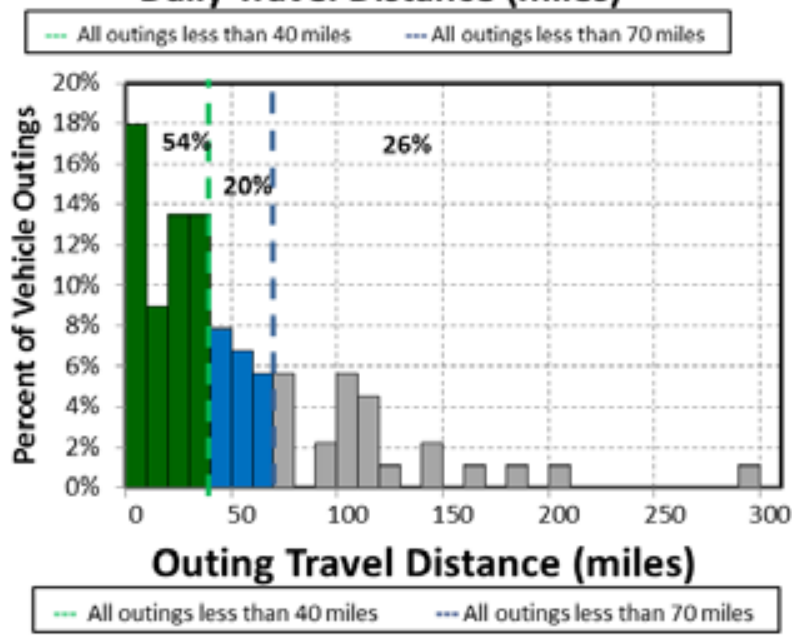

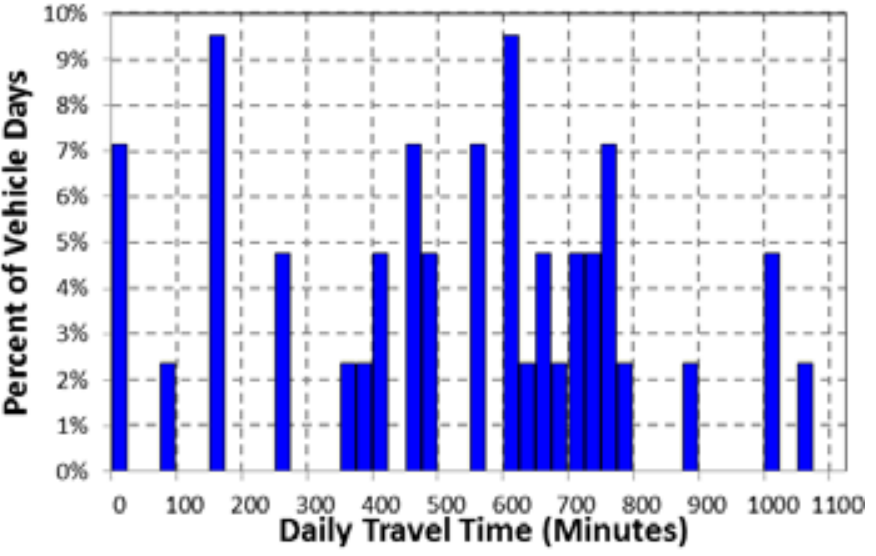

Percent of Trips by Hour of Day

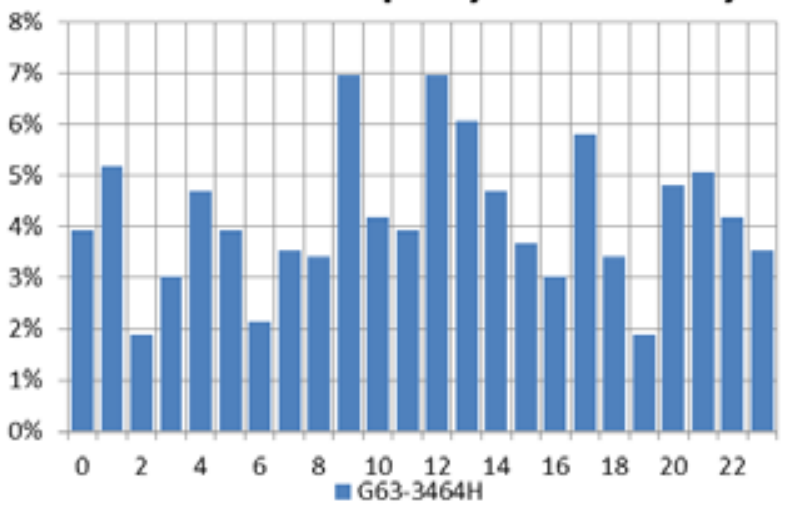

Figure B-7. Vehicle G63-3464H travel graphs.

\section{Vehicle G63-3464H Observations}

Logger 13 collected data on this vehicle for a period of 42 days of the 92-day study period. Validation occurred on $99.9 \%$ of the input data. Data recorded for this vehicle indicated that it has a law enforcement mission for security patrols and typically parks in Area 100, although it parks in other adjacent areas. This vehicle exhibited significant idle time that is typical of enforcement vehicles.

NASA reports that the vehicle odometer indicated 55,856 miles during the study and it travels approximately 35,820 miles per year. The vehicle was used on $59 \%$ of the available days, with an average daily usage of 8.7 hours and a peak daily usage of 17.7 hours on the days it was used. The vehicle was used during all hours of the day.

Figure B-15 shows $28 \%$ of daily travel and $74 \%$ of all outings are within the typically advertised range of a BEV of approximately 70 miles. Further, $14 \%$ of daily travel and $54 \%$ of outings are within the typically advertised CD mode of 40 miles for PHEVs.

A BEV could not meet the daily travel requirements due to the extended operation. With $54 \%$ of outings within the capability of a PHEV, there may exist additional charge opportunities to include

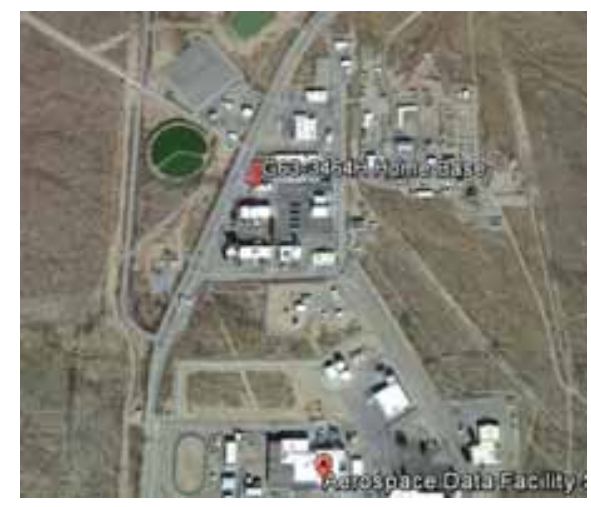
more daily travel in CD mode. Typically, a PHEV is more desirable for enforcement missions due to the lack of range limitations. 
Vehicle G63-0404D

\begin{tabular}{|l|l|c|}
\hline & Make/Model/Year & Chevrolet Silverado/2006 \\
\cline { 2 - 3 } & EPA Class Size & Pickup Truck \\
\cline { 2 - 3 } & Mission & Support \\
\hline VIN & 1GBHK23G26F231638 \\
\cline { 2 - 3 } & Parking Location Figure B-16 \\
\hline & Fleet Vehicle ID & G63-0404D \\
\hline & Fuel Type & Gas \\
\cline { 2 - 3 } & EPA Label/MPG (City/Hwy/Combined) & $15 / 19 / 17$ \\
\hline & EPA GHG Emissions (Grams CO $/$ Mi) & 523 \\
\hline & Study Logger ID & 14 \\
\hline & Total Vehicle Days/Total Study Days & $61 / 92$ \\
\hline
\end{tabular}

\begin{tabular}{|l|c|c|c|c|}
\hline \multicolumn{5}{|c|}{ Vehicle G63-0404D Travel Summary } \\
\hline & $\begin{array}{c}\text { Per Day } \\
\text { Average/Peak }\end{array}$ & $\begin{array}{c}\text { Per Outing } \\
\text { Average/Peak }\end{array}$ & $\begin{array}{c}\text { Per Trip } \\
\text { Average/Peak }\end{array}$ & Total \\
\hline Travel Distance (Miles) & $22.5 / 215.4$ & $8.1 / 214.7$ & $2.7 / 88.7$ & 1,376 \\
\hline Travel Time (Minutes) & $69.0 / 389.0$ & $24.8 / 382.0$ & $8.3 / 242.0$ & 4,220 \\
\hline Idle Time (Minutes) & $14.5 / \mathrm{NA}$ & $5.2 / \mathrm{NA}$ & $1.7 / \mathrm{NA}$ & 885 \\
\hline
\end{tabular}

\begin{tabular}{|c|c|c|c|c|}
\hline \multicolumn{2}{|c|}{ Total Stops } & \multicolumn{2}{c|}{ Stop Duration } \\
\hline $\begin{array}{c}\text { Distance From } \\
\begin{array}{c}\text { Home Base } \\
\text { (Miles) }\end{array}\end{array}$ & Stops & Percentages & Stop Duration (Hours) & Stops \\
\hline Less than 10 & 413 & $94.3 \%$ & Less than 2 & 350 \\
\hline 10 to 20 & 4 & $0.9 \%$ & 2 to 4 & 23 \\
\hline 20 to 40 & 18 & $4.1 \%$ & 4 to 8 & 11 \\
\hline Greater than 40 & 3 & $0.7 \%$ & Greater than 8 & 54 \\
\hline
\end{tabular}

Vehicle G63-0404D Stops > 2 Hours

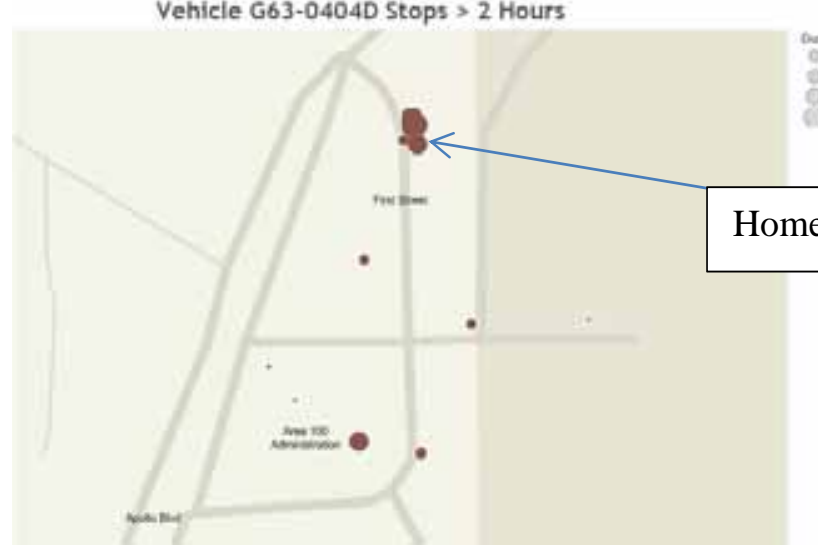

Figure B-16. Vehicle G63-0404D stops.

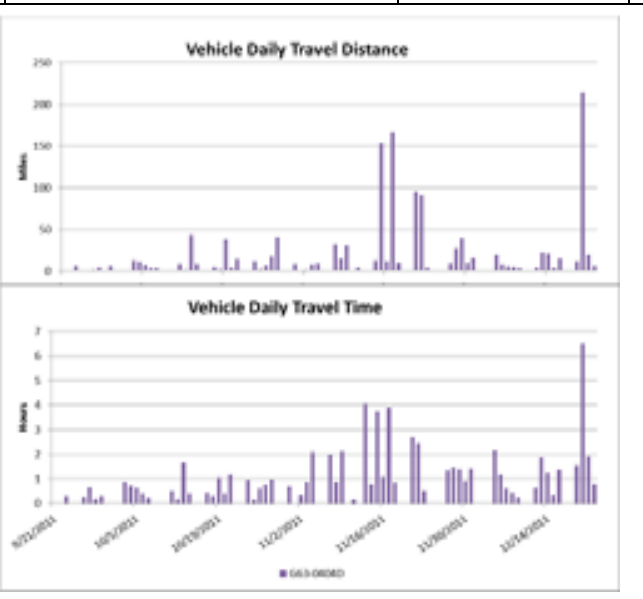

Figure B-17. Vehicle G63-0404D history. 

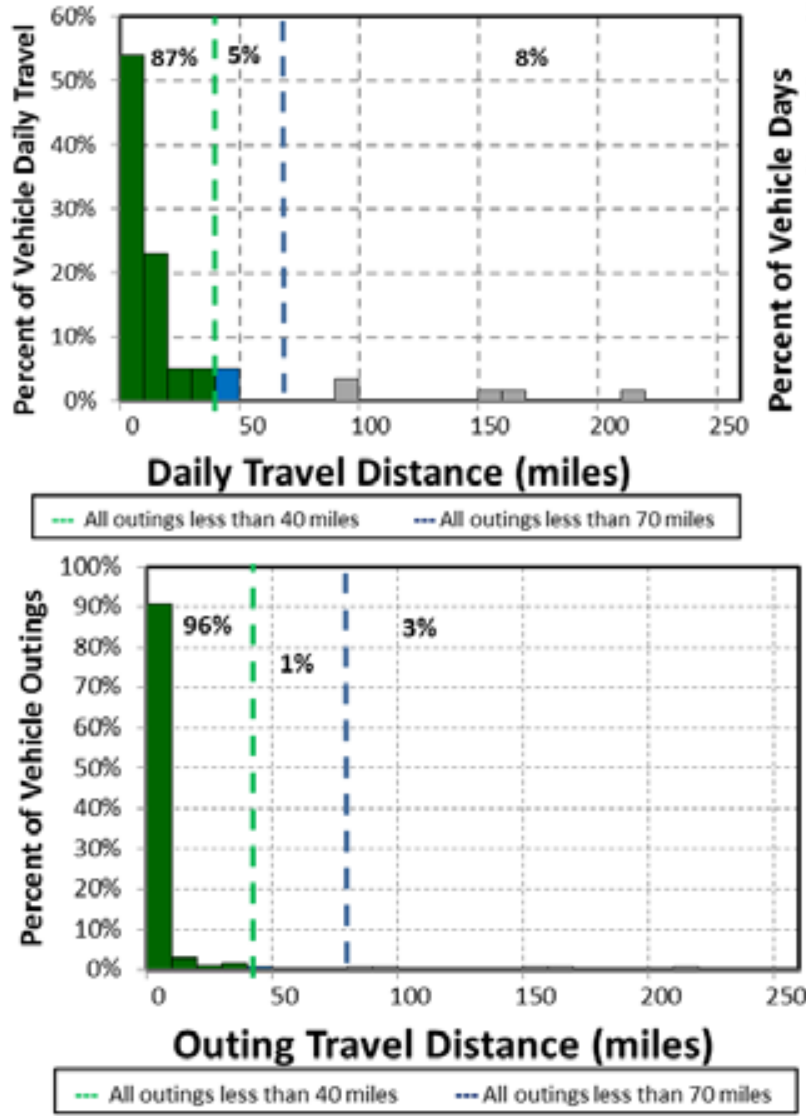

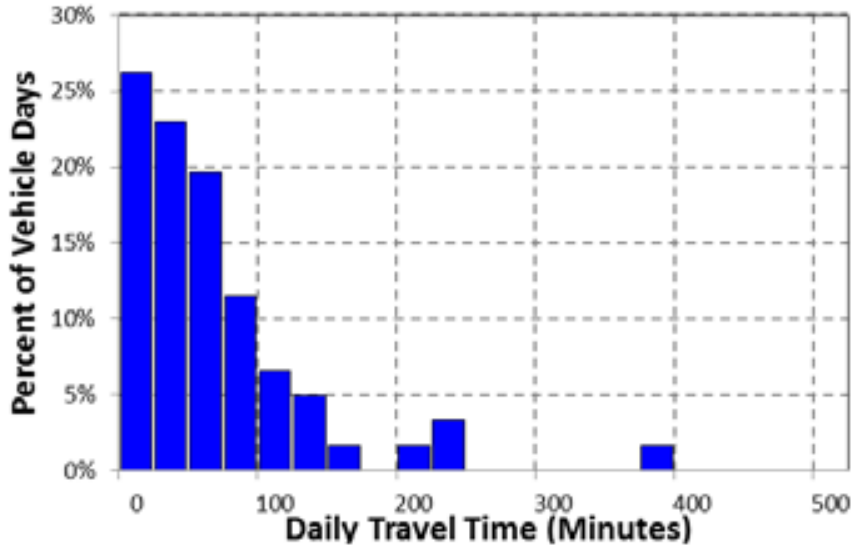

Percent of Trips by Hour of Day

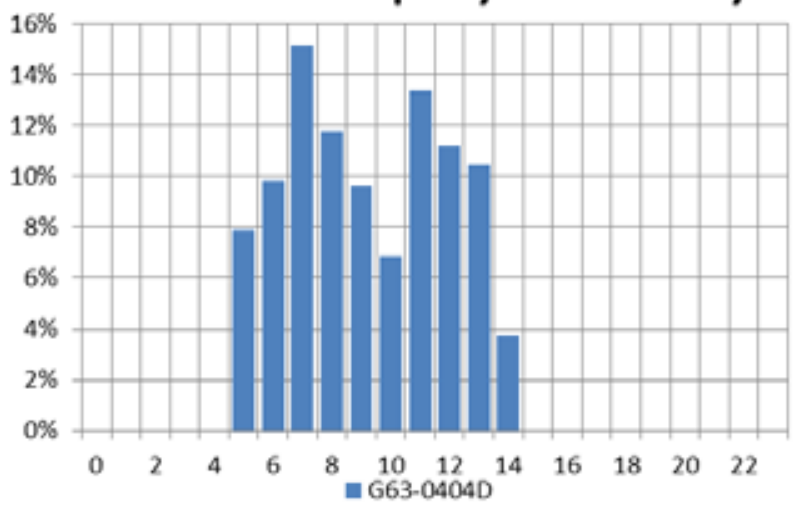

Figure B-8. Vehicle G63-0404D travel graphs.

\section{Vehicle G63-0404D Observations}

Logger 14 collected data on this vehicle for a period of 61 days of the 92-day study period. Validation occurred on $99.7 \%$ of the input data. Data recorded for this vehicle indicated that it has a support mission for communications and typically parks north of Area 100, although it also parks in other nearby areas.

NASA reports that the vehicle odometer indicated 62,073 miles during the study and it travels approximately 10,440 miles per year. The vehicle was used on $66 \%$ of available days, with an average daily usage of 1.2 hours and a peak daily usage of 6.5 hours on the days it was used. The vehicle was used during typical day shift hours.

Figure B-18 shows $92 \%$ of daily travel and $97 \%$ of all outings are within the typically advertised range of a BEV of approximately 70 miles. Further, $87 \%$ of daily travel and $96 \%$ of outings are within the typically advertised CD mode of 40 miles for PHEVs. The vehicle parked overnight in areas not classified here as the home base; explaining the long trips and outings.

A BEV could meet $92 \%$ of the daily travel without additional charging opportunities. With $96 \%$ of outings within the capability of a PHEV, there exists sufficient charge opportunities to include more daily travel in CD mode. A fleet of BEVs and PHEVs is likely to

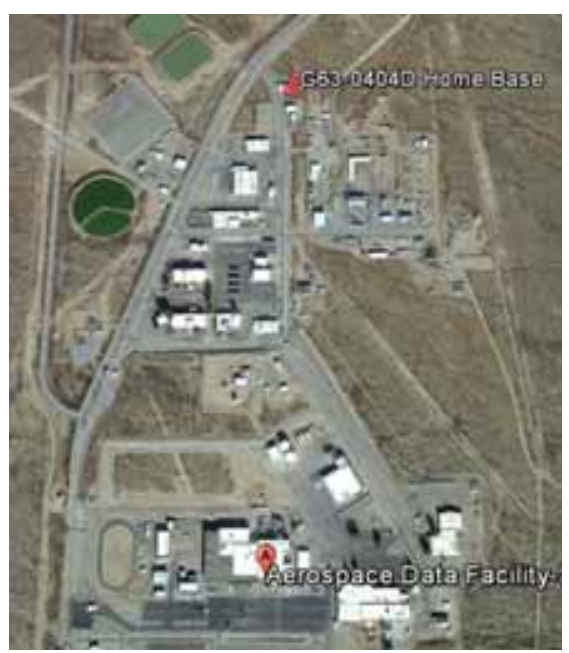
allow daily travel without requiring additional charge times, providing the PEVs meet other mission requirements. The survey information suggests no other special requirements exist for this support activity. 
Vehicle G63-1990L

\begin{tabular}{|c|c|c|}
\hline & Make/Model/Year & Ford F250/2011 \\
\hline & EPA Class Size & Pickup Truck \\
\hline 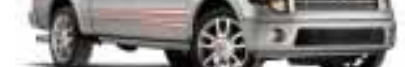 & Mission & Law Enforcement \\
\hline & VIN & 1FT7W2B62BEC26167 \\
\hline & Parking Location & See Figure B-19 \\
\hline & Fleet Vehicle ID & G63-1990L \\
\hline & Fuel Type & Gas/E85 \\
\hline & EPA Label/MPG (City/Hwy)* & $17 / 23 / 1912 / 17 / 14$ \\
\hline & EPA GHG Emissions (Grams $\mathrm{CO}_{2} / \mathrm{Mi}$ )* & $468 / 450$ \\
\hline & Study Logger ID & 15 \\
\hline & Total Vehicle Days/Total Study Days & $56 / 92$ \\
\hline
\end{tabular}

\begin{tabular}{|l|c|c|c|c|}
\hline \multicolumn{5}{|c|}{ Vehicle G63-1990L Travel Summary } \\
\hline & $\begin{array}{c}\text { Per Day } \\
\text { Average/Peak }\end{array}$ & $\begin{array}{c}\text { Per Outing } \\
\text { Average/Peak }\end{array}$ & $\begin{array}{c}\text { Per Trip } \\
\text { Average/Peak }\end{array}$ & Total \\
\hline Travel Distance (Miles) & $121.9 /$ & $69.7 /$ & $6.7 /$ & 6,827 \\
\hline Travel Time (Minutes) & $635.0 /$ & $363.1 /$ & $34.8 /$ & 35,582 \\
\hline Idle Time (Minutes) & $163.8 / \mathrm{NA}$ & $93.6 / \mathrm{NA}$ & $9.0 / \mathrm{NA}$ & 9,172 \\
\hline
\end{tabular}

\begin{tabular}{|c|c|c|c|c|}
\hline \multicolumn{2}{|c|}{ Total Stops } & \multicolumn{2}{c|}{ Stop Duration } \\
\hline $\begin{array}{c}\text { Distance From } \\
\text { Home Base (Miles) }\end{array}$ & Stops & Percentages & Stop Duration (Hours) & Stops \\
\hline Less than 10 & 906 & $99.7 \%$ & Less than 2 & 872 \\
\hline 10 to 20 & 2 & $0.3 \%$ & 2 to 4 & 14 \\
\hline 20 to 40 & 0 & $0 \%$ & 4 to 8 & 10 \\
\hline Greater than 40 & 0 & $0 \%$ & Greater than 8 & 13 \\
\hline
\end{tabular}

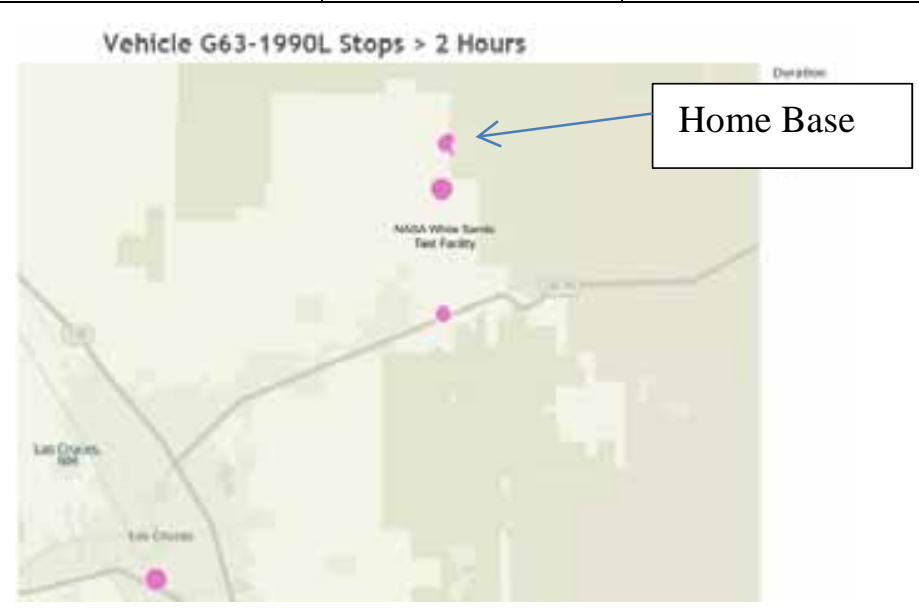

Figure B-19. Vehicle G63-1990L stops.

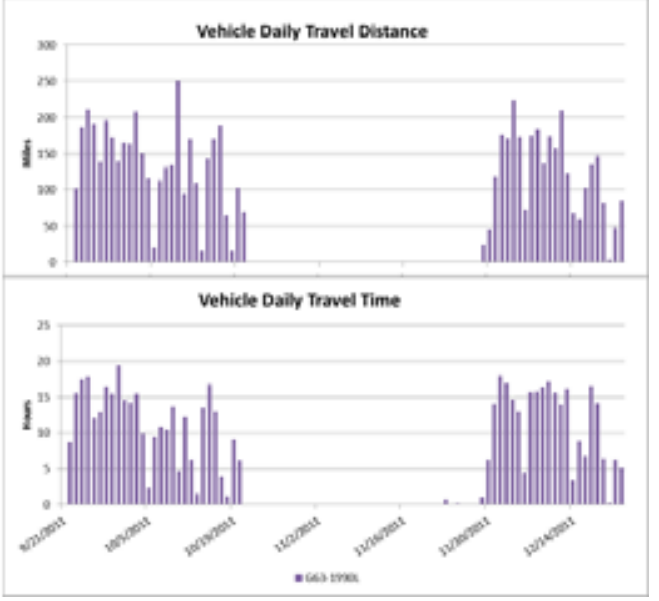

*Economy for F250 not available. Information is for F150.

Figure B-20. Vehicle G63-1990L history. 

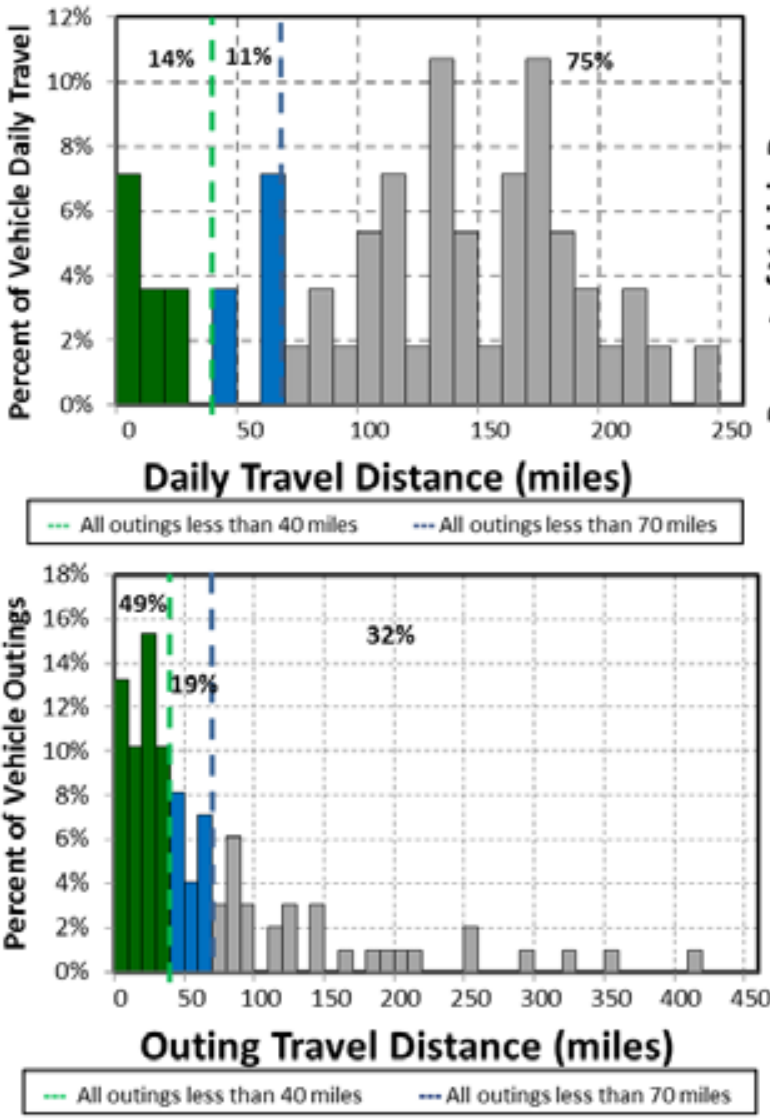
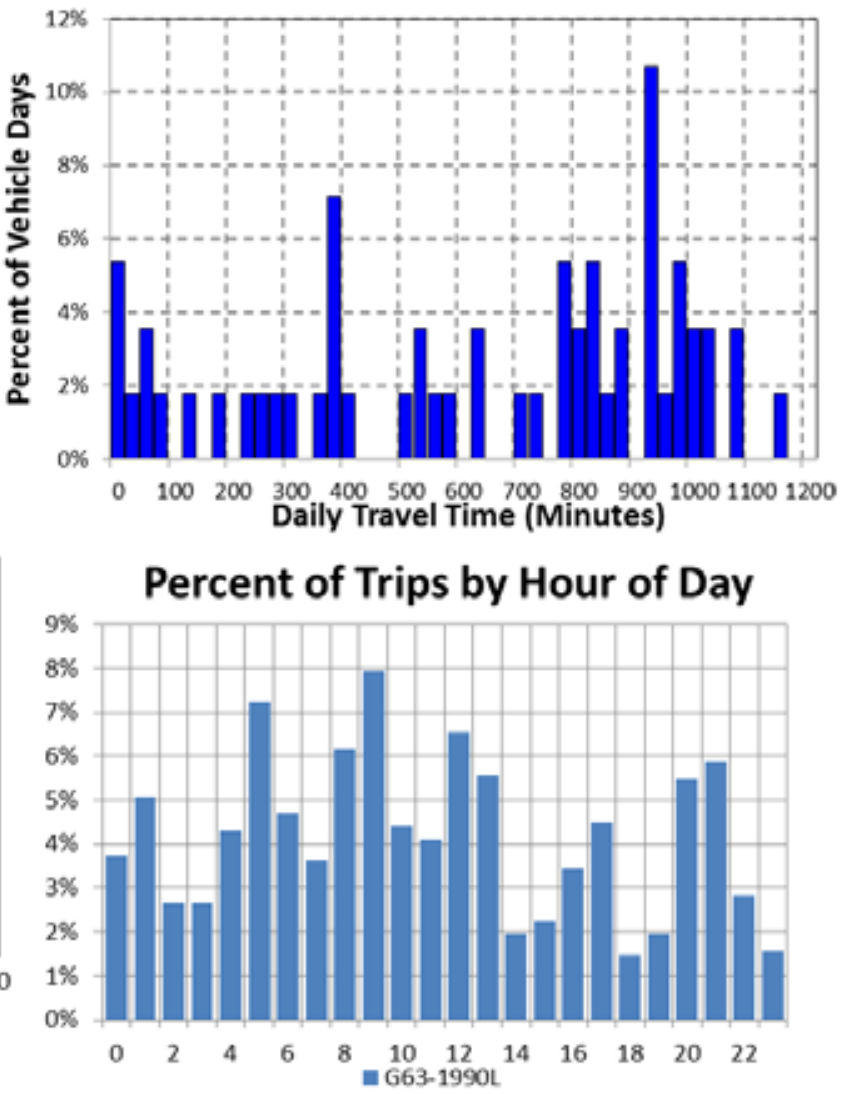

Figure B-9. Vehicle G63-1990L travel graphs.

\section{Vehicle G63-1990L Observations}

Logger 15 collected data on this vehicle for a period of 56 days of the 92-day study period. Validation occurred on $99.7 \%$ of the input data. Data recorded for this vehicle indicated that it has a law enforcement mission for security patrols and Area 100 is assumed for a home base, although it parks in other areas. This vehicle exhibited significant idle time that is typical of enforcement vehicles.

NASA reports that the vehicle odometer indicated 18,984 miles during the study and it travels approximately 34,212 miles per year. The vehicle was used on $61 \%$ of available days, with an average daily usage of 10.6 hours and a peak daily usage of 19.5 hours on the days it was used. The vehicle was used during all hours of the day.

Figure B-21 shows that $25 \%$ of daily travel and $68 \%$ of all outings are within the typically advertised range of a BEV of approximately 70 miles. Further, $14 \%$ of daily travel and $49 \%$ of outings are within the typically advertised CD mode of 40 miles for PHEVs.

A BEV could not meet the daily travel requirements due to extended operation. With $49 \%$ of outings within the capability of a PHEV, there may exist additional charge opportunities to include more daily travel in CD mode. Typically, a PHEV is

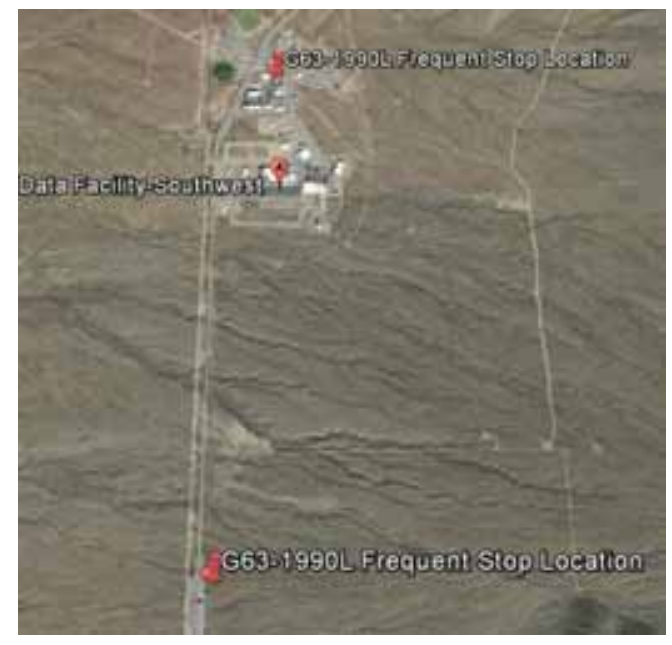
more desirable for enforcement missions due to the lack of range limitations. 


\section{Vehicle G62-1017D}

\begin{tabular}{|l|l|c|}
\hline & Make/Model/Year & Ford F150/2006 \\
\hline EPA Class Size & Pickup Truck \\
\hline Mission & Support \\
\hline VIN & 1FTRE14V16NB05319 \\
\hline Parking Location & See Figure B-22 \\
\hline Fleet Vehicle ID & G62-1017D \\
\cline { 2 - 3 } & Fuel Type & Gas/E85 \\
\cline { 2 - 3 } & EPA Label/MPG (City/Hwy) & $12 / 17 / 1410 / 13 / 11$ \\
\hline & EPA GHG Emissions (Grams CO $/$ Mi) & $635 / 572$ \\
\cline { 2 - 3 } & Study Logger ID & 16 \\
\cline { 2 - 3 } & Total Vehicle Days/Total Study Days & $7 / 33$ \\
\hline
\end{tabular}

\begin{tabular}{|l|c|c|c|c|}
\hline \multicolumn{5}{|c|}{ Vehicle G62-1017D Travel Summary } \\
& $\begin{array}{c}\text { Per Day } \\
\text { Average/Peak }\end{array}$ & $\begin{array}{c}\text { Per Outing } \\
\text { Average/Peak }\end{array}$ & $\begin{array}{c}\text { Per Trip } \\
\text { Average/Peak }\end{array}$ & Total \\
\hline Travel Distance (Miles) & $12.3 / 22.3$ & $14.3 / 37.1$ & $3.7 / 11.1$ & 86 \\
\hline Travel Time (Minutes) & $229 / 386.0$ & $267.2 / 813.0$ & $69.7 / 292.0$ & 1,603 \\
\hline Idle Time (Minutes) & $74.9 / \mathrm{NA}$ & $87.3 / \mathrm{NA}$ & $22.8 / \mathrm{NA}$ & 524 \\
\hline
\end{tabular}

\begin{tabular}{|c|c|c|c|c|}
\hline \multicolumn{2}{|c|}{ Total Stops } & \multicolumn{2}{c|}{ Stop Duration } \\
\hline $\begin{array}{c}\text { Distance From } \\
\text { Home Base (Miles) }\end{array}$ & Stops & Percentages & Stop Duration (Hours) & Stops \\
\hline Less than 10 & 17 & $100 \%$ & Less than 2 & 10 \\
\hline 10 to 20 & 0 & $0 \%$ & 2 to 4 & 2 \\
\hline 20 to 40 & 0 & $0 \%$ & 4 to 8 & 0 \\
\hline Greater than 40 & 0 & $0 \%$ & Greater than 8 & 5 \\
\hline
\end{tabular}

Vehicle G62-1017D Stops > 2 Hours

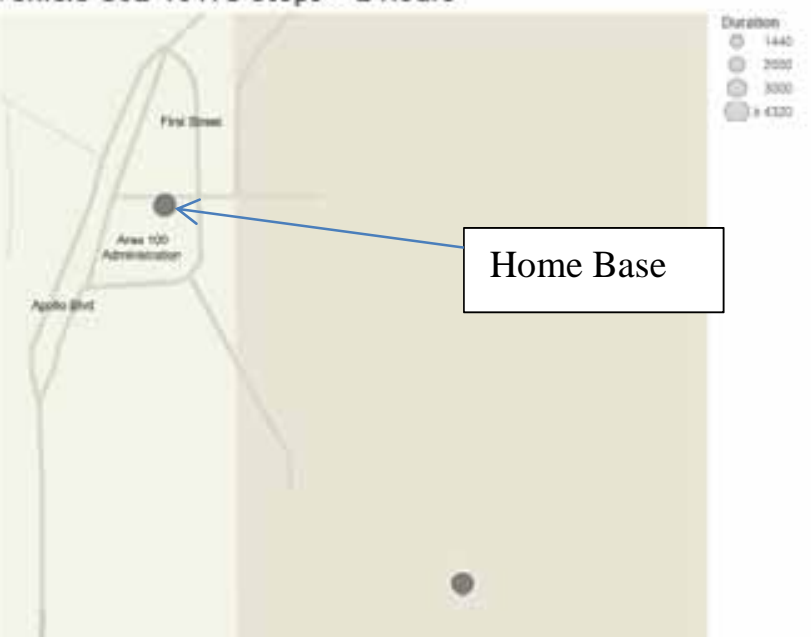

Figure B-22. Vehicle G62-1017D stops.

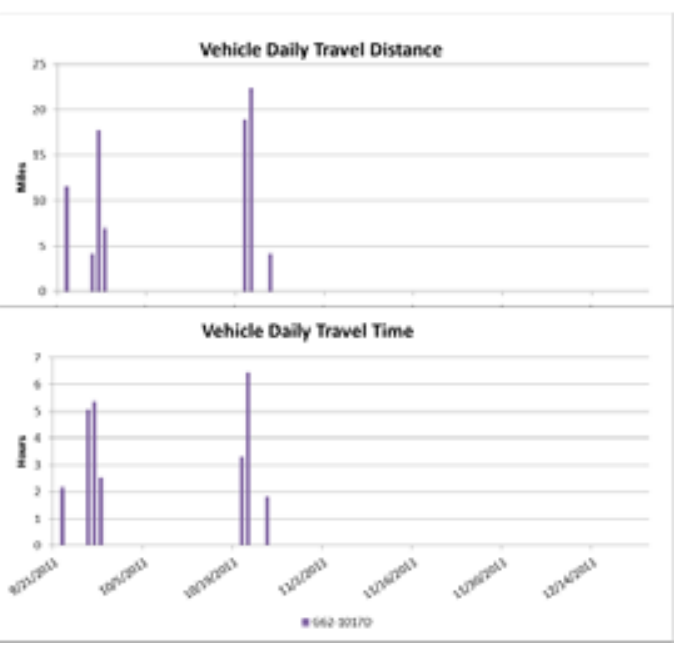

Figure B-23. Vehicle G62-1017D history. 

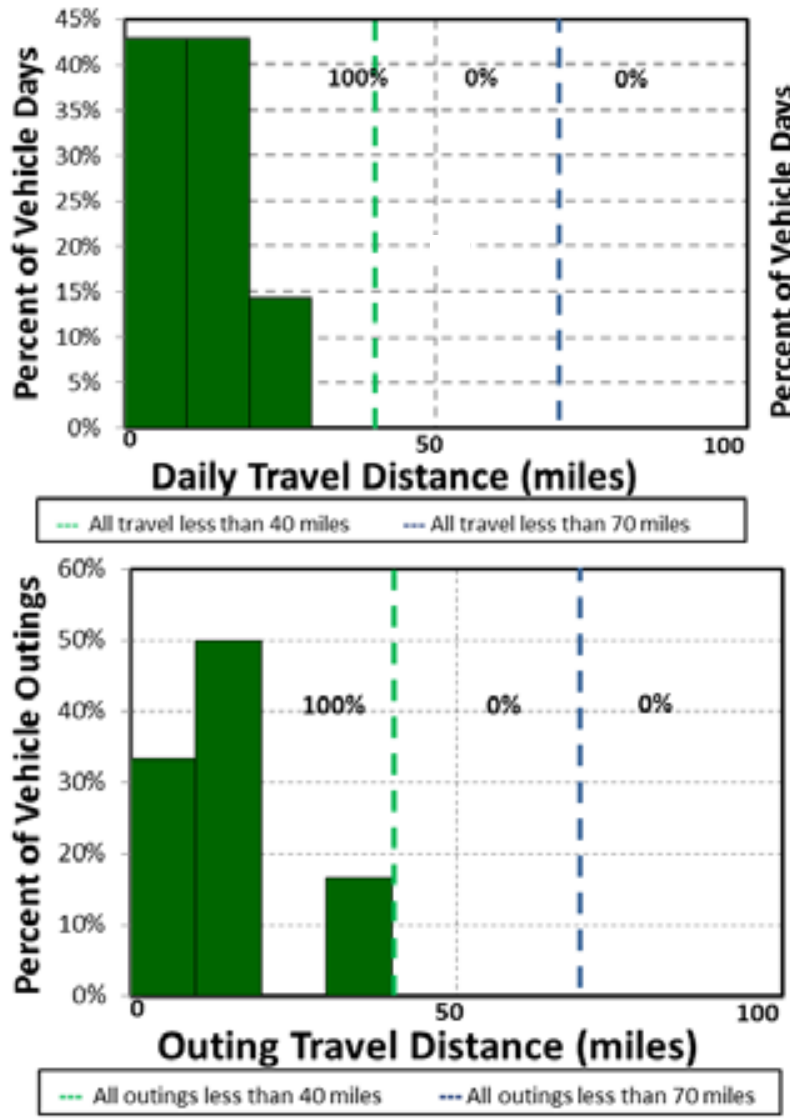

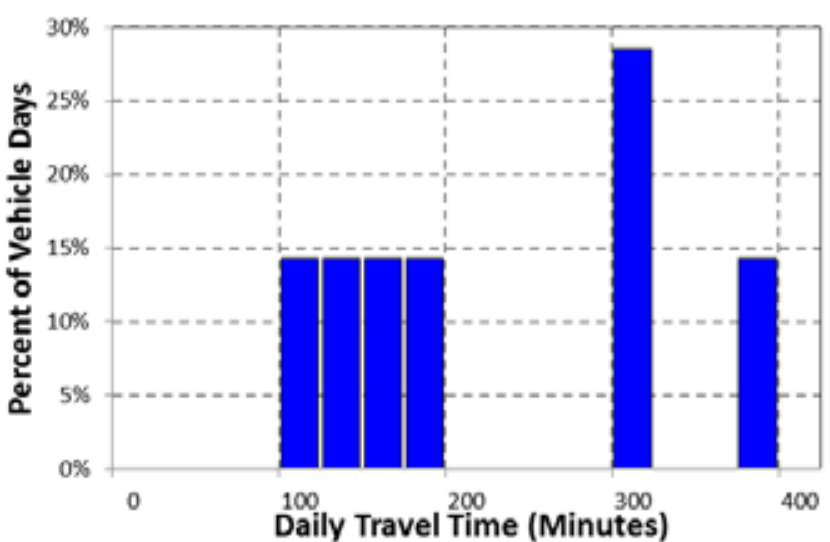

Percent of Trips by Hour of Day

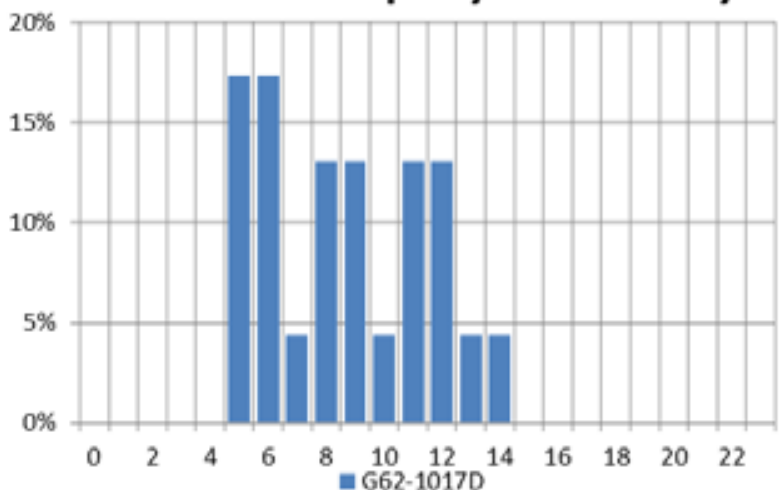

Figure B-10. Vehicle G62-1017D travel graphs.

\section{Vehicle G62-1017D Observations}

Logger 16 collected data on this vehicle for a period of 7 days of the 33-day study period. Reasons for the early removal of the logger are unknown. Validation occurred on $98.6 \%$ of the input data. Data recorded for this vehicle indicated that it has a support mission for environmental testing and typically parks in Area 100.

NASA reports that the vehicle odometer indicated 17,812 miles during the study and it travels approximately 4,308 miles per year. The vehicle was used on $66 \%$ of the available days, with an average daily usage of 3.8 hours and a peak daily usage of 6.4 hours on the days it was used. The vehicle was used during typical day shift hours.

Figure B-24 shows that $100 \%$ of daily travel and $100 \%$ of all outings are within the typically advertised range of a BEV of approximately 70 miles. Further, $100 \%$ of daily travel and $100 \%$ of outings are within the typically advertised CD mode of 40 miles for PHEVs.

A BEV could meet all of the daily travel without additional charging opportunities. The survey information suggests no

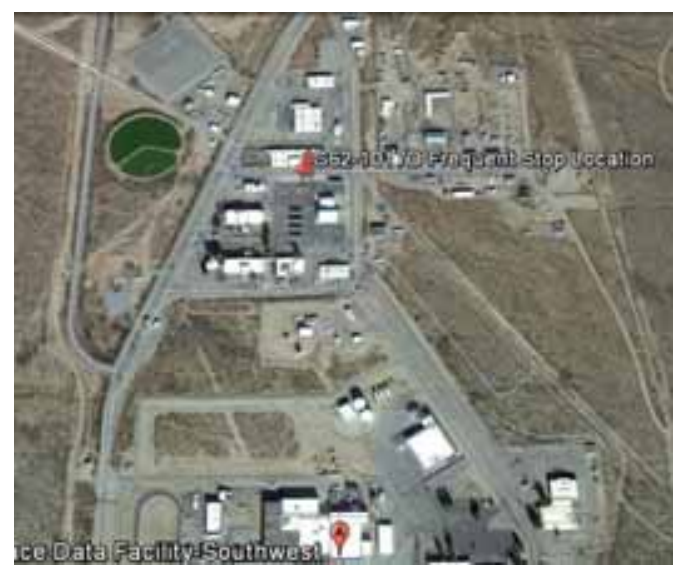
other special requirements exist for this support activity. 


\section{Vehicle G41-5523H}

\begin{tabular}{|c|c|c|}
\hline \multirow{11}{*}{ 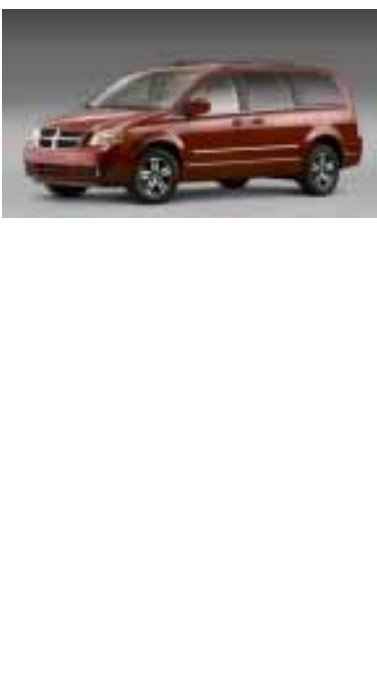 } & Make/Model/Year & Dodge Gr Caravan/2009 \\
\hline & EPA Class Size & Minivan \\
\hline & Mission & Support \\
\hline & VIN & 2D8HN44E09R628243 \\
\hline & Parking Location & See Figure B-25 \\
\hline & Fleet Vehicle ID & G41-5523H \\
\hline & Fuel Type & Gas/E85 \\
\hline & EPA Label/MPG (City/Hwy) & $17 / 24 / 1911 / 16 / 13$ \\
\hline & EPA GHG Emissions (Grams $\mathrm{CO}_{2} / \mathrm{Mi}$ ) & $468 / 484$ \\
\hline & Study Logger ID & 17 \\
\hline & Total Vehicle Days/Total Study Days & $22 / 92$ \\
\hline
\end{tabular}

\begin{tabular}{|l|c|c|c|c|}
\hline \multicolumn{5}{|c|}{ Vehicle G41-5523H Travel Summary } \\
\hline & $\begin{array}{c}\text { Per Day } \\
\text { Average/Peak }\end{array}$ & $\begin{array}{c}\text { Per Outing } \\
\text { Average/Peak }\end{array}$ & $\begin{array}{c}\text { Per Trip } \\
\text { Average/Peak }\end{array}$ & Total \\
\hline Travel Distance (Miles) & $40.5 / 133.1$ & $55.7 / 133.1$ & $9.5 / 49.4$ & 891 \\
\hline Travel Time (Minutes) & $61.0 / 192.0$ & $84.4 / 192.0$ & $14.4 / 59.0$ & 1,350 \\
\hline Idle Time (Minutes) & $5.8 / \mathrm{NA}$ & $8.0 / \mathrm{NA}$ & $1.4 / \mathrm{NA}$ & 128 \\
\hline
\end{tabular}

\begin{tabular}{|c|c|c|c|c|}
\hline \multicolumn{2}{|c|}{ Total Stops } & \multicolumn{2}{c|}{ Stop Duration } \\
\hline $\begin{array}{c}\text { Distance From } \\
\text { Home Base (Miles) }\end{array}$ & Stops & Percentages & Stop Duration (Hours) & Stops \\
\hline Less than 10 & 49 & $66.2 \%$ & Less than 2 & 48 \\
\hline 10 to 20 & 10 & $13.5 \%$ & 2 to 4 & 5 \\
\hline 20 to 40 & 15 & $20.3 \%$ & 4 to 8 & 0 \\
\hline Greater than 40 & 0 & $0 \%$ & Greater than 8 & 21 \\
\hline
\end{tabular}

Vehicle G41-5523H Stops > 2 Hours

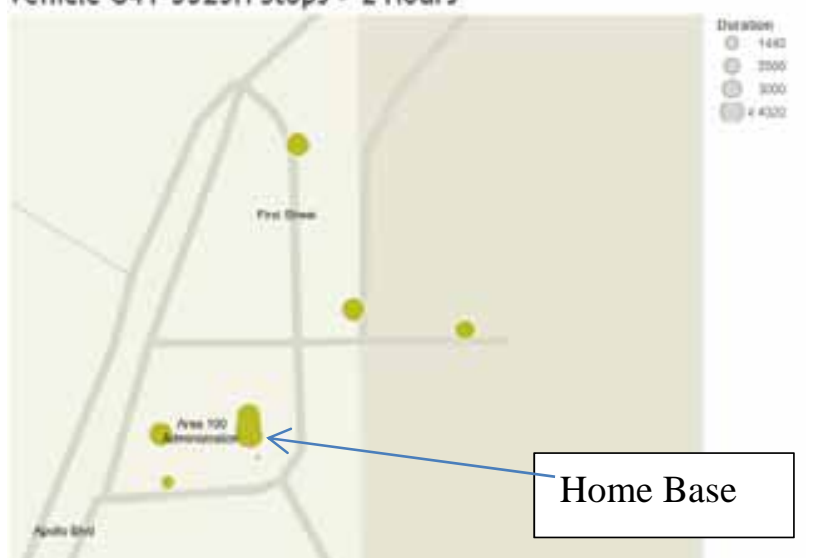

Figure B-25. Vehicle G41-5523H stops.

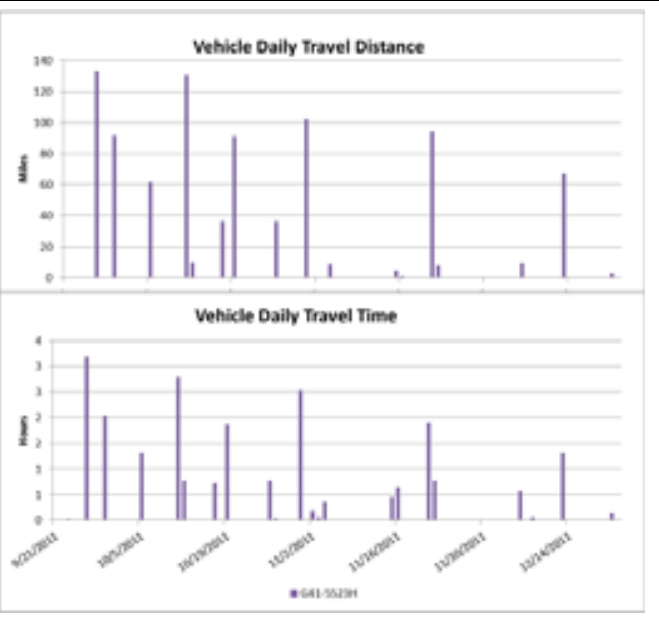

Figure B-26. Vehicle G41-5523H history. 


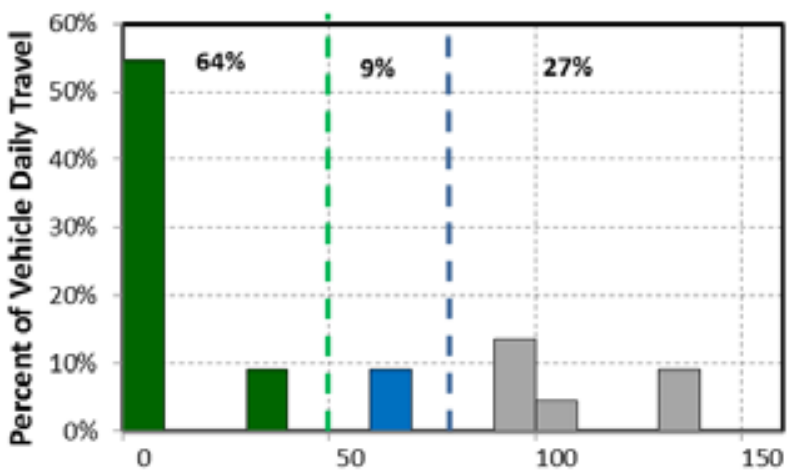

\section{Daily Travel Distance (miles)}
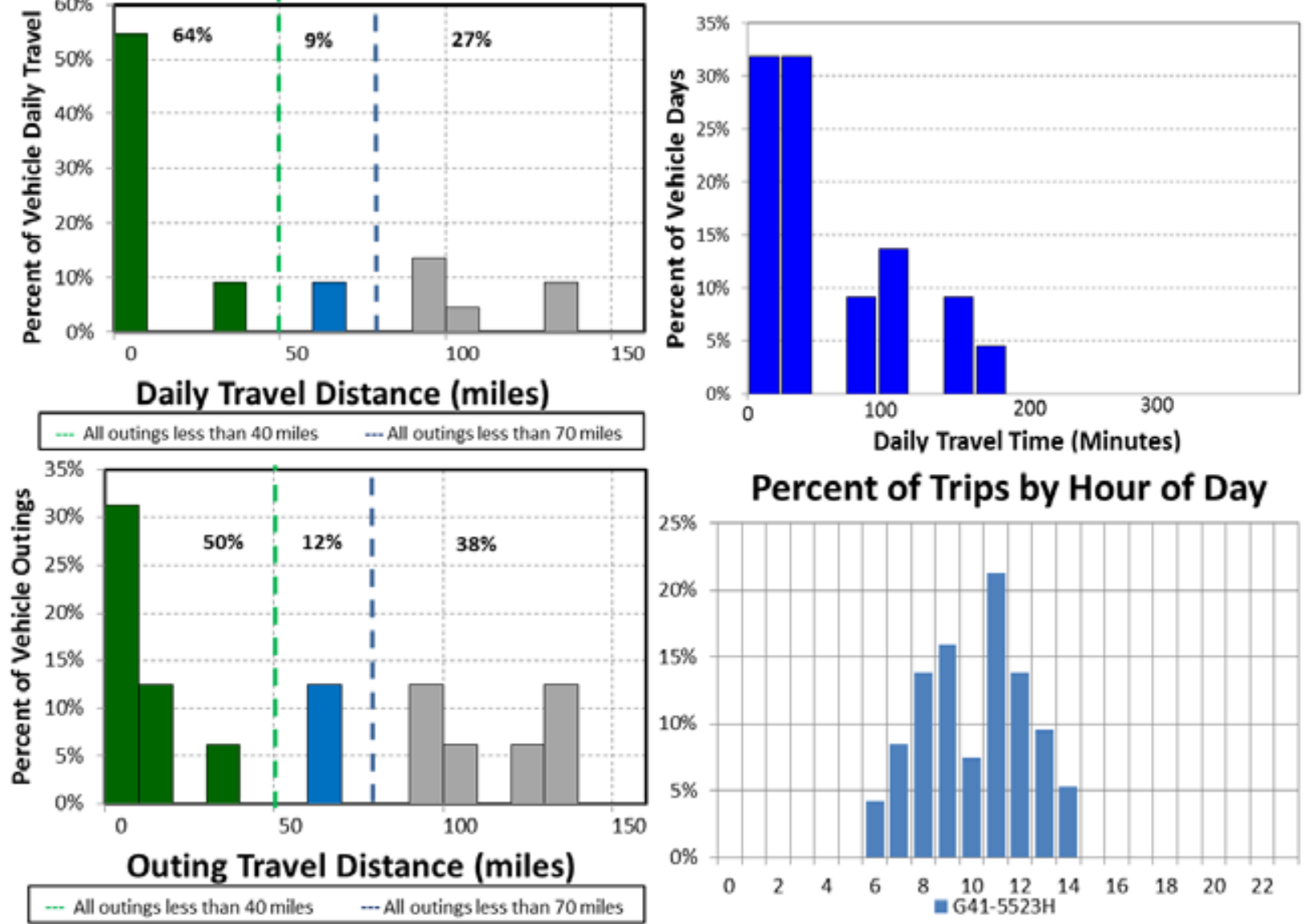

Figure B-11. Vehicle G41-5523H travel graphs.

\section{Vehicle G41-5523H Observations}

Logger 17 collected data on this vehicle for a period of 22 days of the 92-day study period. Validation occurred on $100 \%$ of the input data. Data recorded for this vehicle indicated that it has a support mission for space shuttle ground support and typically parks in Area 100, although it also parks in other nearby areas.

NASA reports that the vehicle odometer indicated 11,082 miles during the study and it travels approximately 5,280 miles per year. The vehicle was used on $24 \%$ of the available days, with an average daily usage of 1.0 hour and a peak daily usage of 3.2 hours on the days it was used. The vehicle was used during typical day shift hours.

Figure B-27 shows $73 \%$ of daily travel and $62 \%$ of all outings are within the typically advertised range of a BEV of approximately 70 miles. Further, $64 \%$ of daily travel and $50 \%$ of outings are within the typically

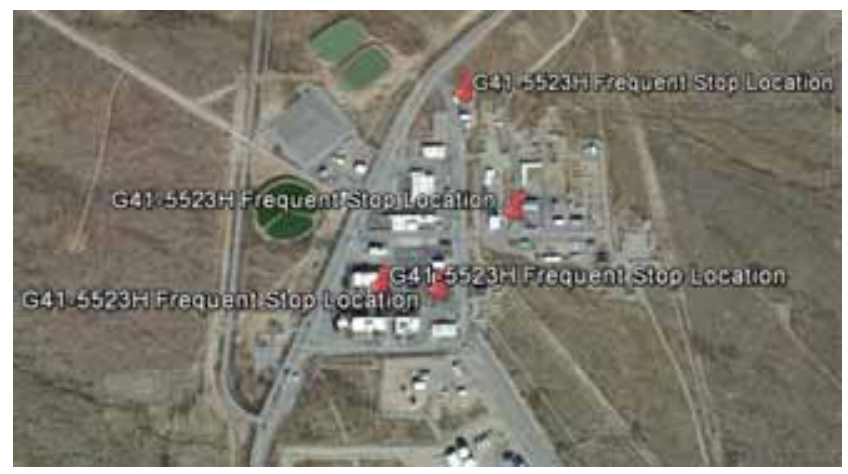
advertised CD mode of 40 miles for PHEVs.

A BEV could meet $73 \%$ of the daily travel without additional charging opportunities. With $50 \%$ of outings within the capability of a PHEV, there exists sufficient charge opportunities to include more daily travel in CD mode. A fleet of BEVs and PHEVs is likely to allow daily travel without requiring additional charge times, providing the PEV meets other mission requirements. The survey information suggests no other special requirements exist for this support activity. 


\section{Vehicle G63-1722B}

\begin{tabular}{|l|l|c|}
\hline & Make/Model/Year & Chev. Silverado 2500/2005 \\
\cline { 2 - 3 } & EPA Class Size & Pickup Truck \\
\hline Mission & Support \\
\hline VIN & See Figure B-28 \\
\cline { 2 - 3 } & Parking Location & G63-1722B \\
\hline Fleet Vehicle ID & Gas \\
\hline Fuel Type & $10 / 12 / 11$ \\
\hline & EPA Label/MPG (City/Hwy) & 808 \\
\hline & EPA GHG Emissions (Grams CO $/$ Mi) & 18 \\
\hline & Study Logger ID & $60 / 92$ \\
\cline { 2 - 3 } & Total Vehicle Days/Total Study Days & . \\
\hline
\end{tabular}

\begin{tabular}{|l|c|c|c|c|}
\hline \multicolumn{5}{|c|}{ Vehicle G63-1722B Travel Summary } \\
\hline & $\begin{array}{c}\text { Per Day } \\
\text { Average/Peak }\end{array}$ & $\begin{array}{c}\text { Per Outing } \\
\text { Average/Peak }\end{array}$ & $\begin{array}{c}\text { Per Trip } \\
\text { Average/Peak }\end{array}$ & Total \\
\hline Travel Distance (Miles) & $40.1 /$ & $12.7 /$ & $2.4 /$ & 2,407 \\
\hline Travel Time (Minutes) & $153.0 /$ & $48.3 /$ & $9.2 /$ & 9,180 \\
\hline Idle Time (Minutes) & 25.1/NA & $7.9 / \mathrm{NA}$ & $1.5 / \mathrm{NA}$ & 1,503 \\
\hline
\end{tabular}

\begin{tabular}{|c|c|c|c|c|}
\hline \multicolumn{2}{|c|}{ Total Stops } & \multicolumn{2}{c|}{ Stop Duration } \\
\hline $\begin{array}{c}\text { Distance From } \\
\text { Home Base (Miles) }\end{array}$ & Stops & Percentages & Stop Duration (Hours) & Stops \\
\hline Less than 10 & 817 & $100 \%$ & Less than 2 & 747 \\
\hline 10 to 20 & 0 & $0 \%$ & 2 to 4 & 12 \\
\hline 20 to 40 & 0 & $0 \%$ & 4 to 8 & 0 \\
\hline Greater than 40 & 0 & $0 \%$ & Greater than 8 & 58 \\
\hline
\end{tabular}

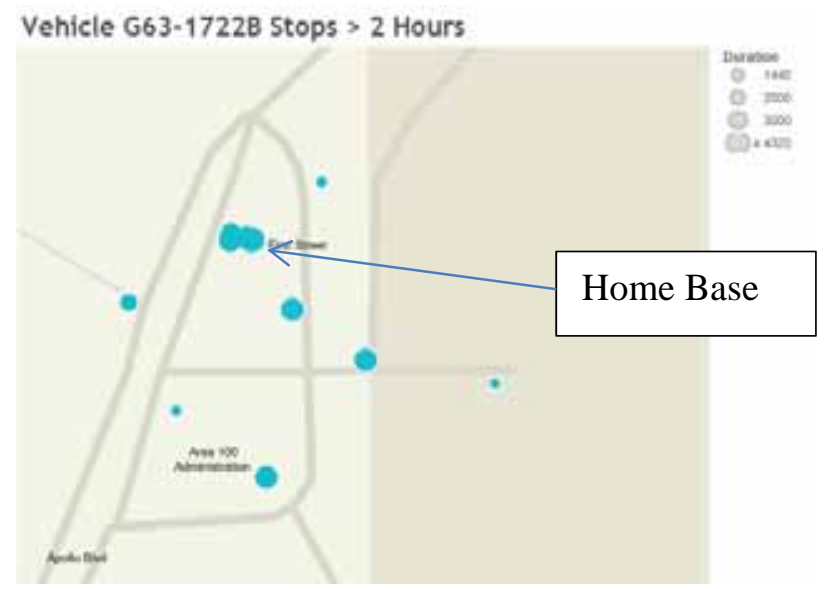

Figure B-28. Vehicle G63-1722B stops.

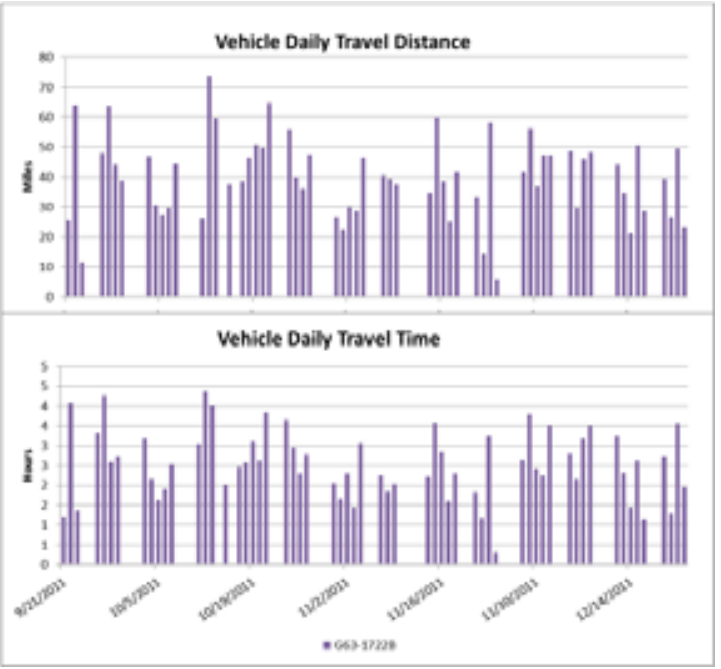

Figure B-29. Vehicle G63-1722B history. 


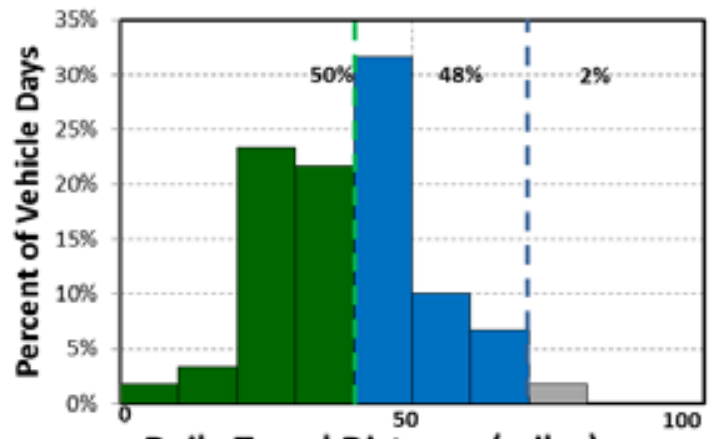

Daily Travel Distance (miles)

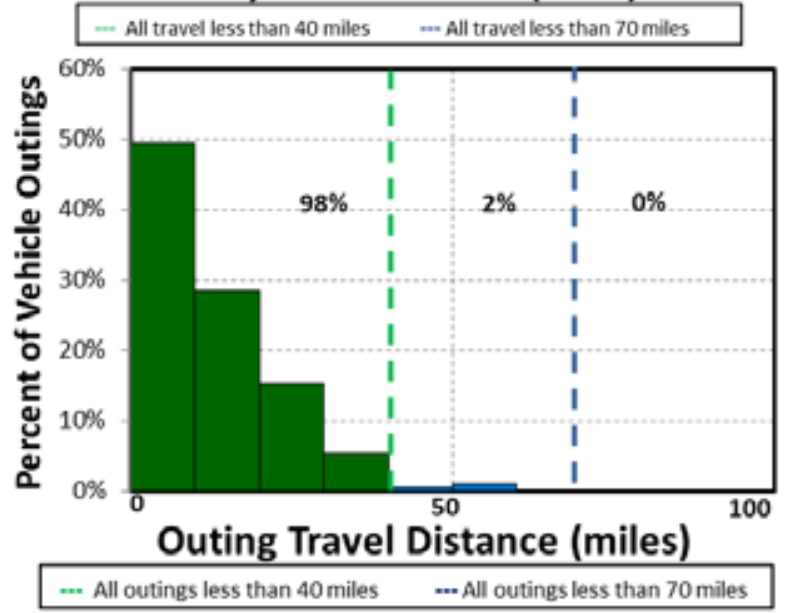

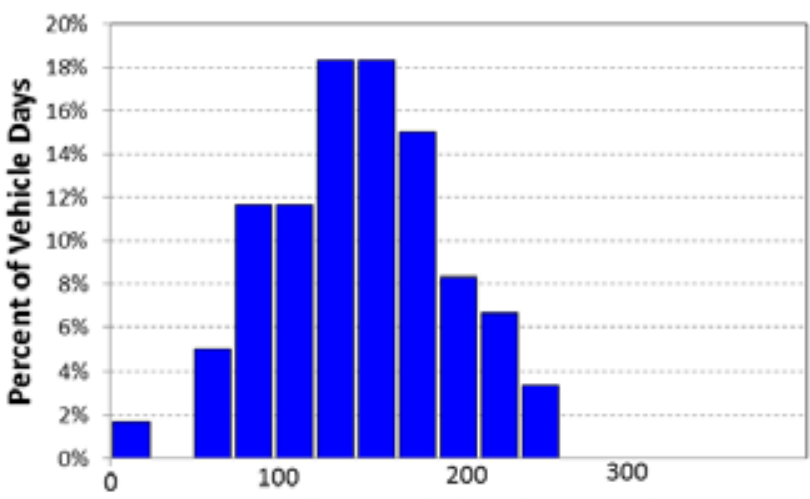

Dailv Travel Time (Minutes)

Percent of Trips by Hour of Day

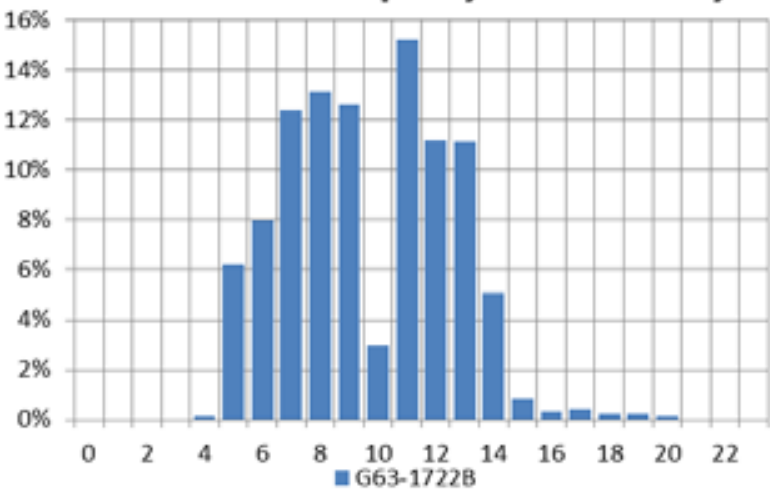

Figure B-12. Vehicle G63-1722B travel graphs.

\section{Vehicle G63-1722B Observations}

Logger 18 collected data on this vehicle for a period of 60 days of the 92-day study period. Validation occurred on $99.9 \%$ of the input data. Data recorded for this vehicle indicated that it has a support mission for maintenance and typically parks north of Area 100, although it also parks in other nearby areas.

NASA reports the vehicle odometer indicated 40,716 miles during the study and it travels approximately 9,108 miles per year. The vehicle was used on $65 \%$ of the available days, with an average daily usage of 2.6 hours and a peak daily usage of 4.4 hours on the days it was used. The vehicle was used during typical day shift hours.

Figure B-30 shows that $98 \%$ of daily travel and $100 \%$ of all outings are within the typically advertised range of a BEV of approximately 70 miles. Further, 50\% of daily travel and $98 \%$ of outings are within the typically advertised CD mode of 40 miles for PHEVs.

A BEV could meet $98 \%$ of the daily travel without additional charging opportunities. With $98 \%$ of the outings within the capability of a PHEV, there exists sufficient charge opportunities to include more daily travel in CD mode. A fleet of BEVs and PHEVs is likely to allow daily travel without requiring additional charge times,

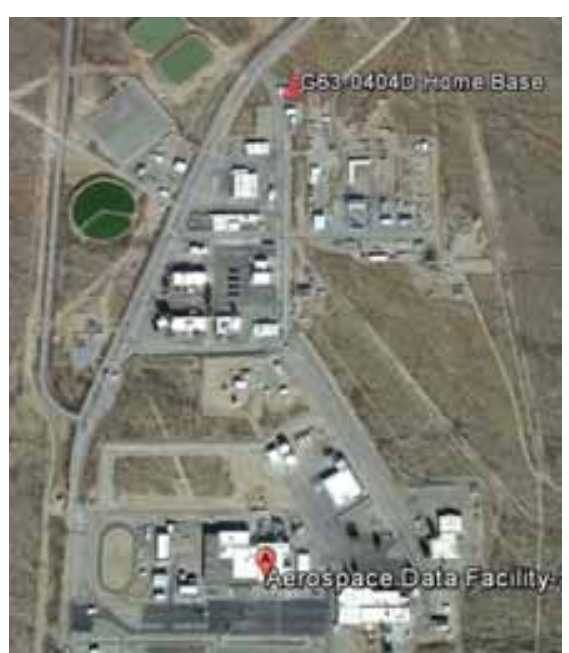
providing the PEV meets other mission requirements. The survey information suggests no other special requirements exist for this support activity. 


\section{Appendix C \\ National Fuel Cost and GHG Savings}

Section 5 notes that fuel cost and GHG savings are calculated on a local and a national basis. Local savings are of higher interest to the facility, while national figures are of higher interest in evaluating all sites. Section 5 provides the savings on the local level. Table C- 1 presents these savings on a national basis for the PEV replacement of monitored vehicles.

Table C-2. Fuel cost and GHG savings on a national basis.

\begin{tabular}{|c|c|c|c|c|c|}
\hline Mission & $\begin{array}{c}\text { Replacement } \\
\text { Model }\end{array}$ & $\begin{array}{l}\text { Extrapolated } \\
\text { U.S. Yearly } \\
\mathrm{CO}_{2} \mathrm{e} \text { Avoided } \\
\text { (lb- } \mathrm{CO}_{2} \mathrm{e} / \mathrm{year} \text { ) }\end{array}$ & $\%$ reduction & $\begin{array}{l}\text { Extrapolated } \\
\text { U.S.Yearly } \\
\text { Fuel Cost } \\
\text { Reduction }\end{array}$ & $\%$ reduction \\
\hline Support & Rav4 & 5,569 & $50 \%$ & $\$ 1,552$ & $81 \%$ \\
\hline Support & Rav4 & 3,619 & $40 \%$ & $\$ 1,204$ & $77 \%$ \\
\hline Support & Rav4 & 4,017 & $33 \%$ & $\$ 1,556$ & $75 \%$ \\
\hline Support & VTRUX PU & 1,523 & $39 \%$ & $\$ 520$ & $77 \%$ \\
\hline Law Enforcement & Outlander & 2,553 & $43 \%$ & $\$ 796$ & $79 \%$ \\
\hline Support & eNV200 & 5,954 & $48 \%$ & $\$ 1,699$ & $81 \%$ \\
\hline Law Enforcement & Outlander & 1,843 & $36 \%$ & $\$ 659$ & $76 \%$ \\
\hline Support & eNV200 & 3,549 & $57 \%$ & $\$ 888$ & $84 \%$ \\
\hline Support & VTRUX PU & 1,119 & $31 \%$ & $\$ 453$ & $74 \%$ \\
\hline Support & Rav4 & 10,511 & $63 \%$ & $\$ 2,451$ & $86 \%$ \\
\hline & 40,258 & $47 \%$ & $\$ 11,177$ & $80 \%$ \\
\hline \multicolumn{2}{|l|}{ Total Pool } & 35,862 & $48 \%$ & $\$ 10,322$ & $80 \%$ \\
\hline \multicolumn{2}{|l|}{ Total Enforcement } & 4,396 & $40 \%$ & $\$ 1,4556$ & $77 \%$ \\
\hline
\end{tabular}

As presented in Section 5, a fleet of 32 ICE, 70 BEVs, and 35 PHEVs could potentially provide sufficient support for the various missions at WSTF. Using an average savings per vehicle, Table C-2 provides the avoided GHG and fuel cost savings should these replacements occur.

Table C-3. Extrapolated greenhouse gas emissions avoided and fuel cost savings for the entire fleet.

\begin{tabular}{ccccc}
\hline & $\begin{array}{c}\text { Extrapolated U.S. } \\
\text { Yearly } \mathrm{CO}_{2} \text { e Avoided } \\
\text { (lb-CO } \mathrm{C}_{2} \text {-year) }\end{array}$ & \% reduction & $\begin{array}{c}\text { Extrapolated U.S. } \\
\text { Yearly Fuel Cost } \\
\text { Reduction } \\
\text { (\$/year) }\end{array}$ & \% reduction \\
\hline Mission & 130,894 & $49 \%$ & $\$ 36,766$ & $81 \%$ \\
Enforcement & 33,850 & $41 \%$ & $\$ 10,906$ & $78 \%$ \\
Pool & 65,589 & $47 \%$ & $\$ 18,829$ & $78 \%$ \\
Transport & 173,988 & $49 \%$ & $\$ 49,156$ & $81 \%$ \\
\hline Total & 404,321 & $48 \%$ & $\$ 115,657$ & $80 \%$ \\
\hline
\end{tabular}

